\title{
Template-Directed Synthesis of Bivalent, Broad-Spectrum Hosts for Neuromuscular Blocking Agents
}

\author{
Allison J. Selinger, ${ }^{[a]}$ Natalie A. Cavallin, ${ }^{[a]}$ and Fraser Hof ${ }^{*[a]}$ \\ [a] A. J. Selinger, N. A. Cavillin, Prof. F. Hof \\ Department of Chemistry and Centre for Advanced Materials and Related Technologies (CAMTEC) \\ University of Victoria \\ 3800 Finnerty Rd., Victoria, BC V8P 5C2, Canada \\ E-mail: fhof@uvic.ca \\ Supporting information for this article is given via a link at the end of the document.
}

\begin{abstract}
We report on the synthesis of bivalent water soluble calix[4]arene and calix[5]arene hosts, Super-sCx4 and Super-sCx5 as new broad-spectrum supramolecular binders of neuromuscular blocking agents (NMBAs). Synthesis was achieved using the target bisquaternary amine NMBAs as a template to link two highly anionic $p$-sulfonatocalixarene building blocks in aqueous solution. Bivalent anionic hosts Super-sCx4 and Super-sCx5 bind by engaging both quaternary amines present on a variety of NMBAs. We report low $\mu \mathrm{M}$ binding to structurally diverse alkyl, steroidal, curarine and benzylisoquinoline NMBAs with high selectivity over the neurotransmitter acetylcholine.
\end{abstract}

Neuromuscular blocking agents (NMBAs) are frequently administered in clinical practice during anesthesia. NMBAs block the action of acetylcholine (ACh) by binding nicotinic acetylcholine receptors $(\mathrm{nAChR})$ at the post synaptic endplate of the neuromuscular junction. ${ }^{[1]} \mathrm{A}$ variety of structurally diverse NMBAs are used in clinical practice to accommodate different pharmacological needs. ${ }^{[2]}$ Although NMBAs vary in structure, they adhere to a pharmacophore model having two alkyl ammonium ions separated by $\sim 14 \AA$ in their lowest energy conformation. ${ }^{[3]}$ NMBAs can thus span the inner diameter of the nAChR and simultaneously block both ACh binding pockets (Figure 1a). After surgery, NMBA reversal facilitates patient recovery.

While NMBAs are bivalent, all reported supramolecular reversal agents contain a single macrocyclic binding motif. ${ }^{[4]}$ Supramolecular reversal agents administered by intravenous injection bind free NMBAs in the blood, lowering the concentration of NMBAs at the neuromuscular junction and reversing effects. ${ }^{[5]}$ Several NMBA reversal agents have been developed from macrocyclic hosts, including cyclodextrins, cucurbiturils and pillararenes (Figure 1b). These hosts operate via an inclusion binding mode that is inherently limited by the size of the host cavity and the fit of the NMBA. Sugammadex, a y-cyclodextrin host that is approved for clinical use in over 50 countries, reverses steroidal NMBAs vecuronium and rocuronium. ${ }^{[6]}$ However, its cavity is too small to achieve reversal of wider curarine and benzylisoquinoline NMBAs and it is similarly inactive towards the thinner NMBA suxamethonium. ${ }^{[7]}$ Likewise, pillar[5]arene is too small to form a threaded complex with steroidal NMBAs, but thioether carboxylate decafunctionalized pillar[5]arene can form a nesting complex with rocuronium. ${ }^{[8]}$ Water-soluble carboxylatopillar[6]arene strongly binds the thinner NMBA suxamethonium, ${ }^{[9]}$ and sulfated Pillar[6]maxQ strongly binds steroidal NMBA's. ${ }^{[10]}$ Calabadion 2, an acyclic cucurbituril, has broader binding preferences, reversing steroidal and benzylisoquinoline NMBAs, vecuronium, rocuronium and cisatracurium but binding to suxamethonium has not been reported. ${ }^{[11]}$ a)

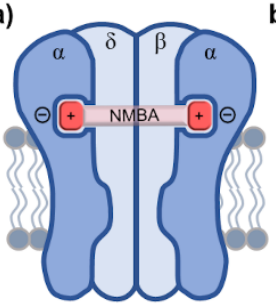

b)

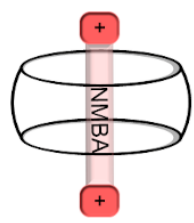

c)

monovalent: Sugammadex, bivalent: this work Calabadion 2, Pillar[6]MaxQ

Figure 1. a) Cross section of $n A C h R$ inhibited by an NMBA binding both ACh sites. b) Supramolecular reversal agents reported to date contain a single binding site. c) We propose a reversal agent with dual binding sites separated by a flexible linker.

To complement a family of molecules with diverse biscationic structures but a common, geometrically defined pharmacophore, we chose a conceptually new approach: building bivalent hosts using two promiscuous, but carefully spaced binding pockets (Figure 1c and Figure 2). We selected $p$ sulfonatocalixarenes ( $\mathrm{s} \mathrm{C} \times 4$ and $\mathrm{s} \mathrm{C} \times 5)$, as their anionic upper rims and dynamic bowl like cavities are known to bind many kinds of

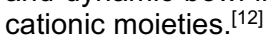




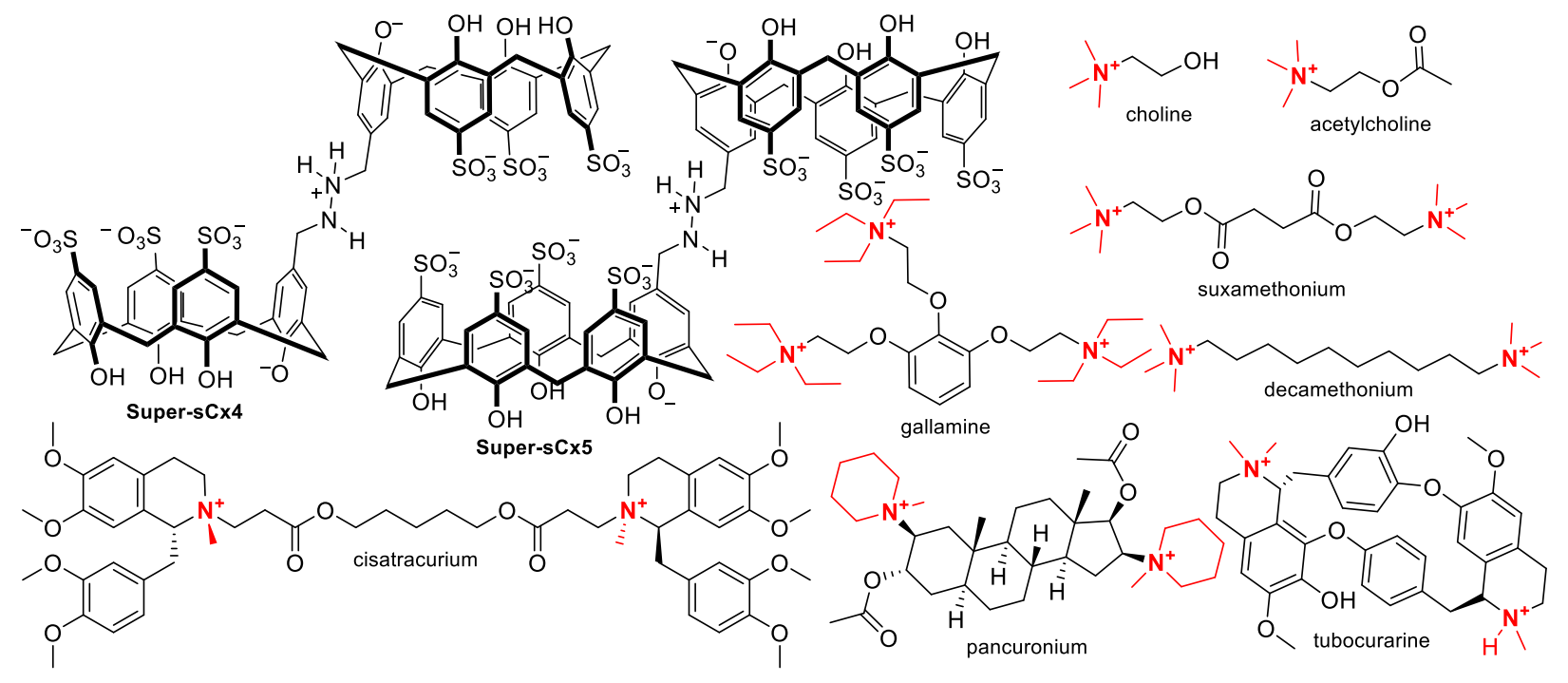

Figure 2. Chemical structures of bivalent calixarene hosts, NMBAs and cholines.

a)

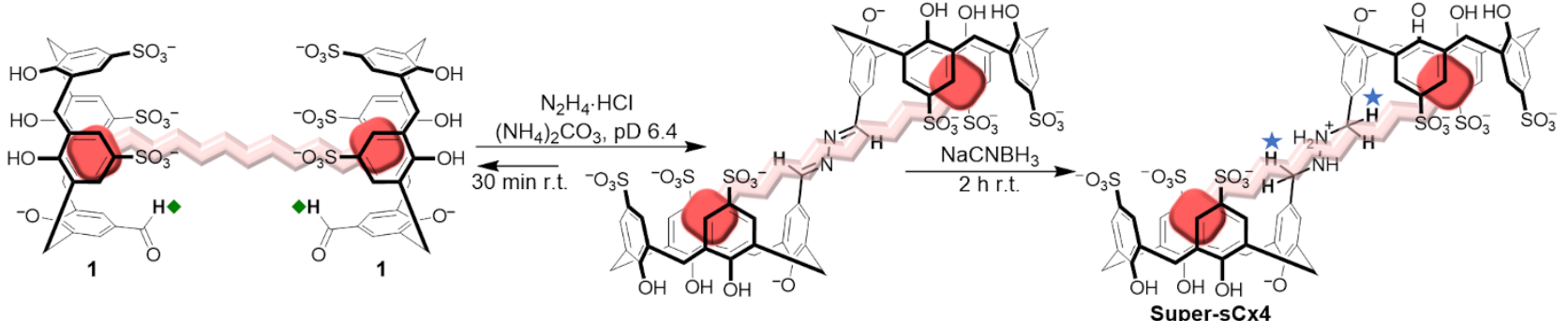

b)

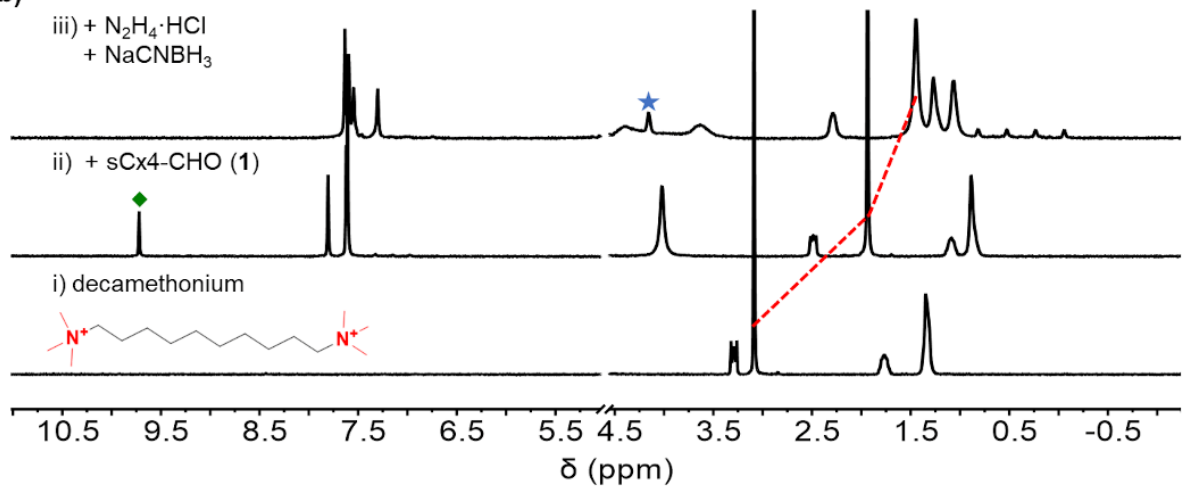

c)

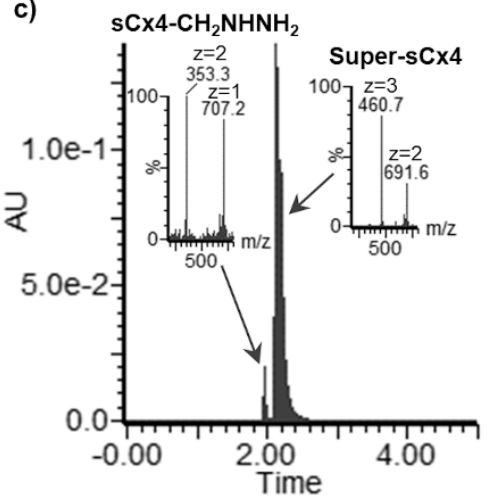

d)

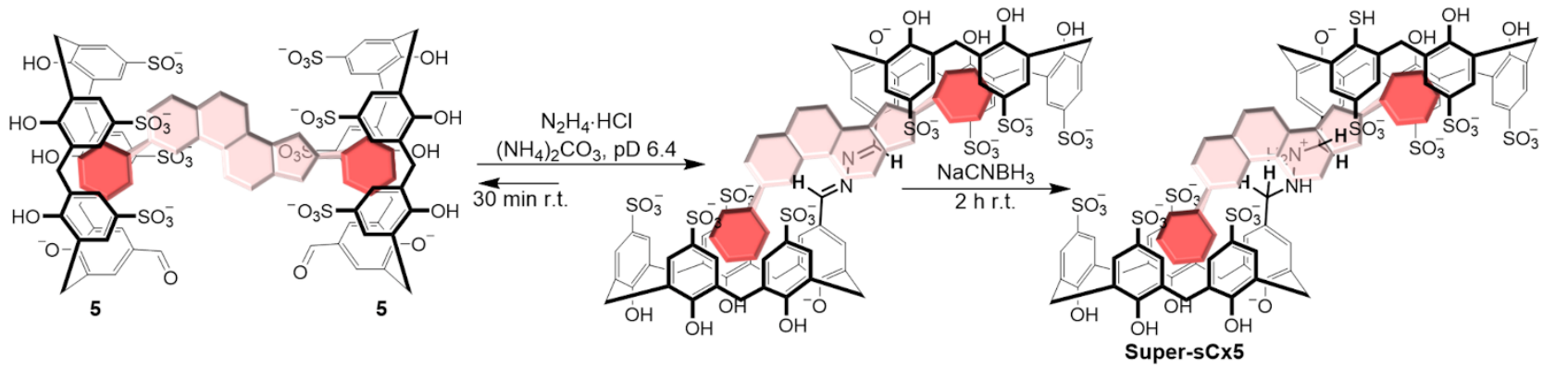

Figure 3. NMBA templated synthesis forms bivalent calixarene hosts with a flexible hydrazine linker. a) Synthetic scheme of Super-sCx4 templated by decamethonium in $\left(\mathrm{NH}_{4}\right)_{2} \mathrm{CO}_{3}(50 \mathrm{mM}, \mathrm{pD} 6.4)$ in $\mathrm{D}_{2} \mathrm{O}$. b) ${ }^{1} \mathrm{H}$ NMR spectrum of i) decamethonium ii) addition of 2 eq sCx4-CHO (1) (aldehyde highlighted by green diamond) iii) final crude after completed reductive amination (hydrazine linkage highlighted by blue star). Red dotted line shows encapsulation of methyl peaks throughout the reaction. c) UPLC-MS of final crude shows major product formation of bivalent Super-s $\mathbf{C x} 4$ and minor formation of monovalent $\mathbf{s} \mathrm{Cx}_{\mathbf{4}}-\mathrm{CH}_{2} \mathrm{NHNH}_{2}$. d) Synthetic scheme of Super-sCx5 templated by pancuronium in $\left(\mathrm{NH}_{4}\right)_{2} \mathrm{CO}_{3}(50 \mathrm{mM}, \mathrm{pD} 6.4)$ in $\mathrm{D}_{2} \mathrm{O}$. 
Templated synthesis with the NMBA decamethonium was effective at creating a new bivalent host (Figure 3a). Simple models predicted that a very short linker would be needed between calixarenes, and we repeatedly found that late-stage covalent coupling was hampered by the mutual repulsion of two highly anionic calixarene building blocks. To overcome this barrier, monofunctionalized $\mathrm{sCx} 4-\mathrm{CHO}$ (1) and decamethonium were mixed in a 2:1 ratio in aqueous solution. In situ ${ }^{1} \mathrm{H}$ NMR showed upfield shifts of bound decamethonium methyl groups (Figure 3bii). 1D DOSY NMR on the uncomplexed calixarene $\mathrm{SCx} 4-\mathrm{CHO}$ (1) provided a hydrodynamic radius of $7.4 \pm 0.3 \AA{ }^{[13]}$ which increased to $11.7 \pm 0.3 \AA$ upon complexation with decamethonium supporting the formation of a templated 2:1 complex under the reaction conditions (Table 1, Figure S58). Addition of hydrazine creates a complex system with two reversible imine bonds and calixarenes engaged on either end of the templating NMBA. Reduction of imine bonds locks the structure, forming the bivalent host Super-sCx4. Continuous NMBA complexation throughout the reaction is observed by further upfield shifted methyl peaks in the final crude reaction mix (Figure 3biii). UPLC-MS of the crude reaction identified the bivalent host Super-sCx4 as the major product $(50 \%$ isolated yield) with minor formation of monovalent sCx4-CH $\mathrm{NHNH}_{2}$ (Figure 3c).

We also developed a bivalent calix[5]arene analogue (Figure 3d). Novel building block sCx5-CHO (5) was synthesized in four steps by site-specific functionalization of the calix[5]arene scaffold (See SI). Initial templation attempts with $\mathrm{sCx5-CHO} \mathrm{(5)}$ and decamethonium showed the guest adopting a folded conformation inside the larger $\mathrm{SCx} 5-\mathrm{CHO}(5)$ cavity, forming a 1:1 complex (Figure S25) and preventing the success of the templated synthesis. The steroidal NMBA pancuronium was selected as a more rigid template, as it has been shown to form a 2:1 complex with similarly sized cucurbit[7] ril. $^{[14]}$ Monofunctionalized sCx5-CHO (5) and pancuronium were equilibrated in a 2:1 ratio in aqueous solution. Upfield shifts of the quaternary amine methyl groups were observed by in situ ${ }^{1} \mathrm{H}$ NMR reaction monitoring (Figure S26). 1D DOSY NMR of the complexed calixarene supports the formation of a 2:1 complex (Table 1, Figure S63). Bivalent Super-sCx5 was isolated in a 25\% yield after HPLC purification, and a slightly larger hydrodynamic radius of $12.6 \pm 0.2 \AA$ for Super-sCx5 was determined (Table 1, Figure S65)

Templation by NMBAs is essential to the formation of each bivalent host. Control reactions without NMBA templates produced little or no detectable Super-sCx products (UPLC-MS), instead resulting in the formation of monovalent $\mathbf{s} \mathbf{C} 4-\mathbf{C H}_{2} \mathbf{N H N H}_{2}$ and $\mathbf{s} \mathbf{C} \times \mathbf{5}-\mathrm{CH}_{2} \mathrm{NHNH}_{2}$, and other reduced monovalent calixarenes (Figure S24 and S27).

A wide variety of NMBA's form 1:1 complexes with the new bivalent hosts. Suxamethonium was selected for detailed 1D DOSY investigation as it displayed distinguishable sharp peaks in ${ }^{1} \mathrm{H}$ NMR when complexed with either Super-sCx4 or Super-sCx5. The hydrodynamic radii of suxamethonium complexes with hosts Super-sCx4 (11.2 $\pm 0.6 \AA)$ and Super-sCx5 $(12.4 \pm 0.6 \AA)$ were similar to the values for the respective isolated Super-sCx host (Table 1, Figure S61 and S66). The 1:1 complexation demonstrated by DOSY is further supported by molecular modeling (see SI). Conformational searches were carried out on complexes of each Super-sCx host with a panel of structurally diverse NMBAs (decamethonium, suxamethonium, gallamine, pancuronium, tubocurarine and cisatracurium). In all cases, the most stable energy-minimized structures involved two quaternary amines from the NMBAs being engaged within the two pockets of the bivalent hosts (See SI).
Table 1. Diffusion coefficients and hydrodynamic radii determined by 1D DOSY.

\begin{tabular}{|c|c|c|}
\hline Compound & $\mathrm{D}\left(10^{-10} \mathrm{~m}^{2} / \mathrm{s}\right)$ & $\mathrm{r}_{\mathrm{H}}(\AA)$ \\
\hline $\mathrm{sCx} 4-\mathrm{CHO}(1)^{[13]}$ & $3.29 \pm 0.02$ & $7.4 \pm 0.3$ \\
\hline $\mathrm{sCx} 4-\mathrm{CHO}(1) \bullet$ decamethonium $^{[\mathrm{a}]}$ & $2.16 \pm 0.05$ & $11.7 \pm 0.3$ \\
\hline $\mathrm{sCx} 4-\mathrm{CH}_{2} \mathrm{NHNH}_{2}{ }^{[b]}$ & $2.77 \pm 0.05$ & $9.1 \pm 0.2$ \\
\hline Super-sCx $4^{[b]}$ & $2.22 \pm 0.02$ & $11.4 \pm 0.1$ \\
\hline Super-sCx4•suxamethonium ${ }^{[b]}$ & $2.3 \pm 0.1$ & $11.2 \pm 0.6$ \\
\hline $\mathrm{sCx} 5-\mathrm{CHO}(5)^{[b]}$ & $2.79 \pm 0.03$ & $9.0 \pm 0.1$ \\
\hline $\mathrm{sCx} 5-\mathrm{CHO}(\mathbf{5}) \cdot$ pancuronium $^{[\mathrm{a}]}$ & $2.2 \pm 0.2$ & $11 \pm 1$ \\
\hline $\mathrm{sC} \times 5-\mathrm{CH}_{2} \mathrm{NHNH}_{2}{ }^{[\mathrm{b}]}$ & $2.7 \pm 0.1$ & $9.5 \pm 0.5$ \\
\hline Super-sCx $5^{[b]}$ & $2.00 \pm 0.03$ & $12.6 \pm 0.2$ \\
\hline Super-sCx5•suxamethonium ${ }^{[b]}$ & $2.04 \pm 0.09$ & $12.4 \pm 0.6$ \\
\hline
\end{tabular}

[a] $\left(\mathrm{NH}_{4}\right)_{2} \mathrm{CO}_{3}(50 \mathrm{mM}, \mathrm{pD} 6.4)$ in $\mathrm{D}_{2} \mathrm{O}(500 \mathrm{MHz}, 297 \mathrm{~K})[\mathrm{b}]$

$\mathrm{NaH}_{2} \mathrm{PO}_{4} / \mathrm{Na}_{2} \mathrm{HPO}_{4}(50 \mathrm{mM}, \mathrm{pD} 7.4)$ in $\mathrm{D}_{2} \mathrm{O}(500 \mathrm{MHz}, 297 \mathrm{~K})$

Six-point ${ }^{1} \mathrm{H}$ NMR titrations of NMBAs demonstrate qualitatively that matching of bivalent guests with bivalent hosts is required for strong 1:1 binding. The upfield shifts of NMBA methyl groups were monitored upon addition of hosts into NMBAs, with all titrations exhibiting fast exchange on the NMR time scale (See $\mathrm{SI}$ ). Titrations of bivalent hosts Super-sCx4 and Super-sCx5 into NMBAs displayed strong binding, resulting in saturation of chemical shift perturbation at 1.0-1.5 equivalents. Titrations with monovalent control hosts $\mathbf{s} \mathbf{C} 4-\mathrm{CH}_{2} \mathrm{NHNH}_{2}$ and sCx5$\mathbf{C H}_{2} \mathrm{NHNH}_{2}$ did not display saturation at $\leq 3$ equivalents, demonstrating that the monovalent control compounds have weaker complexes of higher stoichiometries. Similarly, titrations of the bivalent Super-sCx4 and Super-sCx5 hosts into choline and acetylcholine showed weaker, unsaturated binding curves.

The new hosts exhibit pan-selective NMBA binding with selectivity over acetylcholine. We used an indicator-displacement assay (IDA) to determine equilibrium dissociation constant $\left(K_{d}\right)$ values. Competitive titrations of NMBAs into the pre-formed Super-sCx•LCG complexes were conducted, with displacement of LCG resulting in increased fluorescence (Figure 4). ${ }^{[15]}$ SupersCx4 exhibited stronger binding to the thinner NMBAs, suxamethonium $(71 \pm 8 \mu \mathrm{M})$ and decamethonium $(63 \pm 9 \mu \mathrm{M})$, with selectivity over acetylcholine (Table 2). Super-sCx5 exhibited strong broad-specturm binding to all NMBAs tested (2$18 \mu \mathrm{M})$ and selectivity over acetylcholine (Table 2). Notably the larger calix[5]arene cavity offered strong binding to both the thinner NMBA suxamethonium $(14 \pm 3 \mu \mathrm{M})$ and the bulkier NMBA cisatracurium $(6 \pm 3 \mu \mathrm{M})$.

This work provides a new approach to developing reversal agents, using the target as a template to build synthetically challenging hosts in aqueous solution. While several examples of upper-rim-linked bivalent calixarenes exist, ${ }^{[16]}$ making covalent connections between highly anionic building blocks is especially challenging. The large magnitude of repulsive anionic charge of p-sulfonatocalixarenes poses a challenge to forming a short flexible linkage between the upper rims. Templation has been widely used, from small ion templation of macrocycles, ${ }^{[17]}$ to larger complex architectures like nanorings, ${ }^{[18]}$ nanorods, ${ }^{[19]}$ molecular knots, ${ }^{[20]}$ and polymers. ${ }^{[21]}$ More recently, templation has been applied to dynamic combinatorial chemistry, by forming mixtures of synthetic building blocks that favor linkage around a desired template. ${ }^{[22]}$ 
a)

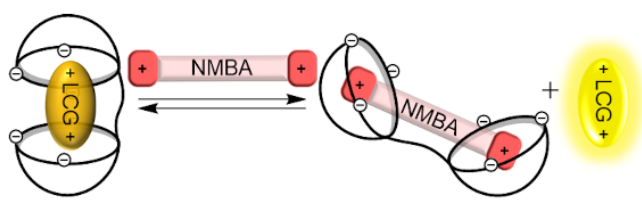

b)

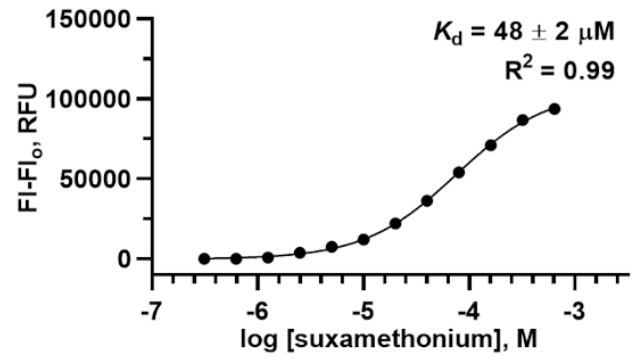

Figure 4. Indicator displacement assay determines binding interactions of bivalent hosts to NMBAs a) Cartoon illustration of lucigenin displacement upon NMBA binding of Super-sCx host b) Competitive titration of suxamethonium (up to $640 \mu \mathrm{M})$ into Super-sCx4 $(5 \mu \mathrm{M})$ and lucigenin $(0.25 \mu \mathrm{M})$. Solutions in $\mathrm{NaH}_{2} \mathrm{PO}_{4} / \mathrm{Na}_{2} \mathrm{HPO}_{4}(10 \mathrm{mM}, \mathrm{pD} 7.4), \lambda_{\mathrm{ex}}=369 \mathrm{~nm} \lambda_{\mathrm{em}}=485 \mathrm{~nm}$.

Specific ternary complexes are required to drive the successful synthesis of new bivalent hosts. Reactions in the absence of template consistently failed to provide bivalent hosts. The transient 2:1 complex of $\mathbf{s} \mathbf{C x} 4-\mathbf{C H O}$ and decamethonium was directly observed in the reaction mixture by using in situ DOSY NMR (Figure S58), while the mix of sCx5-CHO with decamethonium failed to generate a 2:1 complex (Figure S25) and also failed to produce the desired bivalent host. This situation was improved by using pancuronium as the template for Super-sCx $\mathbf{5}$ synthesis The success of a very short hydrazine linker and the NMR evidence for bis-hydrazone formation during the templation reaction means that upper-rim sulfonates are as close as $8 \AA$ in the transient ternary complexes.

In some sense, a pharmacophore model is a useful message of promiscuity. It teaches us that many drugs presenting related functional groups in a similar $3 D$ arrangement can be active against the same target. When paired with a promiscuous host macrocycle, the use of a single template during synthesis can provide bivalent hosts that have broad-spectrum activity and yet retain useful selectivity (e.g. over monovalent competitors). While it seems that only certain NMBAs are suitable for a given templation reaction, the bivalent hosts in this work, once synthesized, have good affinity for NMBAs and weak affinity for neurotransmitters. We are careful not to claim any pharmacological advantage for this combination of properties, but we point out that it is complementary to and distinct from the properties of other NMBA reversal agents.

Sulfonated calixarenes have demonstrated in vivo activity in several models of intoxication and have favorable toxicity profiles. $\mathrm{sCx} 4$ itself is biocompatible with low toxicity $(100 \mathrm{mg} / \mathrm{kg}$ in mice) making it an excellent candidate for the development of novel supramolecular drug reversal agents. ${ }^{[23]}$ Sulfonatocalixarenes, however, are also known for forming intrinsically weak ( mM) complexes with a large variety of cationic guests in salty water. ${ }^{[12]}$ Until now, this has limited their biological applications to those that involve targeted analytes that exist at relatively high in vivo concentrations. ${ }^{[24]} \mathrm{We}$ are exploring the application of this templation approach to other host classes, as well as the potential for Super-sCx hosts in a variety of in vivo applications.

Table 2. Equilibrium dissociation constants of Super-sCx hosts and their selectivity for NMBAs vs. acetylcholine.

\begin{tabular}{lccc}
\hline Guest & Super-sCx4 $\left(K_{d}, M\right)^{[a]}$ & Selectivity over ACh (fold) & Super-sCx5 (Kd, M) ${ }^{[a]}$ \\
\hline Lucigenin & $6 \pm 2 \times 10^{-7}$ & - & $3 \pm 1 \times 10^{-7}$ \\
Choline & $2 \pm 1 \times 10^{-2}$ & - & $1.1 \pm 0.7 \times 10^{-3}$ \\
Acetylcholine & $9 \pm 5 \times 10^{-3}$ & - & $1.4 \pm 0.8 \times 10^{-3}$ \\
Decamethonium & $6.3 \pm 0.9 \times 10^{-5}$ & 140 & $1.8 \pm 0.4 \times 10^{-5}$ \\
Suxamethonium & $7.1 \pm 0.8 \times 10^{-5}$ & 130 & $1.4 \pm 0.3 \times 10^{-5}$ \\
Gallamine & $8 \pm 6 \times 10^{-6[b]}$ & $1100^{[b]}$ & $2 \pm 2 \times 10^{-6[b]}$ \\
Pancuronium & $1.0 \pm 0.2 \times 10^{-5}$ & 900 & $1.4 \pm 0.3 \times 10^{-5}$ \\
Tubocurarine & $2 \pm 1 \times 10^{-4}$ & 45 & $1.8 \pm 0.8 \times 10^{-5}$ \\
Cisatracurium & $2 \pm 0.4 \times 10^{-4}$ & 45 & $6 \pm 3 \times 10^{-6[b]}$ \\
\hline
\end{tabular}

[a] All studies solutions in phosphate buffer $(10 \mathrm{mM}, \mathrm{pH}$ 7.4). Dissociation constants were determined from fluorescence IDA titrations assuming 1:1 stoichiometry 1:1 binding was supported by molecular modeling of NMBAs with Super-sCx hosts. For binding curves and residuals see SI. [b] Certain structurally complex NMBAs showed complex titration profiles that prove a non-1:1 stoichiometry. The apparent $K_{d}$ values arising from 1:1 fits are provided, but must be considered only as rough approximations of potency for binding. 


\section{Acknowledgements}

The authors thank the Natural Sciences and Engineering Research Council of Canada (NSERC, RGPIN-2019-04806) for financial support. We thank Prof. Dong-Sheng Guo and JuanJuan Li, Nankai University Tianjin, for calix[5]arene starting material. We thank Christopher Barr for expertise in DOSY NMR assistance and CAMTEC for the use of shared facilities.

Keywords: calixarenes • host-guest systems • reversal agents • supramolecular chemistry $\bullet$ template synthesis

[1] J. M. Hunter, N Engl J Med 1995, 332, 1691-1699.

[2] J. Appiah-Ankam, J. M. Hunter, Continuing Education in Anaesthesia Critical Care \& Pain 2004, 4, 2-7.

[3] C. Lee, Pharmacol Ther 2003, 98, 143-169.

[4] a) H. Yin, X. Zhang, J. Wei, S. Lu, D. Bardelang, R. Wang, Theranostics 2021, 11, 1513-1526; b) C. L. Deng, S. L. Murkli, L. D. Isaacs, Chem Soc Rev 2020, 49, 7516-7532.

[5] A. Bom, M. Bradley, K. Cameron, J. K. Clark, J. Van Egmond, H. Feilden, E. J. MacLean, A. W. Muir, R. Palin, D. C. Rees, M. Q. Zhang, Angew Chem Int Ed Engl 2002, 41, 266-270.

[6] M. Shields, M. Giovannelli, R. K. Mirakhur, I. Moppett, J. Adams, Y. Hermens, Br J Anaesth 2006, 96, 36-43.

[7] H. D. de Boer, J. van Egmond, F. van de Pol, A. Bom, L. H. Booij, Br J Anaesth 2006, 96, 473-479.

[8] D. N. Shurpik, O. A. Mostovaya, D. A. Sevastyanov, O. A. Lenina, A. S. Sapunova, A. D. Voloshina, K. A. Petrov, I. V. Kovyazina, P. J. Cragg, Stoikov, II, Org Biomol Chem 2019, 17, 9951-9959.

[9] X. Zhang, Q. Cheng, L. Li, L. Shangguan, C. Li, S. Li, F. Huang, J. Zhang, R. Wang, Theranostics 2019, 9, 31073121.

[10] W. Xue, P. Y. Zavalij, L. Isaacs, Angew Chem Int Ed Engl 2020, 59, 13313-13319.

[11] D. Ma, B. Zhang, U. Hoffmann, M. G. Sundrup, M. Eikermann, L. Isaacs, Angew Chem Int Ed Engl 2012, 51, 11358-11362.
D.-S. Guo, K. Wang, Y. Liu, Journal of Inclusion Phenomena and Macrocyclic Chemistry 2008, 62, 1-21. M. A. Beatty, A. J. Selinger, Y. Li, F. Hof, J Am Chem Soc 2019, 141, 16763-16771. M. A. Gamal-Eldin, D. H. Macart
Chemistry 2014, 92, 243-249.

a) B. B. Ahuja, A. Vigalok, Angewandte Chemie International Edition 2019, 58, 2774-2778; b) R. Zadmard T. Schrader, Angewandte Chemie International Edition 2006, 45, 2703-2706; c) J. Wang, S. G. Bodige, W. H. Watson, C. D. Gutsche, The Journal of Organic Chemistry 2000, 65, 8260-8263; d) A. Bottino, F. Cunsolo, M. Piattelli, D. Garozzo, P. Neri, The Journal of Organic Chemistry 1999, 64, 8018-8020.

[17] a) N. H. Evans, P. D. Beer, Angewandte Chemie International Edition 2014, 53, 11716-11754; b) N. Gimeno, R. Vilar, Coordination Chemistry Reviews 2006, 250, 3161-3189.

[18] D. V. Kondratuk, J. K. Sprafke, M. C. O'Sullivan, L. M. A Perdigao, A. Saywell, M. Malfois, J. N. O'Shea, P. H. Beton, A. L. Thompson, H. L. Anderson, Chemistry - A European Journal 2014, 20, 12826-12834.

[19] Y. Cao, J. Yang, D. Eichin, F. Zhao, D. Qi, L. Kahari, C. Jia, M. Peurla, J. M. Rosenholm, Z. Zhao, S. Jalkanen, J. Li, Angewandte Chemie 2021, 133, 3099-3107.

[20] K. S. Chichak, S. J. Cantrill, A. R. Pease, S. H. Chiu, G. W. Cave, J. L. Atwood, J. F. Stoddart, Science 2004, 304, 1308-1312.

[21] S. Połowiński, Progress in Polymer Science 2002, 27, 537-577.

[22] a) A. Canal-Martín, R. Pérez-Fernández, ACS Omega 2020, 5, 26307-26315; b) R. L. E. Furlan, S. Otto, J. K. M. Sanders, Proceedings of the National Academy of Sciences 2002, 99, 4801-4804; c) S. Otto, R. L. E. Furlan, J. K. M. Sanders, Drug Discovery Today 2002, 7, 117-125

[23] A. W. Coleman, S. Jebors, S. Cecillon, P. Perret, D. Garin, D. Marti-Battle, M. Moulin, New Journal of Chemistry 2008, 32, 780-782.

[24] K. Wang, D. S. Guo, H. Q. Zhang, D. Li, X. L. Zheng, Y. Liu, J Med Chem 2009, 52, 6402-6412.

\section{Entry for the Table of Contents}

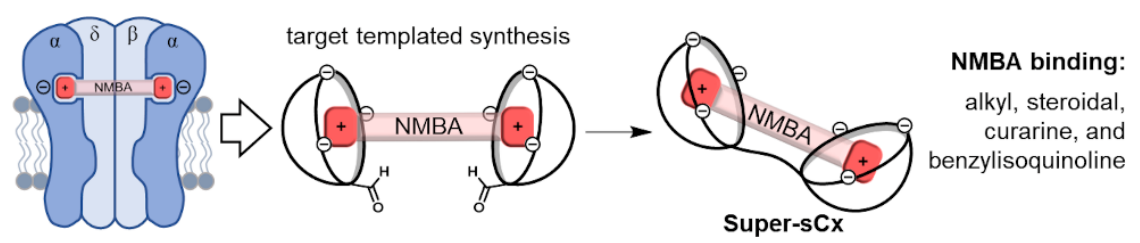

Broad-spectrum binding: New bivalent supramolecular reversal agents are formed by target templated synthesis in aqueous solution. Bivalent anionic Super-sCx calixarene hosts form strong complexes to a variety of structurally diverse target neuromuscular blocking agents.

Institute and/or researcher Twitter usernames:

@Hof_group_news 


\section{Table of Contents}

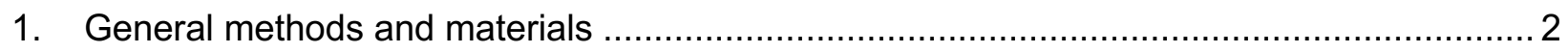

1.1. General NMR spectroscopy methods ............................................................ 2

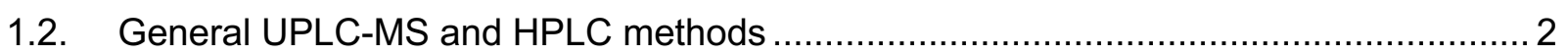

1.3. General HR-MS, MP and IR characterization methods ....................................... 2

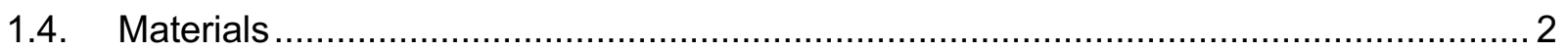

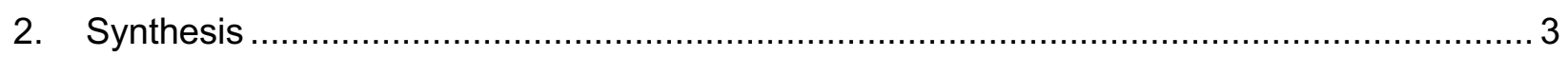

2.1. Characterization data $-{ }^{1} \mathrm{H},{ }^{13} \mathrm{C}$, DEPT-135 NMR and UPLC-MS .......................... 6

2.2. In situ reaction monitoring by ${ }^{1} \mathrm{H}$ NMR and UPLC-MS ...................................... 16

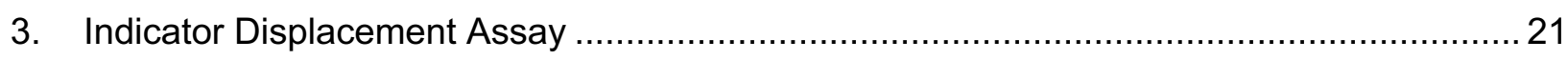

3.1. Determining direct and competitive binding affinities ...................................... 21

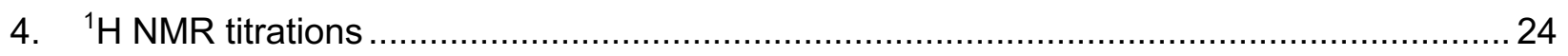

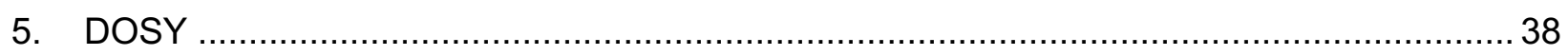

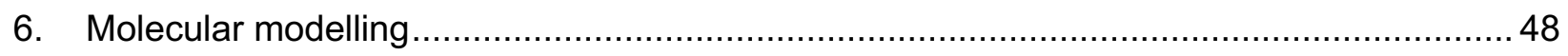

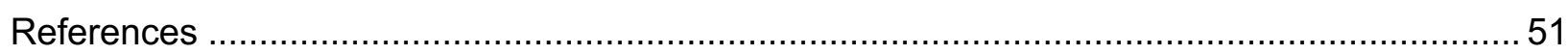

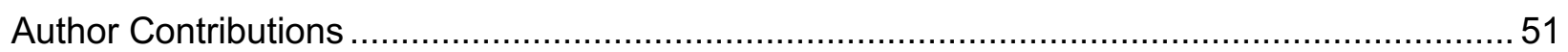




\section{General methods and materials}

\subsection{General NMR spectroscopy methods}

Deuterated solvents were purchased from Sigma Aldrich. Reactions monitored in situ were prepared using ammonium carbonate $(50 \mathrm{mM}, \mathrm{pD} 6.4)$ in $\mathrm{D}_{2} \mathrm{O}$, pD was adjusted using $1 \mathrm{M} \mathrm{DCl}$. Ammonium carbonate was selected due to its lack of interference in ${ }^{1} \mathrm{H}$ NMR and compatibility with UPLC-MS. Adjusting the $\mathrm{pD}$ to 6.4 favored the formation of hydrazone in the initial condensation reaction. ${ }^{1} \mathrm{H}$ NMR titrations were performed in phosphate buffer $(50 \mathrm{mM}, \mathrm{pD} 7.4)$, prepared using sodium phosphate monobasic and sodium phosphate dibasic in $\mathrm{D}_{2} \mathrm{O}$, the $\mathrm{pD}$ was adjusted with $1 \mathrm{M} \mathrm{NaOD/DCl}$.

${ }^{1} \mathrm{H},{ }^{13} \mathrm{C}$, and 1D DOSY were recorded on a Bruker Avance Neo $500 \mathrm{MHz}$ spectrometer or $300 \mathrm{MHz}$ spectrometer as specified. ${ }^{1} \mathrm{H},{ }^{13} \mathrm{C}$ NMR spectra were processed using MestReNova by Mestrelab Research S.L. 1D DOSY experiments were pre-processed using TopSpin and diffusion coefficients were analyzed using Bruker Dynamics Center.

\subsection{General UPLC-MS and HPLC methods}

Reactions were monitored and final host purity was verified using a Waters UPLC-MS equipped with UV/Vis and QDa detector. All samples were filtered through a $13 \mathrm{~mm}$ syringe filter with a $0.45 \mu \mathrm{m}$ PTFE membrane then injected onto an Aquity UPLC BEH C18 $1.7 \mu \mathrm{m}(21 \times 50 \mathrm{~mm})$ column. A gradient of $90 \% \mathrm{H}_{2} \mathrm{O}(0.4 \% \mathrm{FA}) / 10 \% \mathrm{CH}_{3} \mathrm{CN}(0.4 \% \mathrm{FA})$ to $30 \% \mathrm{H}_{2} \mathrm{O}$ $(0.4 \% \mathrm{FA}) / 70 \% \mathrm{CH}_{3} \mathrm{CN}(0.4 \% \mathrm{FA})$ over 5 minutes at $0.5 \mathrm{ml} / \mathrm{min}$ flow was used for all traces. Reaction mixtures were directly purified on a Teledyne ACCQPrep HP150 HPLC system with UV detection set at $280 \mathrm{~nm}$. A Phenomenex Luna C18, 250 $\mathrm{mm} \times 22 \mathrm{~mm}, 5 \mu \mathrm{m}$ preparative column or a Teledyne Redi Sep C18, $150 \mathrm{~mm} \times 20 \mathrm{~mm}, 5 \mu \mathrm{m}$ were used for purification. The column and gradient methods are as specified for each synthetic protocol.

\subsection{General HR-MS, MP and IR characterization methods}

Accurate mass spectra of pure novel compounds were obtained by electrospray ionization using a Thermo Scientific ${ }^{\mathrm{TM}}$ Exactive $^{\mathrm{TM}}$ Plus Orbitrap Ultimate 3000 LC-MS system. The eluent used was a 50:50 mix of Mili- $\mathrm{Q}^{\mathrm{TM}}$ water and Optima $^{\mathrm{TM}}$ Acetonitrile. Melting points were determined using a Gallenkamp Melting Point apparatus. Infrared spectra were collected using a Perkin Elmer 1000 FT-IR spectrometer. IR data was reported as frequency of absorption $\left(\mathrm{cm}^{-1}\right)$ intensity; $\mathrm{s}=$ strong, $\mathrm{m}=$ medium, $\mathrm{w}=$ weak, $\mathrm{br}=$ broad.

\subsection{Materials}

Suxamethonium chloride (>98\%) and decamethonium bromide (>98\%) were purchased from Tokyo Chemical Industry. Choline chloride (>98\%) was purchased from Alfa Aesar. Tubocurarine chloride (98\%), cisatracurium besylate (88\%), pancuronium bromide $(97 \%)$ and gallamine triethiodide $(95 \%)$ were purchased from Toronto Research Chemicals. Acetylcholine chloride (>98\%), hydrazine hydrochloride, sodium cyanoborhydride and lucigenin (LCG) were purchased form Sigma Aldrich. 


\section{Synthesis}

Starting material $\mathrm{sCx} 4-\mathrm{CHO}(1)$ was synthesized following the reported protocols. ${ }^{[1]}$

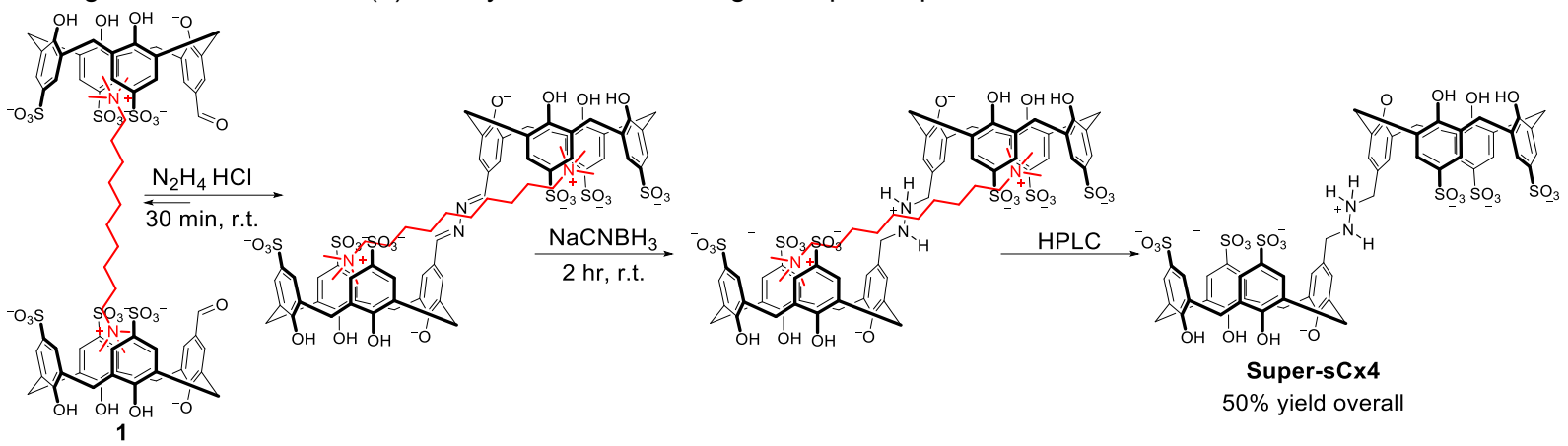

*See main text for schematic version of this figure

Super-sCx4 - templated reaction. sCx4-CHO (1) (30 mg, $0.043 \mathrm{mmol}$, final concentration $=10 \mathrm{mM})$ and decamethonium bromide $(9 \mathrm{mg}, 0.022 \mathrm{mmol}$, final concentration $=5 \mathrm{mM})$ were dissolved in ammonium carbonate in $\mathrm{D}_{2} \mathrm{O}(4.34 \mathrm{~mL}, 50 \mathrm{mM}$, $\mathrm{pD}$ 6.4). The starting material was equilibrated for $15 \mathrm{~min}$ at room temperature with stirring. The dissolved starting material formed a clear colourless solution. ${ }^{1} \mathrm{H}$ NMR of the starting material was taken to verify decamethonium complexation. Hydrazine hydrochloride $\left(0.024 \mathrm{mmol}, 24 \mu \mathrm{L}\right.$ of $1 \mathrm{M}$ solution in $\left.\mathrm{D}_{2} \mathrm{O}\right)$ was added and stirred at room temperature for $30 \mathrm{~min}$. Upon hydrazine hydrochloride addition the reaction formed an orange precipitate. Sodium cyanoborohydride $(0.43 \mathrm{mmol}, 27$ $\mathrm{mg}$ ) was added, and stirred at room temperature for $2 \mathrm{~h}$. Upon sodium cyanoborohydride addition the reaction formed a clear colourless solution. UPLC-MS verified the formation of bivalent Super-sCx4 as the major product (see Figure S23). The reaction mixture was directly purified by HPLC using a gradient of $90 \% \mathrm{H}_{2} \mathrm{O}(0.1 \% \mathrm{TFA}) / 10 \% \mathrm{CH}_{3} \mathrm{CN}(0.1 \%$ TFA) to $68 \% \mathrm{H}_{2} \mathrm{O}(0.1 \%$ TFA $) / 32 \% \mathrm{CH}_{3} \mathrm{CN}(0.1 \%$ TFA) over 17 minutes on a Phenomenex Luna C18, $250 \mathrm{~mm} \times 22 \mathrm{~mm}, 5 \mu \mathrm{m}$ preparative column. Fractions were collected, immediately flash frozen and lyophilized to yield a white fluffy solid ( $15 \mathrm{mg}$, $50 \%$ ). m.p. decomposed $>250^{\circ} \mathrm{C} ;{ }^{1} \mathrm{H}$ NMR $\left(300 \mathrm{MHz}, \mathrm{D}_{2} \mathrm{O}\right): \delta 7.63$ (s, 4H), 7.61 (s, 4H), 7.51 (s, 4H), 7.00 (s, $\left.4 \mathrm{H}\right), 4.02$ (d, J $=10.9 \mathrm{~Hz}, 16 \mathrm{H}), 3.75(\mathrm{~s}, 4 \mathrm{H}) ;{ }^{13} \mathrm{C}$ NMR $\left(126 \mathrm{MHz}, d_{6}-\mathrm{DMSO}\right): \delta 151.6,150.2,149.4,139.5,139.1,130.1,128.1,127.5$, 127.2, 127.0, 126.6, 126.5, 126.4, 126.0, 51.0, 30.9, 30.6; FT-IR: 3243 (br), 1594 (w), 1454 (w), 1136 (m), 1111 (m), 1037 (s), 625 (s), 551 (s) cm ${ }^{-1}$; HRMS (ESI): $\mathrm{m} / \mathrm{z}$ calcd for $\mathrm{C}_{58} \mathrm{H}_{52} \mathrm{~N}_{2} \mathrm{O}_{26} \mathrm{~S}_{6}{ }^{5-} 275.82265[\mathrm{M}-5 \mathrm{H}]^{5-}$; found 275.81569 .

Super-sCx4 - control untemplated reaction. The control reaction was carried out exactly as above but omitting decamethonium bromide. The dissolved starting material formed a clear colourless solution. Upon hydrazine hydrochloride addition the reaction formed a clear light-yellow solution. Upon sodium cyanoborohydride addition the reaction formed a clear colourless solution. UPLC-MS verified that bivalent Super-sCx4 was not synthesized in the absence of the decamethonium template. A mixture of the monovalent hydrazone and reduced starting material sCx4- $\mathrm{CH}_{3}(6)$ were formed (see Figure S24).

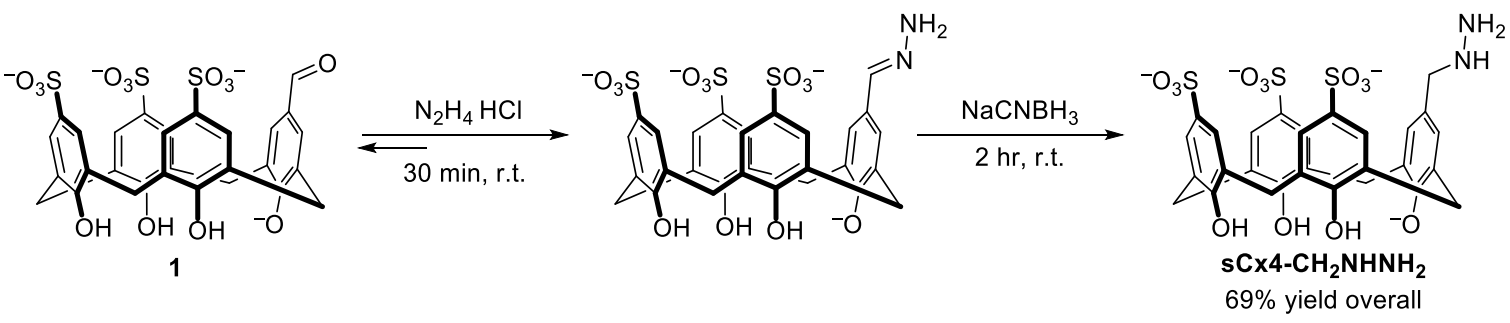

sCx4- $\mathrm{CH}_{2} \mathrm{NHNH}_{2}$. sCx4-CHO (1) $(50 \mathrm{mg}, 0.072 \mathrm{mmol}$, final concentration $=30 \mathrm{mM}$ ) was dissolved in ammonium carbonate in $\mathrm{D}_{2} \mathrm{O}(2.41 \mathrm{~mL}, 50 \mathrm{mM}, \mathrm{pD} 6.4)$, forming a colourless solution. Hydrazine hydrochloride $(0.22 \mathrm{mmol}, 217 \mu \mathrm{L}$ of $1 \mathrm{M}$ solution in $\mathrm{D}_{2} \mathrm{O}$ ) was added. Upon addition the solution turned yellow. The reaction was stirred at room temperature for $30 \mathrm{~min}$, forming a yellow precipitate. Sodium cyanoborohydride $(0.72 \mathrm{mmol}, 45 \mathrm{mg})$ was added, and stirred at room temperature for $2 \mathrm{~h}$, forming a white cloudy solution. A minimal amount of water was added to dissolve the precipitate $(\sim 2 \mathrm{~mL})$. The $\mathrm{crude}$ reaction mixture was directly purified by HPLC using a gradient of $90 \% \mathrm{H}_{2} \mathrm{O}(0.1 \% \mathrm{TFA}) / 10 \% \mathrm{CH}_{3} \mathrm{CN}(0.1 \% \mathrm{TFA})$ to $65 \%$ $\mathrm{H}_{2} \mathrm{O}(0.1 \%$ TFA $) / 35 \% \mathrm{CH}_{3} \mathrm{CN}(0.1 \%$ TFA) over 17 minutes on a Phenomenex Luna C18, $250 \mathrm{~mm} \times 22 \mathrm{~mm}, 5 \mu \mathrm{m}$ preparative column. The fractions were collected, immediately flash frozen and lyophilized, yielding a fluffy white product (35 mg, $69 \%)$. m.p. decomposed $>250^{\circ} \mathrm{C}$; ${ }^{1} \mathrm{H}$ NMR $\left(500 \mathrm{MHz}, \mathrm{D}_{2} \mathrm{O}\right)$ : $\delta 7.81(\mathrm{~s}, 2 \mathrm{H}), 7.68(\mathrm{~d}, J=2.2 \mathrm{~Hz}, 2 \mathrm{H}), 7.63(\mathrm{~s}, 2 \mathrm{H}), 6.88(\mathrm{~s}, 2 \mathrm{H}), 4.24-$ $3.88(\mathrm{~m}, 10 \mathrm{H}) ;{ }^{13} \mathrm{C}$ NMR $\left(126 \mathrm{MHz}, d_{6}\right.$-DMSO): $\delta$ 151.6, 150.2, 149.4, 139.5, 139.1, 130.1, 128.1, 127.5, 127.2, 127.0, 126.6, 126.5, 126.4, 126.0, 51.0, 30.9, 30.6; FT-IR: 3200 (br), 1609 (w), $1460(\mathrm{w}), 1156$ (s), 1040 (s), $626(\mathrm{~s}), 557(\mathrm{~m}) \mathrm{cm}^{-1}$; HRMS (ESI): $m / z$ calcd for $\mathrm{C}_{29} \mathrm{H}_{28} \mathrm{~N}_{2} \mathrm{O}_{13} \mathrm{~S}_{3}{ }^{3-} 235.02512[\mathrm{M}-3 \mathrm{H}]^{3-}$; found 235.01876. 
Calix[5]arene starting material was provided by Prof. Dong-Sheng Guo and Juan-Juan Li, Nankai University Tianjin. 4BzCx5 (2) was synthesized following the reported protocol. ${ }^{[2]}$

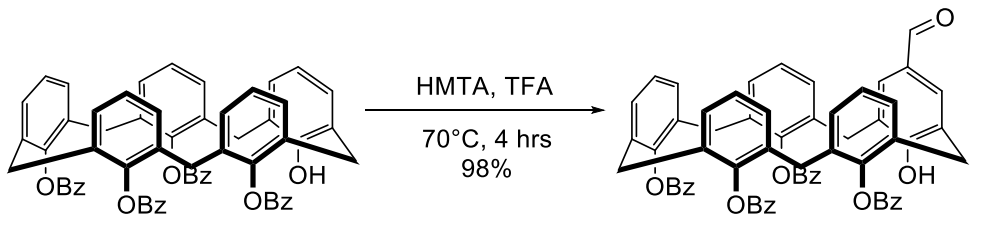

2

3

4Bz-Cx5-CHO (3). 4Bz-Cx5 (2) (500 mg, $0.52 \mathrm{mmol})$ was dissolved in trifluoroacetic acid (5 mL) and hexamethylenetetramine $(665 \mathrm{mg}, 4.75 \mathrm{mmol})$ was added. The solution was heated for $4 \mathrm{~h}$ at $70^{\circ} \mathrm{C}$ forming a clear pink solution. Water was added to the reaction forming a white precipitate. The precipitate was then dissolved upon addition of dichloromethane and the layers were separated. The water layer was back extracted twice with fresh dichloromethane. The combined organic layers were washed twice with water, then twice with brine and dried over $\mathrm{Na}_{2} \mathrm{SO}_{4}$. The filtered organic layer was concentrated to dryness on a rotary evaporator resulting in light yellow crystals ( $500 \mathrm{mg}, 98 \%$ yield). This product was carried forward to debenzoylation after partial characterization, due to poor ionization in HRMS and multiple conformations resulting in intractable NMR spectra. ${ }^{1} \mathrm{H}$ NMR $\left(500 \mathrm{MHz}, \mathrm{CDCl}_{3}\right): \delta 9.91(\mathrm{~s}, 1 \mathrm{H}), 8.39-5.99(\mathrm{~m}, 34 \mathrm{H})$, 4.23-3.11 (m, 10H).
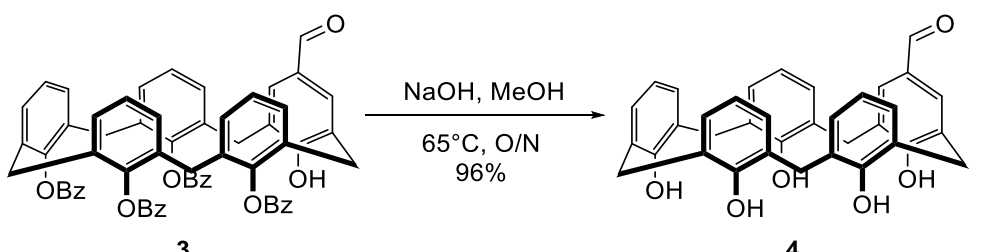

Cx5-CHO (4). 4Bz-Cx5-CHO (3) (500 mg, $0.51 \mathrm{mmol})$ and sodium hydroxide pellets (410 mg, $10.2 \mathrm{mmol})$ were dissolved in methanol $(20 \mathrm{~mL})$. The reaction was heated at reflux overnight forming a clear orange-brown solution. The mixture was quenched with cold $1 \mathrm{M} \mathrm{HCl}$, forming a white precipitate. The precipitate was collected by vacuum filtration then purified using a silica plug $(\sim 10 \mathrm{~g})$. The crude was dissolved in minimal $\mathrm{CH}_{2} \mathrm{Cl}_{2}$ and wet loaded. The plug was run with a starting eluent of $\mathrm{CH}_{2} \mathrm{Cl}_{2}$ with a gradient to $\mathrm{CH}_{2} \mathrm{Cl}_{2}+5 \% \mathrm{MeOH}$, affording a solid white product. (275 mg, yield $96 \%$ ). m.p. decomposed $>250^{\circ} \mathrm{C}$; ${ }^{1} \mathrm{H}$ NMR $\left(300 \mathrm{MHz}, \mathrm{CDCl}_{3}\right)$ : $\delta 9.35(\mathrm{~s}, 1 \mathrm{H}), 9.17(\mathrm{~s}, 1 \mathrm{H}), 8.37(\mathrm{~s}, 2 \mathrm{H}), 8.23(\mathrm{~s}, 2 \mathrm{H}), 6.77-6.99(\mathrm{~m}, 10 \mathrm{H})$, $6.37(\mathrm{t}, J=7.7 \mathrm{~Hz}, 2 \mathrm{H}), 6.35(\mathrm{t}, J=7.7 \mathrm{~Hz}, 2 \mathrm{H}), 3.38(\mathrm{br}, 10 \mathrm{H}) ;{ }^{13} \mathrm{C}$ NMR $\left(126 \mathrm{MHz}, \mathrm{CDCl}_{3}\right): \delta$ 191.0, 156.0, 150.0, 149.9 , 131.4, 130.6, 129.7, 129.4 (2x), 129.4, 127.8, 127.0, 126.8, 126.6, 125.8, 122.1, 121.8, 31.4, 31.3, 31.3; FT-IR: 3249 (br), $1686(\mathrm{~m}), 1596(\mathrm{~m}), 1446(\mathrm{~m}), 753(\mathrm{~s}) \mathrm{cm}^{-1}$; HRMS (ESI): m/z calcd for $\mathrm{C}_{36} \mathrm{H}_{30} \mathrm{O}_{6}{ }^{-} 557.20424[M-\mathrm{H}]^{1-} ;$ found 557.19679.

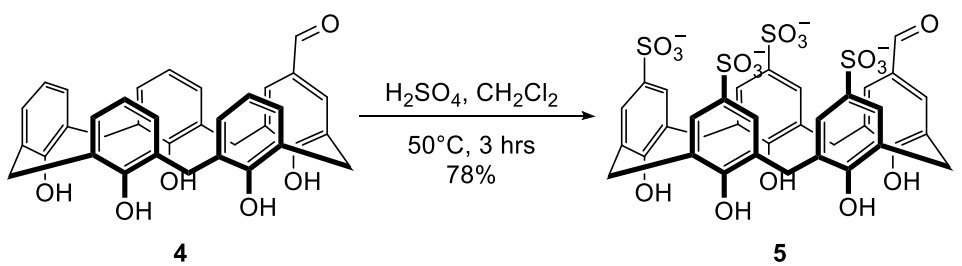

sCx5-CHO (5). CHO-Cx5 (4) (100 mg, $0.18 \mathrm{mmol}$ ) was dissolved in minimal dichloromethane (2 mL). Concentrated sulfuric acid $(192 \mu \mathrm{L}, 3.6 \mathrm{mmol})$ was added and the reaction was heated at $50^{\circ} \mathrm{C}$ for $3 \mathrm{~h}$. An insoluble pink-purple residue formed on the sides of the reaction vial. Dichloromethane was decanted from the reaction. The residue was rinsed with fresh dichloromethane and decanted again. The solid residue was then suspended in ethyl acetate $(\sim 4 \mathrm{~mL})$ by sonication and transferred into a $50 \mathrm{~mL}$ falcon tube. Suspension in ethyl acetate was repeated two more times to completely remove all residue from the reaction vial $\left(\sim 12 \mathrm{~mL}\right.$ total). The suspension was diluted with cold diethyl ether $\left(0^{\circ} \mathrm{C}, \sim 30 \mathrm{~mL}\right)$ forming a grey precipitate. The suspension was centrifuged into a pellet $\left(10 \mathrm{~min}, 4^{\circ} \mathrm{C}, 3400 \mathrm{rpm}\right)$ and the supernatant was decanted. The pellet was resuspended in cold diethyl ether $\left(0^{\circ} \mathrm{C}, \sim 30 \mathrm{~mL}\right)$ with sonication, repeating the centrifugation and decanting process. The pellet was left to air dry overnight then purified by HPLC. A gradient of $90 \% \mathrm{H}_{2} \mathrm{O}(0.1 \% \mathrm{TFA}) / 10 \% \mathrm{CH}_{3} \mathrm{CN}$ $(0.1 \%$ TFA $)$ to $77 \% \mathrm{H}_{2} \mathrm{O}(0.1 \%$ TFA $) / 23 \% \mathrm{CH}_{3} \mathrm{CN}(0.1 \%$ TFA) over 12 minutes was used on a Teledyne Redi Sep C18, 150 $\mathrm{mm} \times 20 \mathrm{~mm}, 5 \mu \mathrm{m}$ preparative column. Fractions were concentrated by rotary evaporator then lyophilized, affording a white fluffy powder (122 mg, 78\%). m.p. decomposed >250 ${ }^{\circ} \mathrm{C} ;{ }^{1} \mathrm{H}$ NMR $\left(300 \mathrm{MHz}, \mathrm{D}_{2} \mathrm{O}\right): \delta 9.62(\mathrm{~s}, 1 \mathrm{H}), 7.70(\mathrm{~s}, 2 \mathrm{H}), 7.64(\mathrm{~d}, J=$ $2.4 \mathrm{~Hz}, 2 \mathrm{H}), 7.60-7.57(\mathrm{~m}, 2 \mathrm{H}), 7.56(\mathrm{~d}, \mathrm{~J}=2.4 \mathrm{~Hz}, 1 \mathrm{H}), 3.92(\mathrm{br}, 10 \mathrm{H}) ;{ }^{13} \mathrm{C}$ NMR $\left(126 \mathrm{MHz}, \mathrm{D}_{2} \mathrm{O}\right): \delta 195.5,158.2,153.8$, 153.7, 135.7 (2x), 132.1, 129.7, 129.7, 129.6, 129.6, 129.5, 129.3, 127.1, 127.1, 127.0, 126.9, 31.4, 31.4, 31.1; FT-IR: 3282 (br), 1664 (w), 1111 (s), 1035 (s), $620(\mathrm{~m}), 554(\mathrm{~m}) \mathrm{cm}^{-1}$; HRMS (ESI): $\mathrm{m} / \mathrm{z}$ calcd for $\mathrm{C}_{36} \mathrm{H}_{30} \mathrm{O}_{18} \mathrm{~S}_{4}{ }^{3-} 291.67717$ [M-3H] ${ }^{3-}$; found 291.66999. 


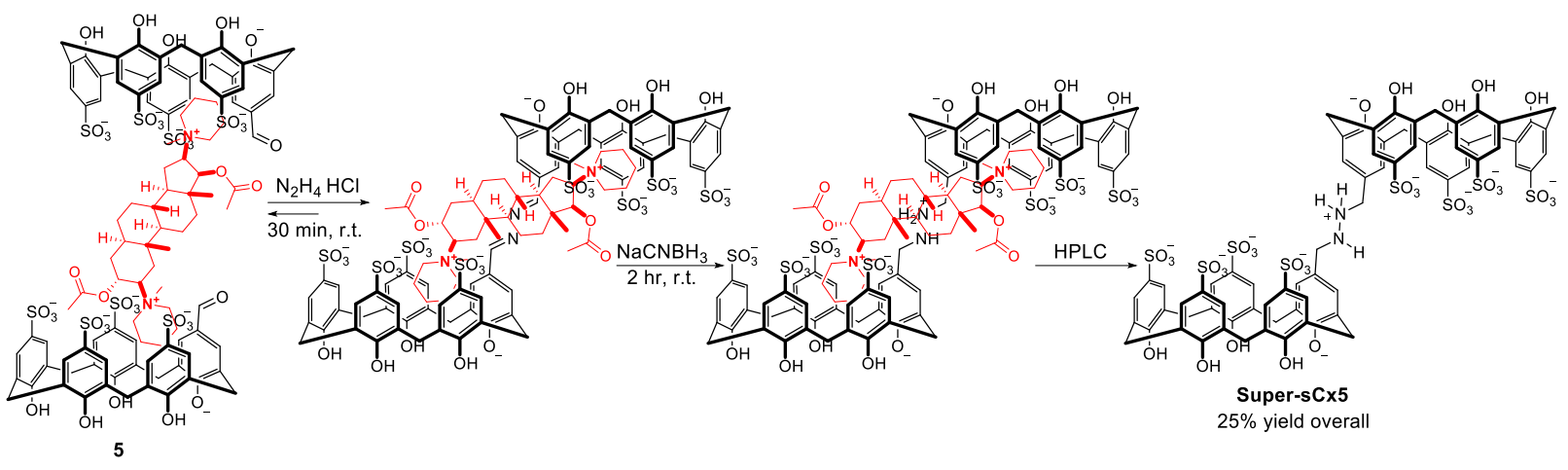

*See main text for schematic version of this figure

Super-sCx5 - templated reaction. sCx5-CHO (5) (30 mg, 0.034, final concentration $=10 \mathrm{mM})$ and pancuronium bromide $(12.6 \mathrm{mg}, 0.017 \mathrm{mmol}$, final concentration $=5 \mathrm{mM})$ were dissolved in ammonium carbonate in $\mathrm{D}_{2} \mathrm{O}(3.43 \mathrm{~mL}, 50 \mathrm{mM}, \mathrm{pD}$ 6.4). The starting material was equilibrated for $15 \mathrm{~min}$ at room temperature with stirring. The dissolved starting material formed a clear colourless solution. ${ }^{1} \mathrm{H}$ NMR of the starting material was taken to verify pancuronium complexation.

Hydrazine hydrochloride $\left(0.019 \mathrm{mmol}, 19 \mu \mathrm{L}\right.$ of $1 \mathrm{M}$ solution in $\left.\mathrm{D}_{2} \mathrm{O}\right)$ was added and stirred at room temperature for $30 \mathrm{~min}$. Upon hydrazine hydrochloride addition the reaction formed an orange solution. Sodium cyanoborohydride $(0.34 \mathrm{mmol}, 22$ $\mathrm{mg}$ ) was added, and stirred at room temperature for $2 \mathrm{~h}$. Upon sodium cyanoborohydride addition the reaction formed a clear colourless solution. UPLC-MS verified the formation of bivalent Super-sCx5 as the major product (see Figure S26). The reaction mixture was directly purified by HPLC using a gradient of $90 \% \mathrm{H}_{2} \mathrm{O}(0.1 \% \mathrm{TFA}) / 10 \% \mathrm{CH}_{3} \mathrm{CN}(0.1 \%$ TFA) to $68 \% \mathrm{H}_{2} \mathrm{O}(0.1 \%$ TFA $) / 32 \% \mathrm{CH}_{3} \mathrm{CN}(0.1 \%$ TFA) over 17 minutes on a Phenomenex Luna C18, $250 \mathrm{~mm} \times 22 \mathrm{~mm}, 5 \mu \mathrm{m}$ preparative column. The fractions were collected, immediately flash frozen and lyophilized to yield a white fluffy solid (6 mg, 25\%). m.p. decomposed $>250^{\circ} \mathrm{C}$; ${ }^{1} \mathrm{H}$ NMR $\left(500 \mathrm{MHz}, \mathrm{D}_{2} \mathrm{O}\right)$ : $\delta 7.64-7.56(\mathrm{~m}, 16 \mathrm{H}), 7.10(\mathrm{~s}, 4 \mathrm{H}), 3.97(\mathrm{~s}, 4 \mathrm{H}), 3.90(\mathrm{~s}, 12 \mathrm{H})$, $3.85(\mathrm{~s}, 8 \mathrm{H}) ;{ }^{13} \mathrm{C}$ NMR $\left(126 \mathrm{MHz}, d_{6}\right.$-DMSO): $\delta 152.2,152.1,151.4,138.7,138.4,130.1,128.4,127.6,127.4,127.4,127.2$, 126.6 (x2), 126.5, 126.3, 124.8, 51.4, 31.5, 31.0, 30.8; FT-IR: 3344 (br), 1594 (w), 1474 (w), 1139 (m), 1113 (s), 1038 (s), $622(\mathrm{~m}), 558(\mathrm{~m}) \mathrm{cm}^{-1}$; HRMS (ESI): $\mathrm{m} / \mathrm{z}$ calcd for $\mathrm{C}_{72} \mathrm{H}_{64} \mathrm{~N}_{2} \mathrm{O}_{34} \mathrm{~S}_{8}{ }^{6-} 291.68510[\mathrm{M}-6 \mathrm{H}]^{6-}$; found 291.67723.

Super-sCx5 - control untemplated reaction. The control reaction was carried out exactly as above but omitting pancuronium bromide. The dissolved starting material formed a clear colourless solution. Upon hydrazine hydrochloride addition the reaction formed a clear light-yellow solution. Upon sodium cyanoborohydride addition the reaction formed a clear colourless solution. UPLC-MS verified that bivalent Super-sCx5 was not synthesized in the absence of the template pancuronium. A mixture of the monovalent hydrazone and reduced starting material sCx5- $\mathrm{CH}_{3}(7)$ were formed (see Figure S27).

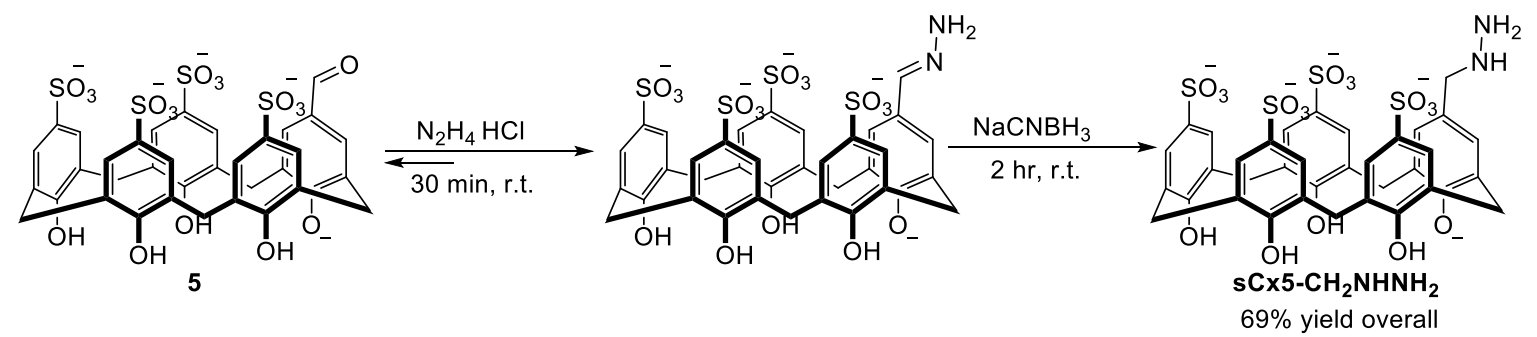

sCx5- $\mathrm{CH}_{2} \mathrm{NHNH}_{2}$. sCx5-CHO (5) $(50 \mathrm{mg}, 0.057 \mathrm{mmol}$, final concentration = $30 \mathrm{mM}$ ) was dissolved in ammonium carbonate in $\mathrm{D}_{2} \mathrm{O}(1.91 \mathrm{~mL}, 50 \mathrm{mM}, \mathrm{pD} 6.4)$, forming a colourless solution. Hydrazine hydrochloride $(0.17 \mathrm{mmol}, 171 \mu \mathrm{L}$ of $1 \mathrm{M}$ solution in $\mathrm{D}_{2} \mathrm{O}$ ) was added. Upon addition the solution turned yellow. The reaction was stirred at room temperature for 30 min. Sodium cyanoborohydride $(0.57 \mathrm{mmol}, 36 \mathrm{mg})$ was added, and stirred at room temperature for $2 \mathrm{~h}$, forming a colourless solution. The crude reaction mixture was directly purified by HPLC using a gradient of $90 \% \mathrm{H}_{2} \mathrm{O}(0.1 \% \mathrm{TFA}) / 10 \% \mathrm{CH} \mathrm{H}_{3} \mathrm{CN}$ (0.1\% TFA) to $65 \% \mathrm{H}_{2} \mathrm{O}\left(0.1 \%\right.$ TFA)/35\% $\mathrm{CH}_{3} \mathrm{CN}(0.1 \%$ TFA) over 17 minutes on a Phenomenex Luna C18, $250 \mathrm{~mm} \times 22$ $\mathrm{mm}, 5 \mu \mathrm{m}$ preparative column. The fractions were collected, immediately flash frozen and lyophilized, yielding a fluffy white product $(28 \mathrm{mg}, 69 \%)$. m.p. decomposed $>250^{\circ} \mathrm{C}$; ${ }^{1} \mathrm{H}$ NMR $\left(500 \mathrm{MHz}, \mathrm{D}_{2} \mathrm{O}\right): \delta 7.73(\mathrm{~d}, \mathrm{~J}=2.3 \mathrm{~Hz}, 2 \mathrm{H}), 7.63(\mathrm{~d}, J=2.3 \mathrm{~Hz}$, $2 \mathrm{H}), 7.59(\mathrm{~d}, J=2.3 \mathrm{~Hz}, 2 \mathrm{H}), 7.53(\mathrm{~d}, J=2.3 \mathrm{~Hz}, 2 \mathrm{H}), 7.01(\mathrm{~s}, 2 \mathrm{H}), 3.99(\mathrm{~s}, 2 \mathrm{H}), 3.96(\mathrm{~s}, 6 \mathrm{H}), 3.90(\mathrm{~s}, 2 \mathrm{H}) .{ }^{13} \mathrm{C} \mathrm{NMR}(126$ $\mathrm{MHz}, d_{6}$-DMSO): $\delta$ 152.2, 151.9, 151.3, 139.0, 138.7, 128.2, 127.5, 127.3, 127.3, 127.0, 126.9, 126.8, 126.4, 126.3, 54.0, 31.1, 30.9, 30.5; FT-IR: 3320 (br), 1593 (w), $1473(\mathrm{w}), 1139(\mathrm{~m}), 1112(\mathrm{~s}), 1037$ (s), $623(\mathrm{~m}), 558(\mathrm{~m}) \mathrm{cm}^{-1}$. HRMS (ESI): $\mathrm{m} / \mathrm{z}$ calcd for $\mathrm{C}_{36} \mathrm{H}_{34} \mathrm{~N}_{2} \mathrm{O}_{17} \mathrm{~S}_{4}{ }^{3-} 297.02468[\mathrm{M}-3 \mathrm{H}]^{3-}$; found 297.01746. 
2.1. Characterization data $-{ }^{1} \mathrm{H},{ }^{13} \mathrm{C}$, DEPT-135 NMR and UPLC-MS

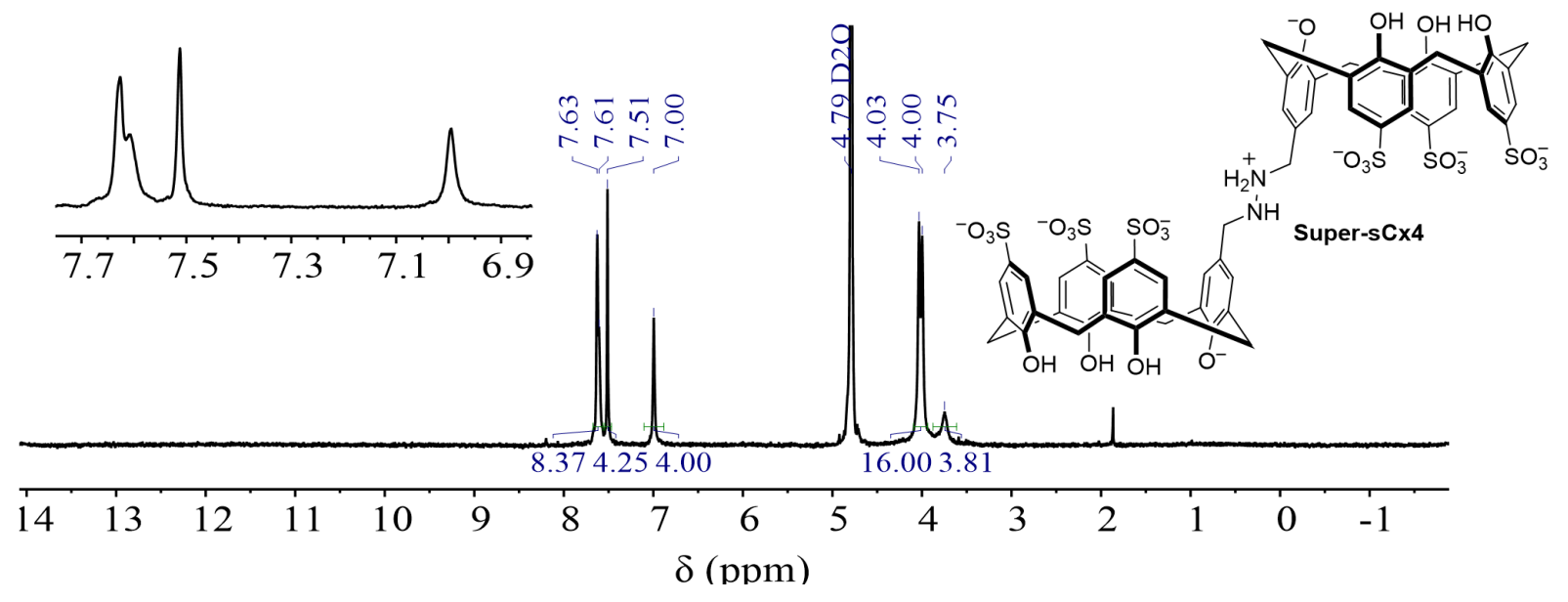

Figure S1. ${ }^{1} \mathrm{H}$ NMR spectrum of bivalent Super-sCx4 $\left(300 \mathrm{MHz}, 300 \mathrm{~K}\right.$, in $\left.\mathrm{D}_{2} \mathrm{O}\right)$.

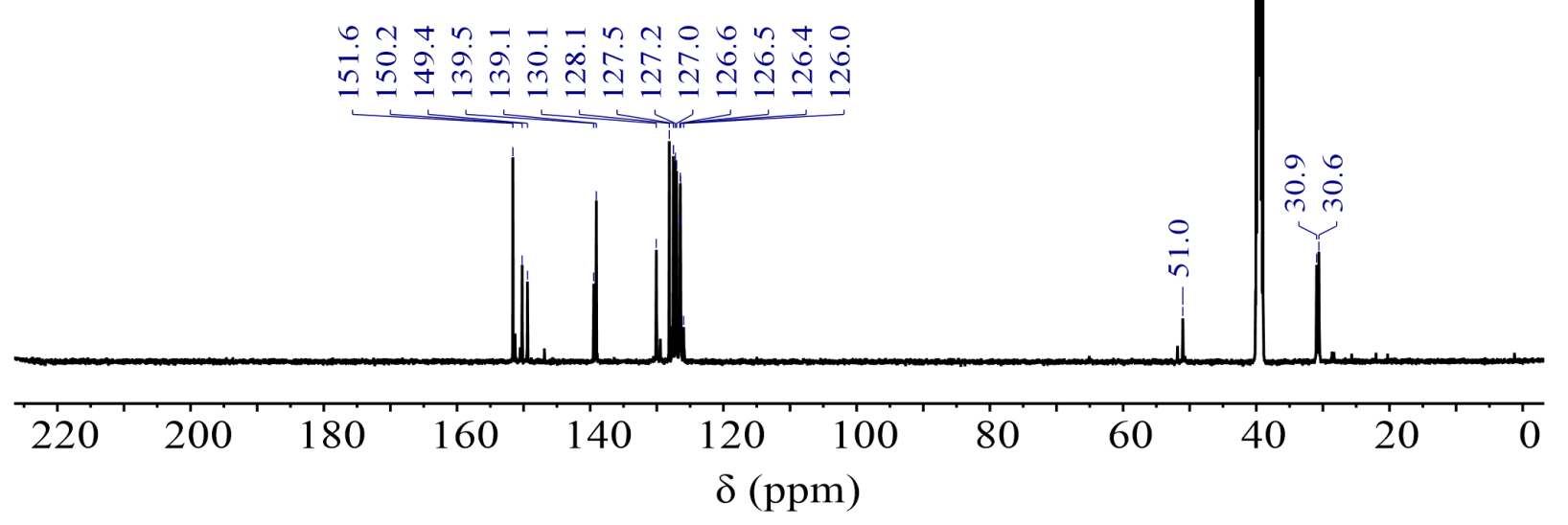

Figure S2. ${ }^{13} \mathrm{C}$ NMR spectrum of bivalent Super-sCx4 (125 MHz, $298 \mathrm{~K}$, in $d_{6}$-DMSO).

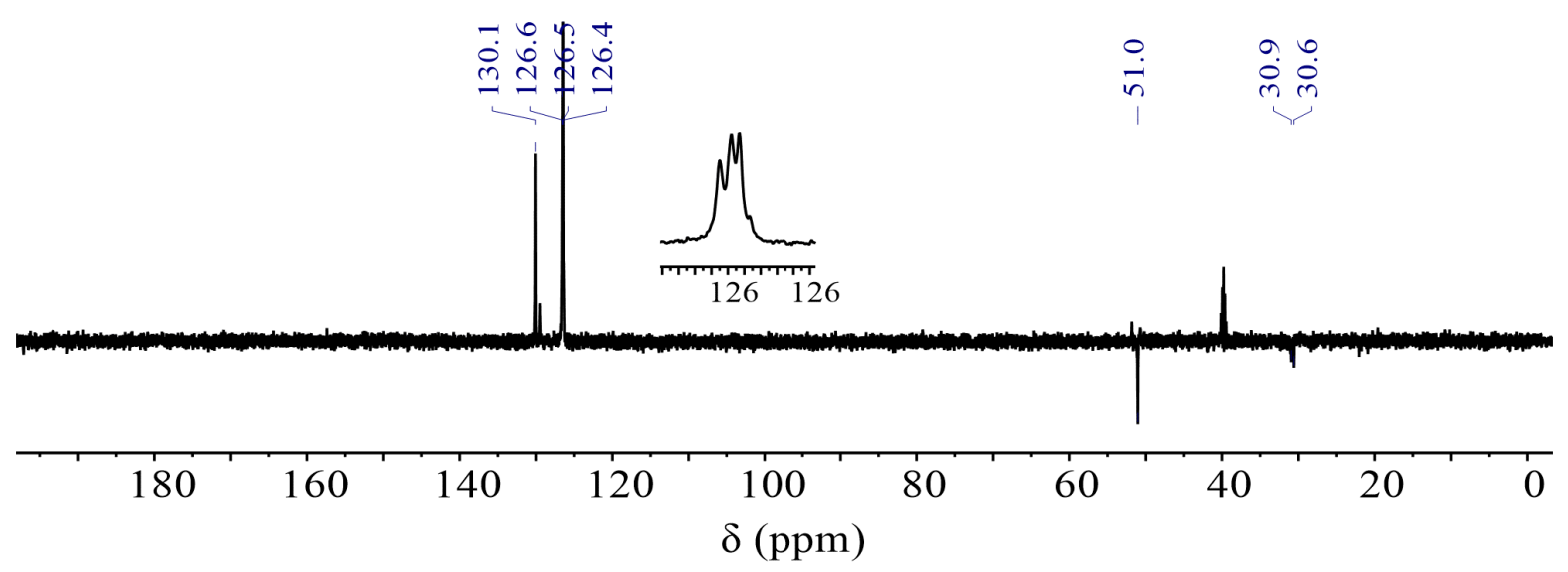


Figure S3. DEPT-135 NMR spectrum of bivalent Super-sCx4 (125 MHz, $298 \mathrm{~K}$, in $d_{6}$-DMSO).
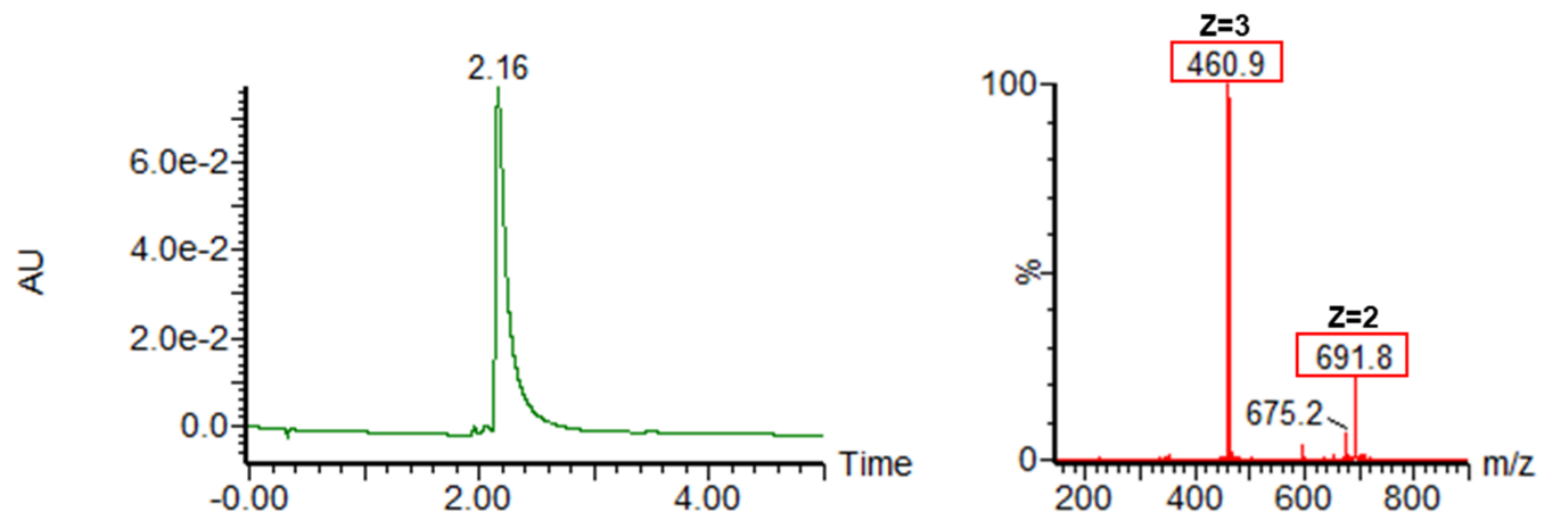

Figure S4. UPLC-MS trace of bivalent Super-sCx4 after preparative HPLC purification. 


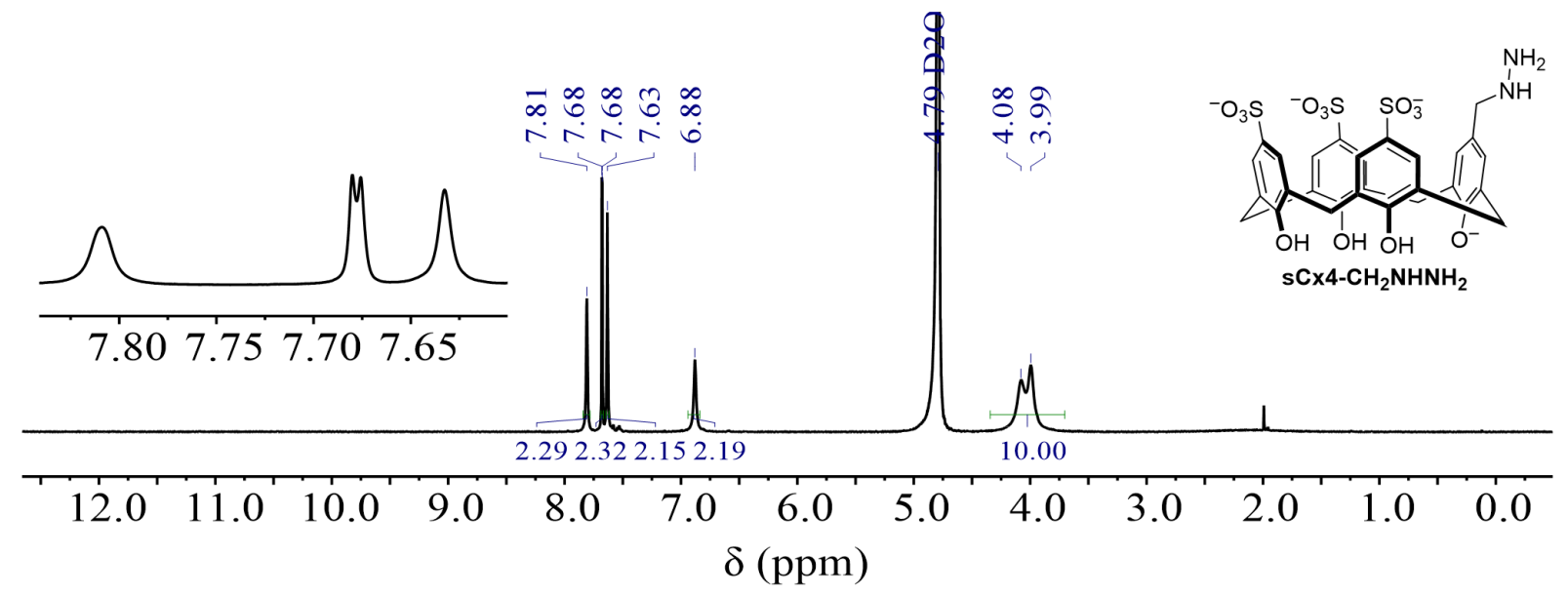

Figure S5. ${ }^{1} \mathrm{H}$ NMR spectrum of monovalent $\mathbf{s} \mathbf{C} \times \mathbf{4}-\mathbf{C H}_{2} \mathbf{N H N H}_{2}\left(500 \mathrm{MHz}, 298 \mathrm{~K}\right.$, in $\left.\mathrm{D}_{2} \mathrm{O}\right)$.

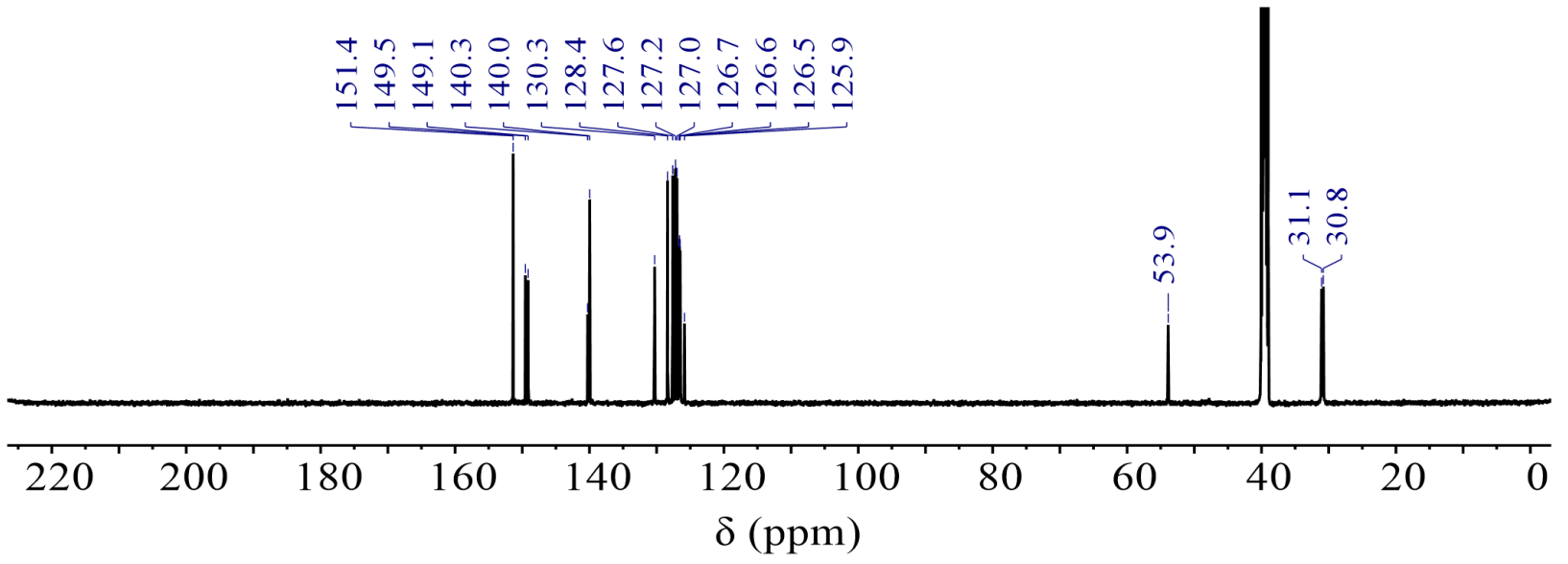

Figure S6. ${ }^{13} \mathrm{C}$ NMR spectrum of monovalent $\mathbf{s} \mathbf{C} \times 4-\mathbf{C H}_{2} \mathbf{N H N H}_{2}\left(125 \mathrm{MHz}, 298 \mathrm{~K}\right.$, in $\left.d_{6}-\mathrm{DMSO}\right)$.

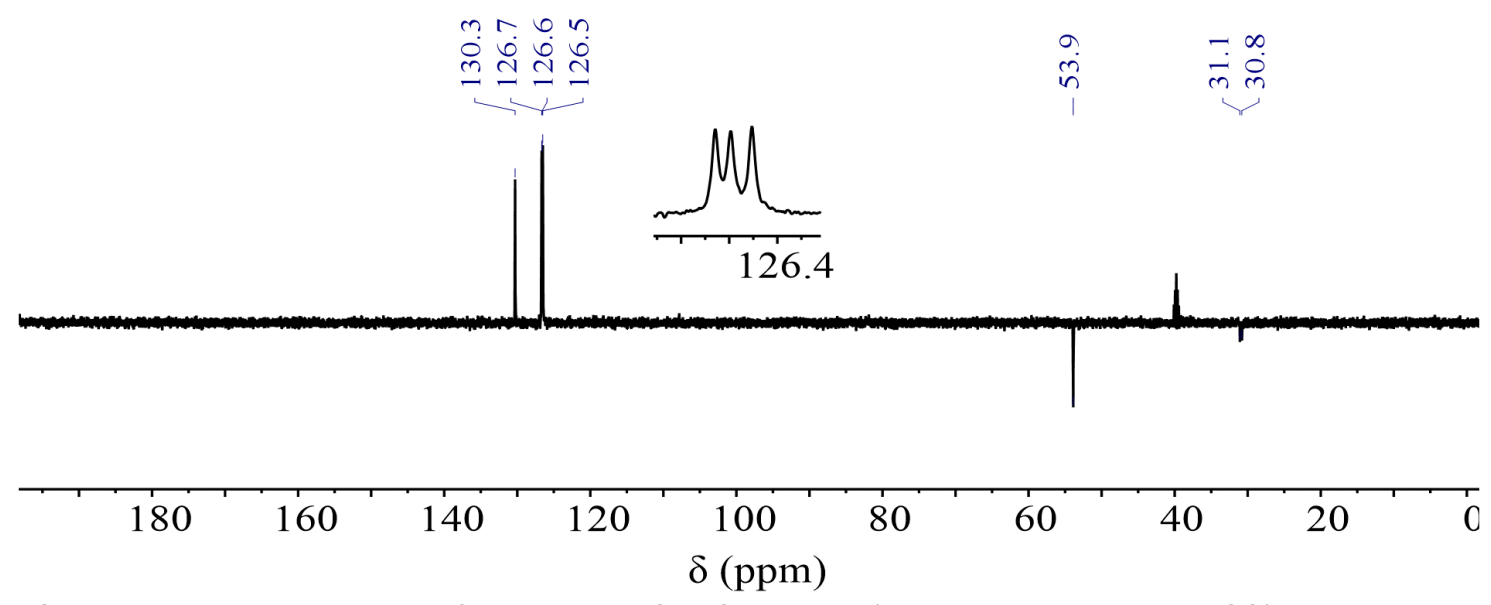

Figure S7. DEPT-135 NMR spectrum of monovalent sCx4-CH $\mathbf{N H N H}_{2}\left(125 \mathrm{MHz}, 298 \mathrm{~K}\right.$, in $\left.d_{6}-\mathrm{DMSO}\right)$. 

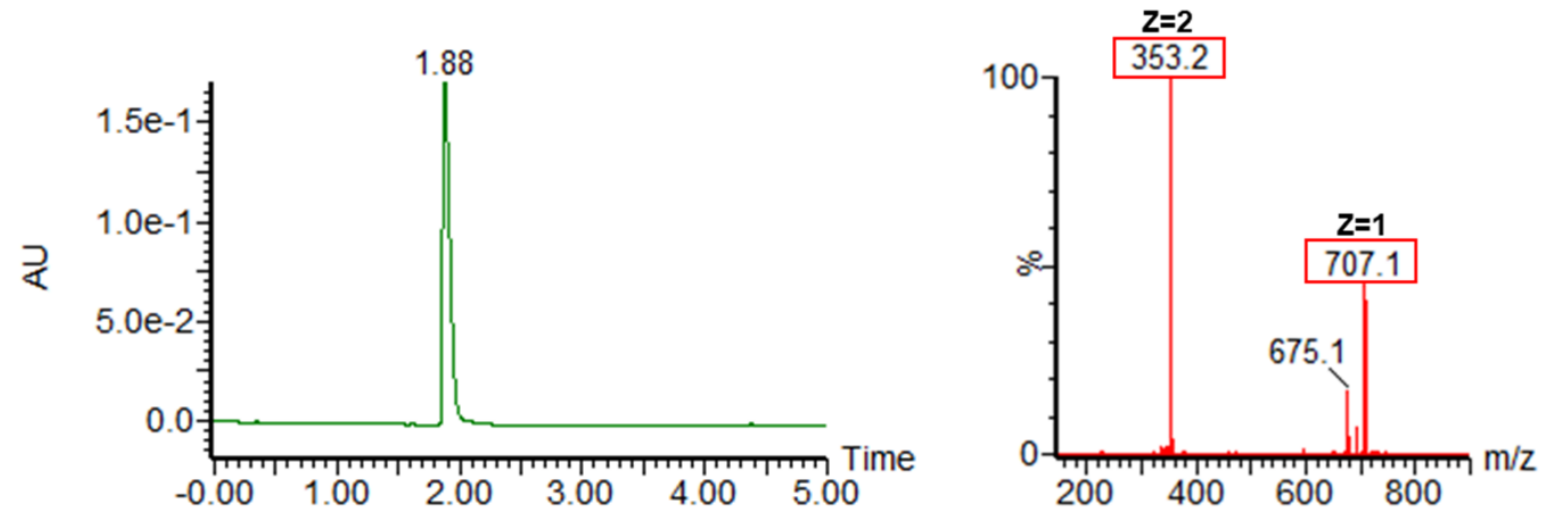

Figure S8. UPLC-MS trace of monovalent $\mathbf{s} \mathbf{C} \times \mathbf{4}-\mathbf{C H}_{2} \mathbf{N H N H}_{2}$ after preparative HPLC purification.

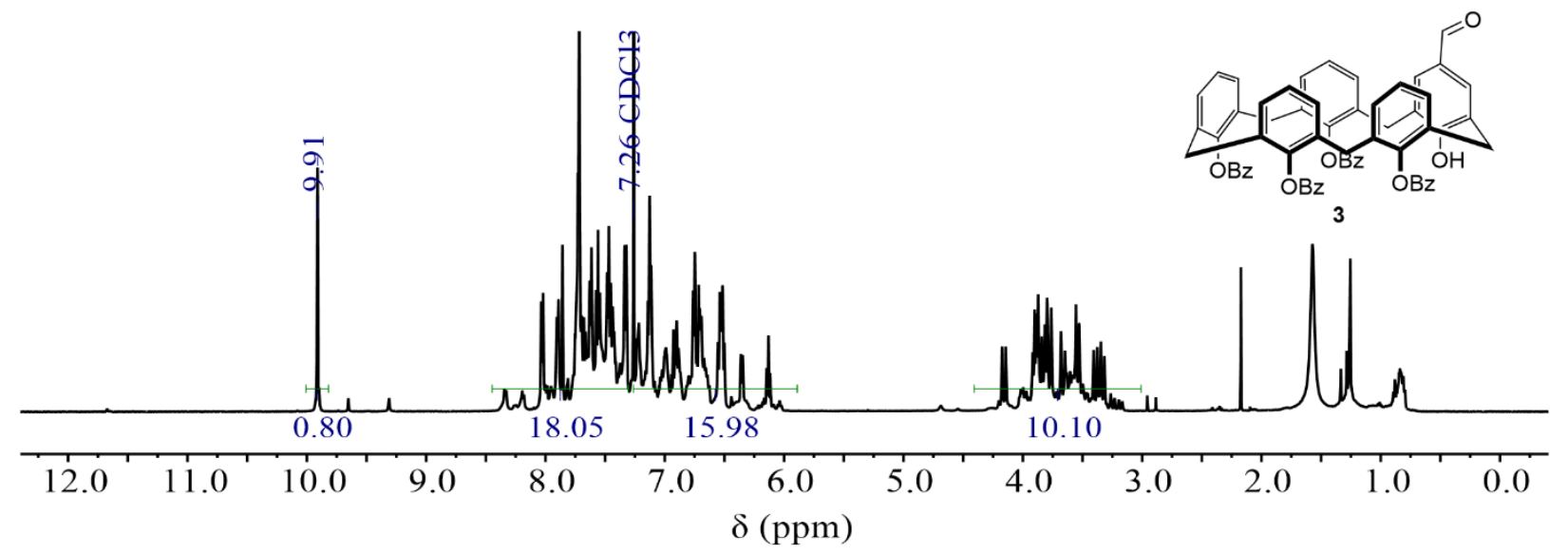

Figure S9. ${ }^{1} \mathrm{H}$ NMR spectrum of 4Bz-Cx5-CHO (3) $\left(500 \mathrm{MHz}, 298 \mathrm{~K}\right.$, in $\left.\mathrm{CDCl}_{3}\right)$. This compound was carried forward without full characterization due to the intractable NMR spectra. 


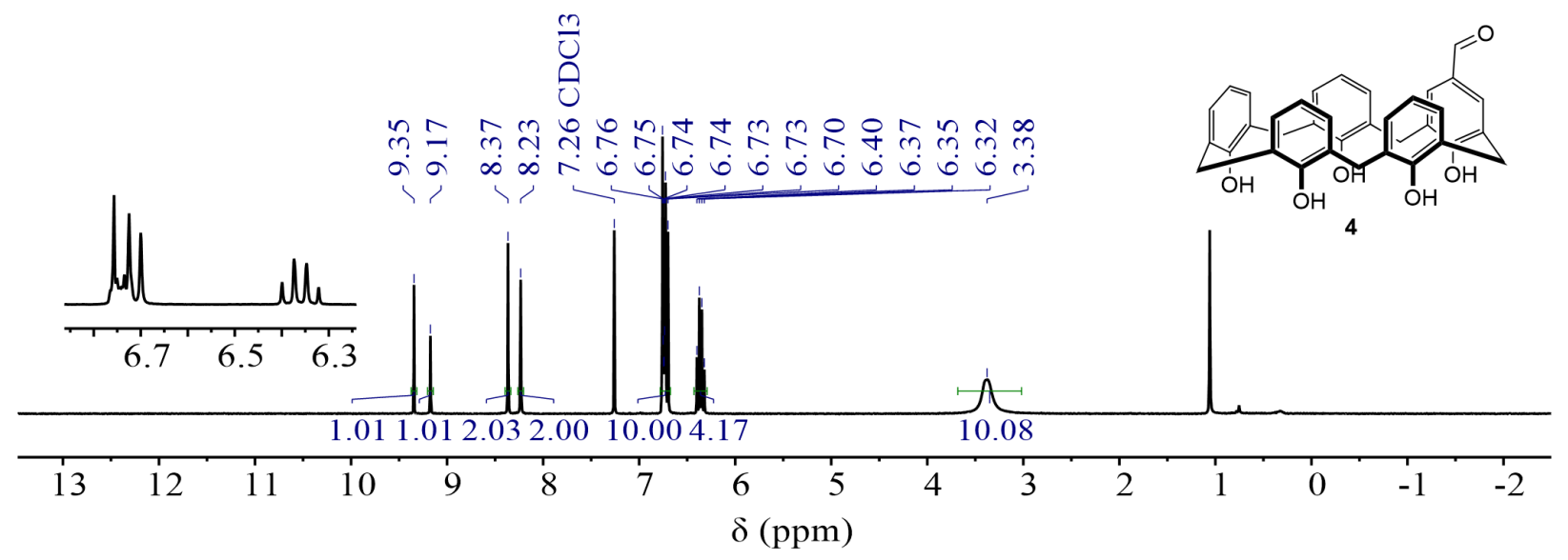

Figure S10. ${ }^{1} \mathrm{H}$ NMR spectrum of $\mathrm{Cx} 5-\mathrm{CHO}(4)\left(300 \mathrm{MHz}, 300 \mathrm{~K}\right.$, in $\left.\mathrm{CDCl}_{3}\right)$.

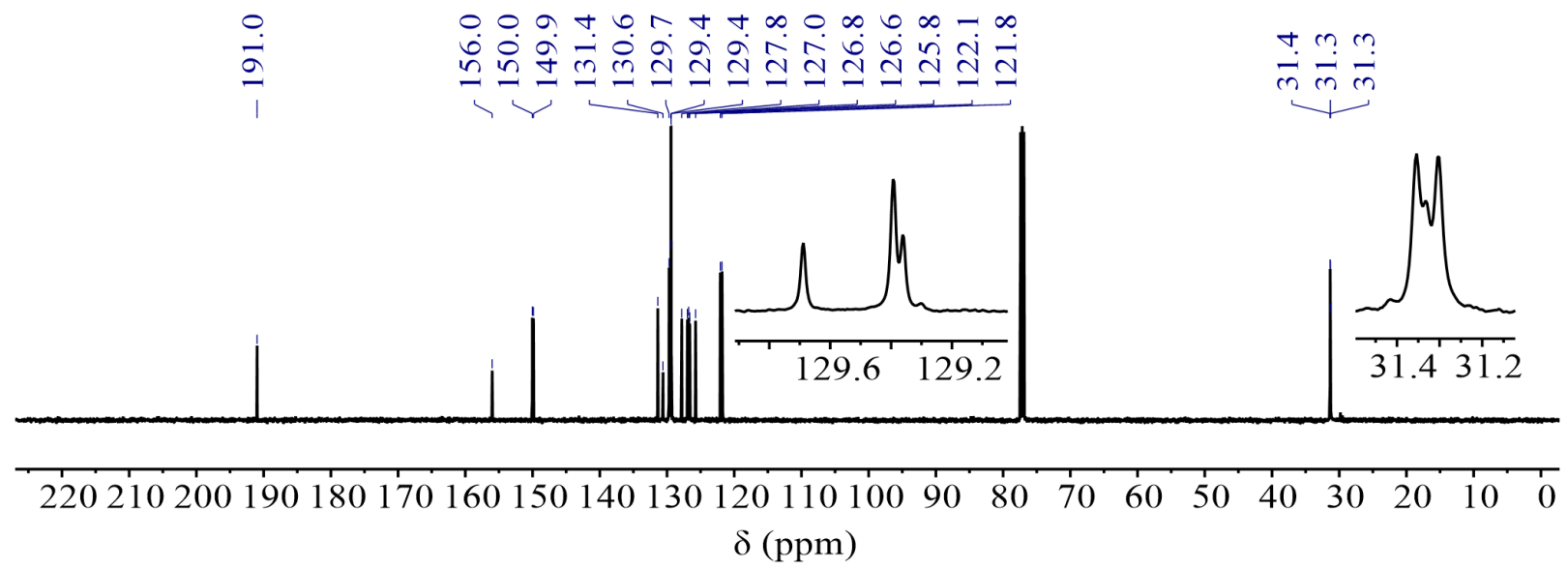

Figure S11. ${ }^{13} \mathrm{C}$ NMR spectrum of $\mathrm{Cx} 5-\mathrm{CHO}(4)\left(125 \mathrm{MHz}, 298 \mathrm{~K}\right.$, in $\left.\mathrm{CDCl}_{3}\right)$. 


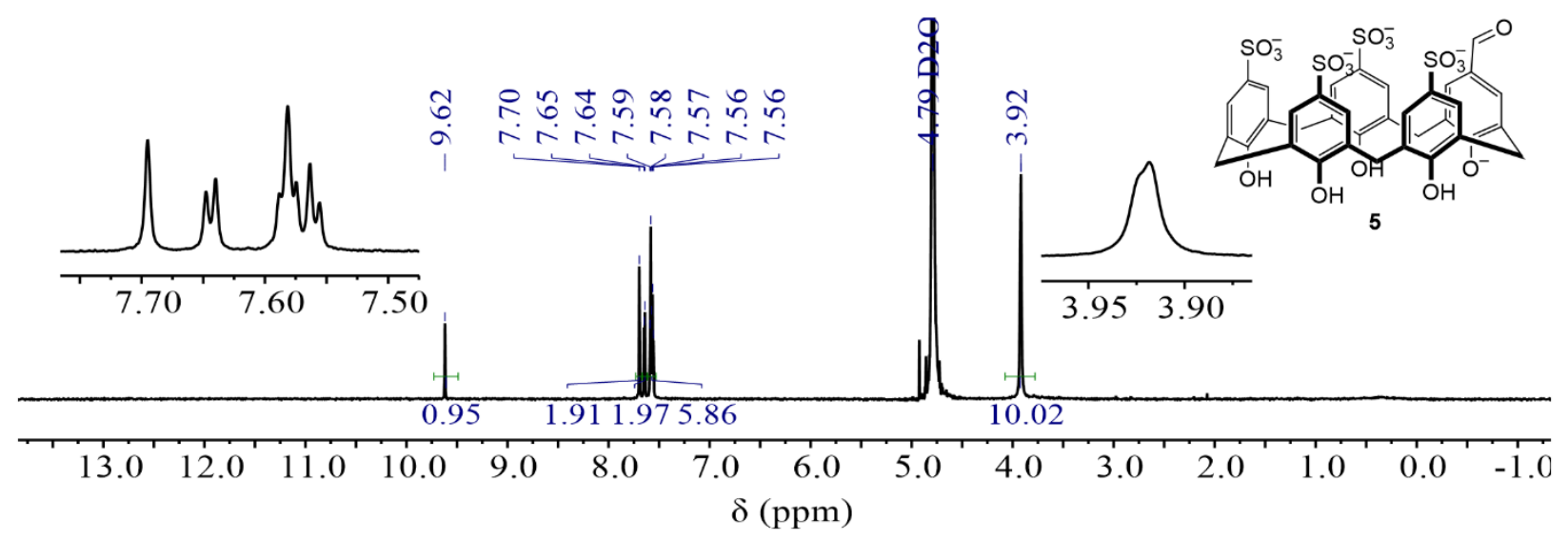

Figure S12. ${ }^{1} \mathrm{H}$ NMR spectrum of $\mathrm{sCx} 5-\mathrm{CHO}(5)\left(300 \mathrm{MHz}, 300 \mathrm{~K}\right.$, in $\left.\mathrm{D}_{2} \mathrm{O}\right)$.
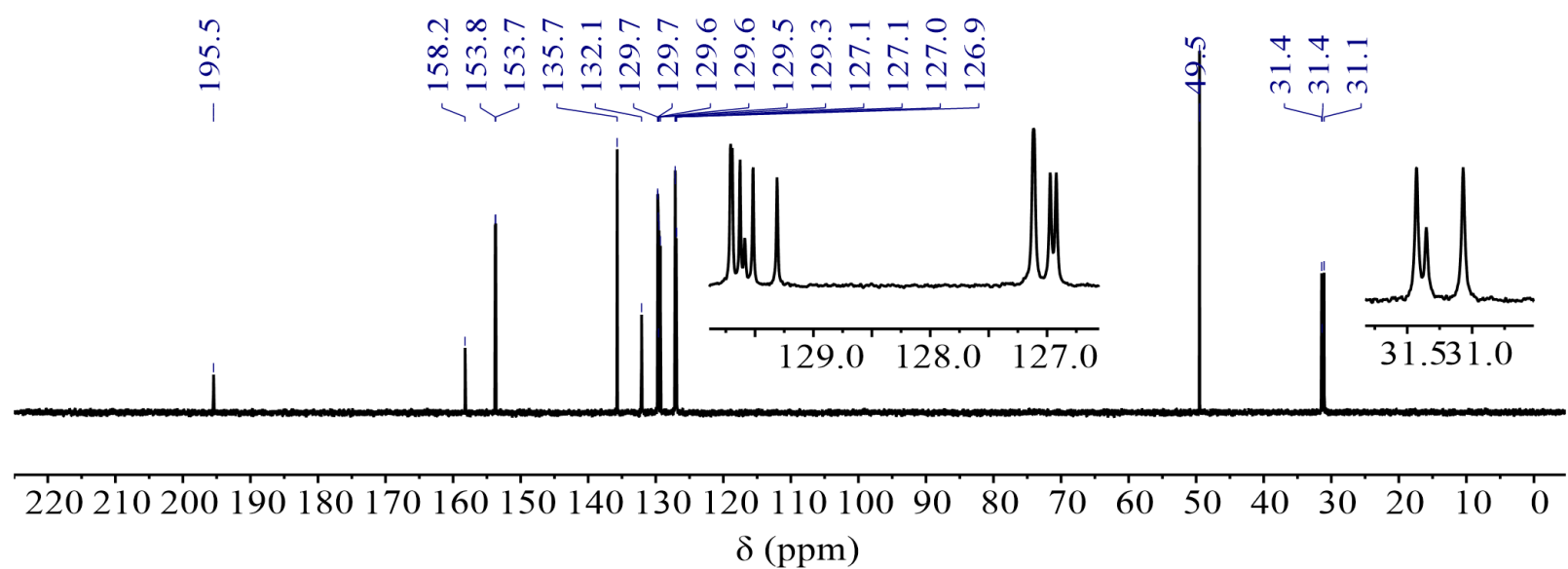

Figure S13. ${ }^{13} \mathrm{C}$ NMR spectrum of sCx5-CHO (5) $\left(125 \mathrm{MHz}, 298 \mathrm{~K}\right.$, in $\left.\mathrm{D}_{2} \mathrm{O}\right)$ calibrated with an external reference $(5 \% \mathrm{MeOH}$ in $\left.\mathrm{D}_{2} \mathrm{O}, 49.5 \mathrm{ppm}\right)$.

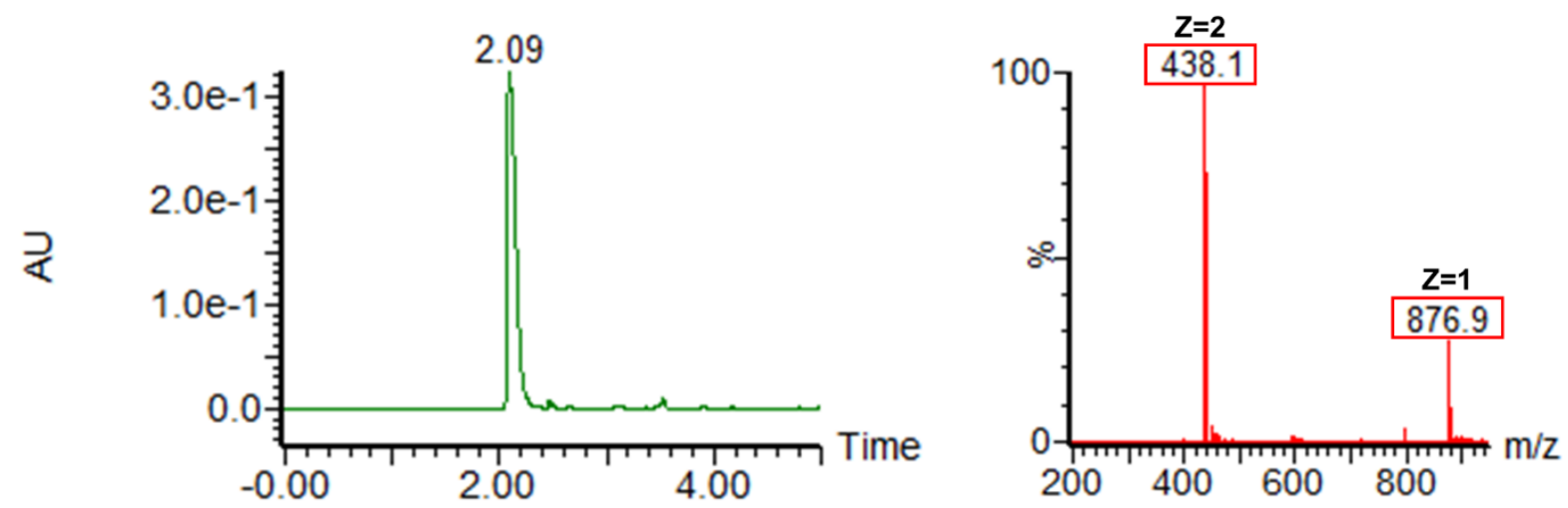

Figure S14. UPLC-MS trace of $\mathrm{sCx} 5-\mathrm{CHO}(5)$ after preparative HPLC purification. 


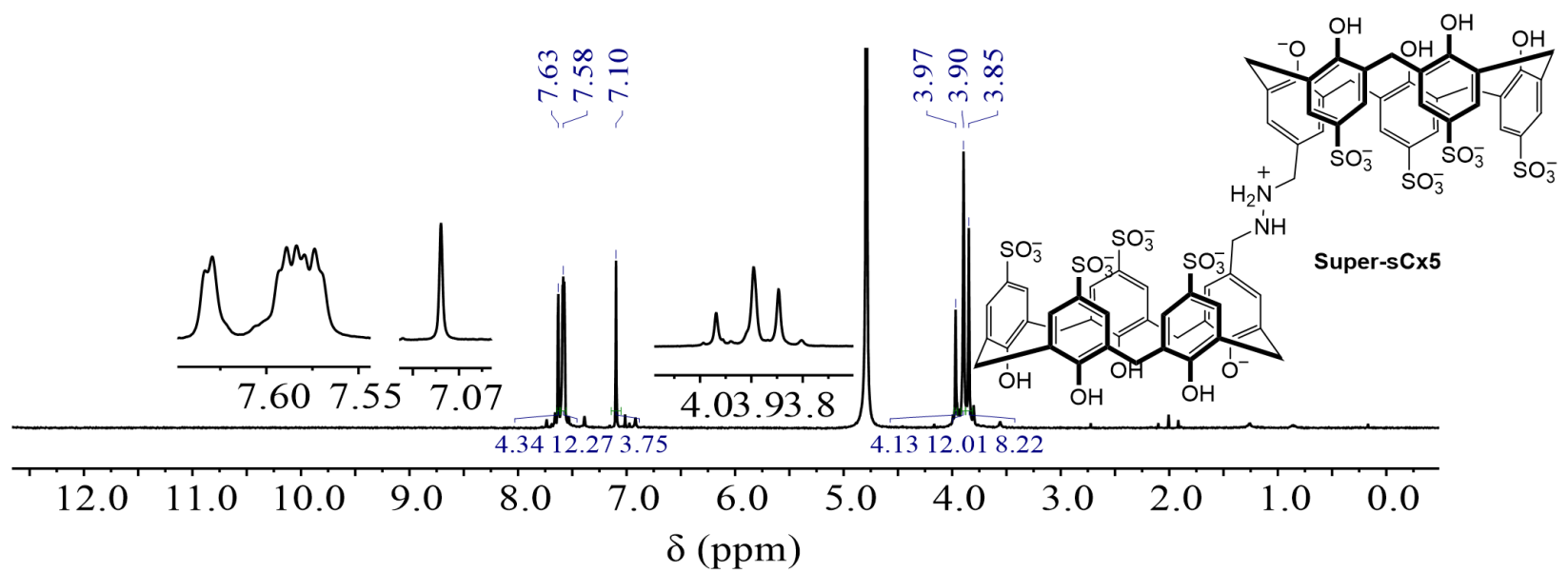

Figure S15. ${ }^{1} \mathrm{H}$ NMR spectrum of bivalent Super-sCx5 (500 MHz, $298 \mathrm{~K}$, in $\left.\mathrm{D}_{2} \mathrm{O}\right)$.

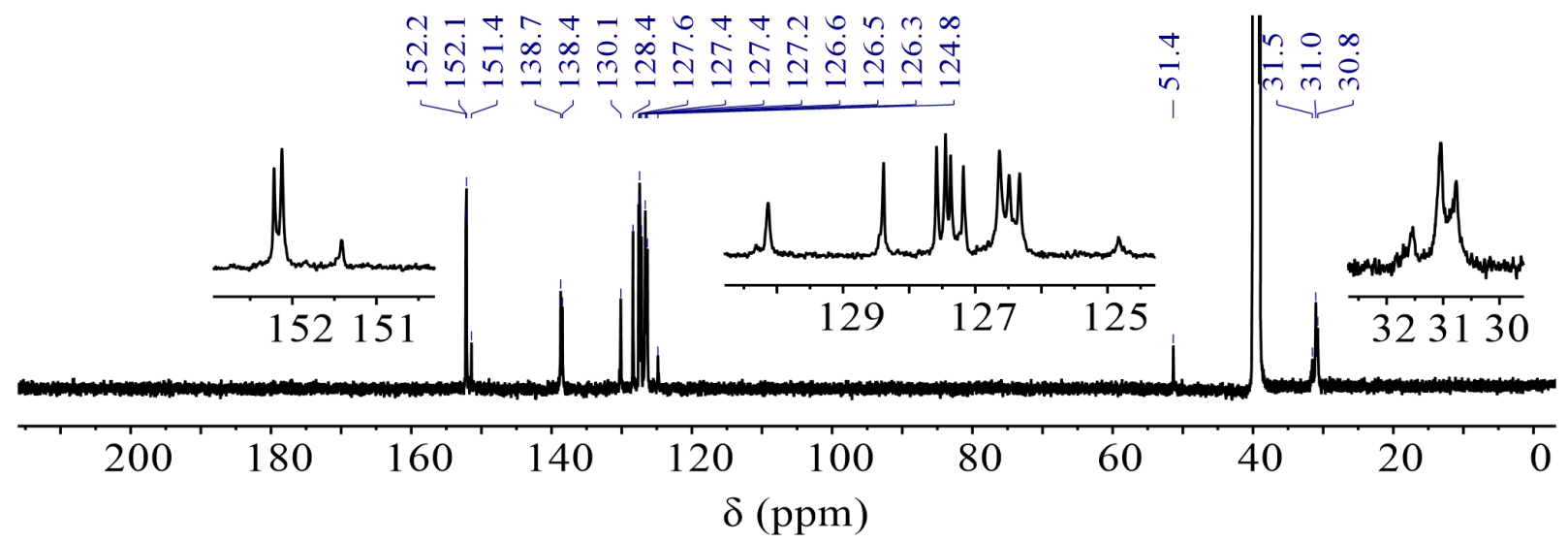

Figure S16. ${ }^{13} \mathrm{C}$ NMR spectrum of bivalent Super-sCx5 (125 MHz, $298 \mathrm{~K}$, in $\left.d_{6}-\mathrm{DMSO}\right)$.

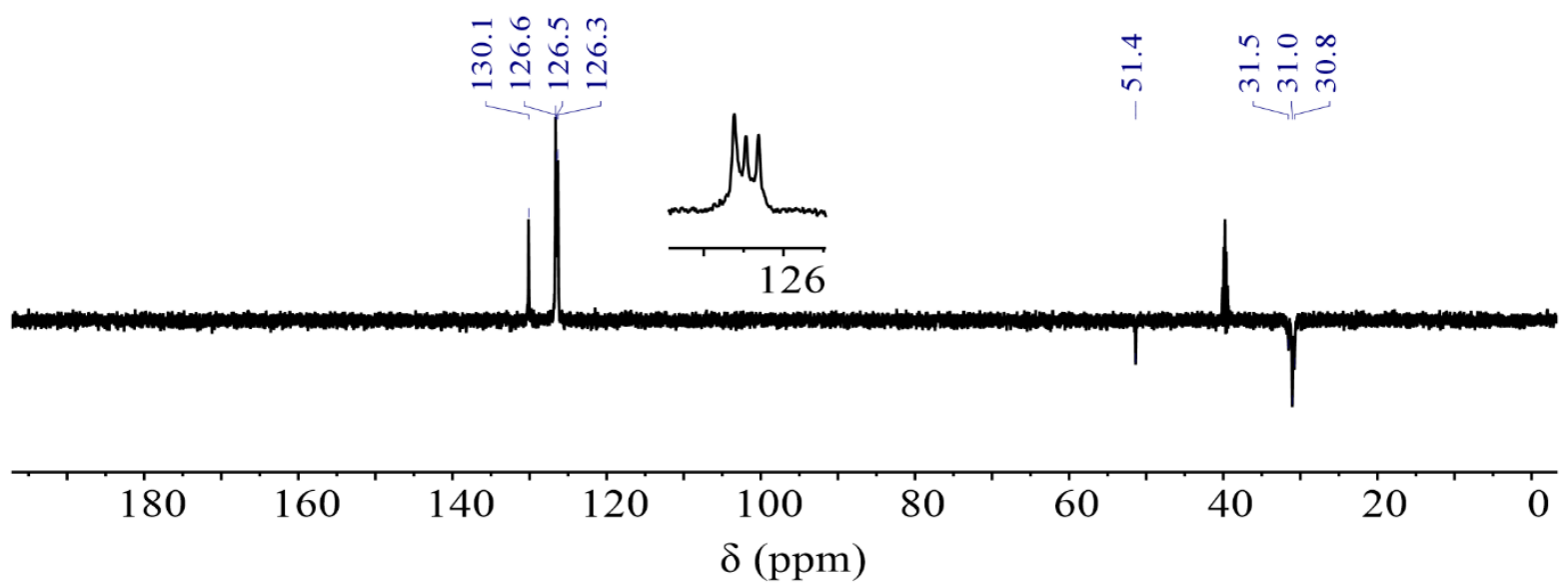

Figure S17. DEPT-135 NMR spectrum of bivalent Super-sCx5 (125 MHz, $298 \mathrm{~K}$, in $d_{6}$-DMSO). 

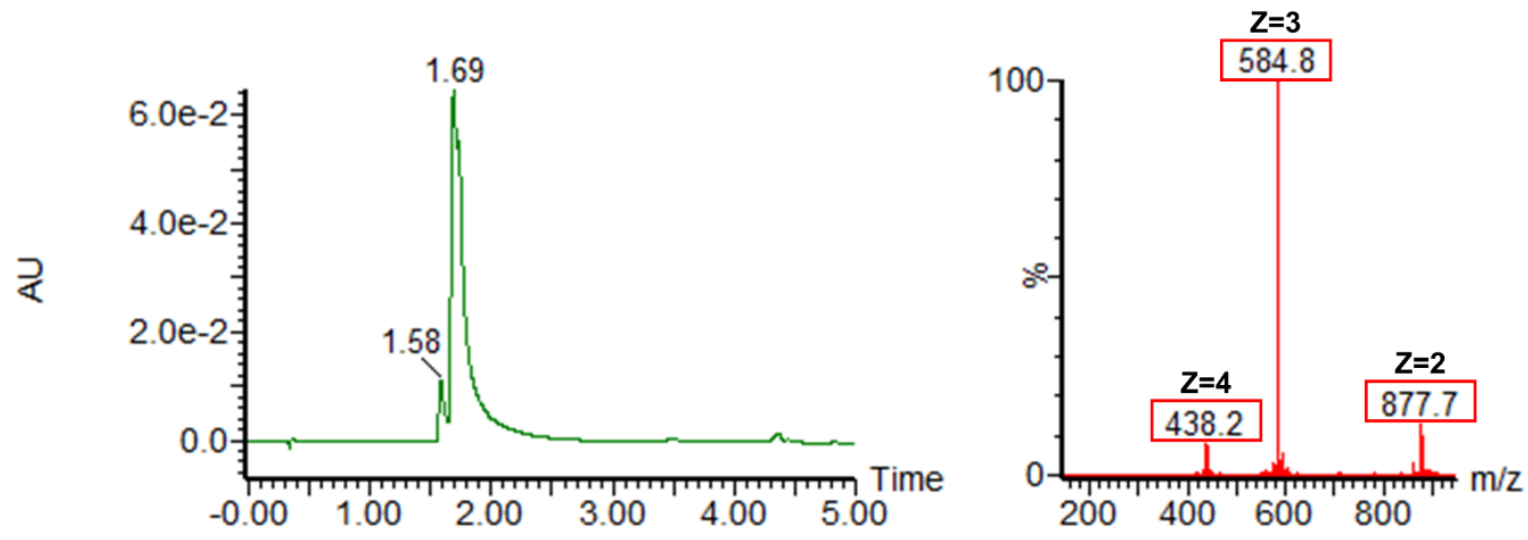

Figure S18. UPLC-MS trace of bivalent Super-sCx5 after preparative HPLC purification. 


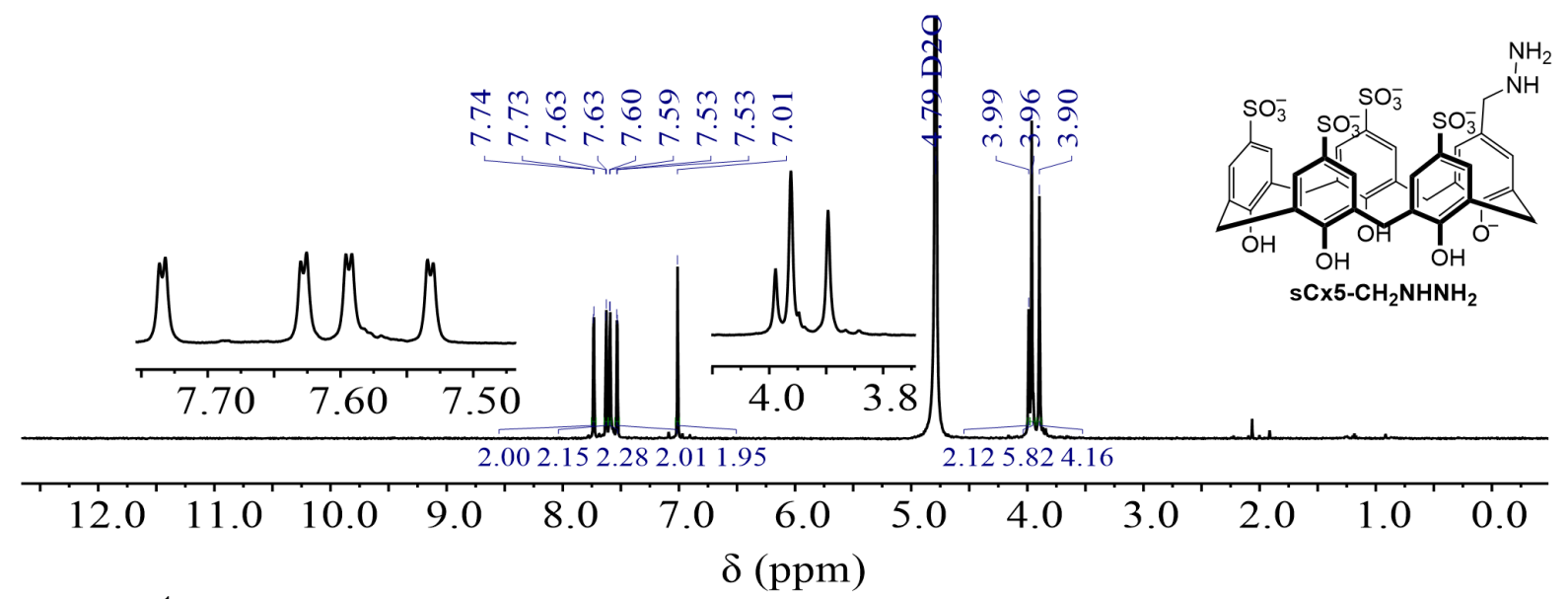

Figure S19. ${ }^{1} \mathrm{H}$ NMR spectrum of monovalent $\mathbf{s} \mathbf{C} \times 5-\mathrm{CH}_{2} \mathbf{N H N H}_{2}\left(500 \mathrm{MHz}, 298 \mathrm{~K}\right.$, in $\left.\mathrm{D}_{2} \mathrm{O}\right)$.

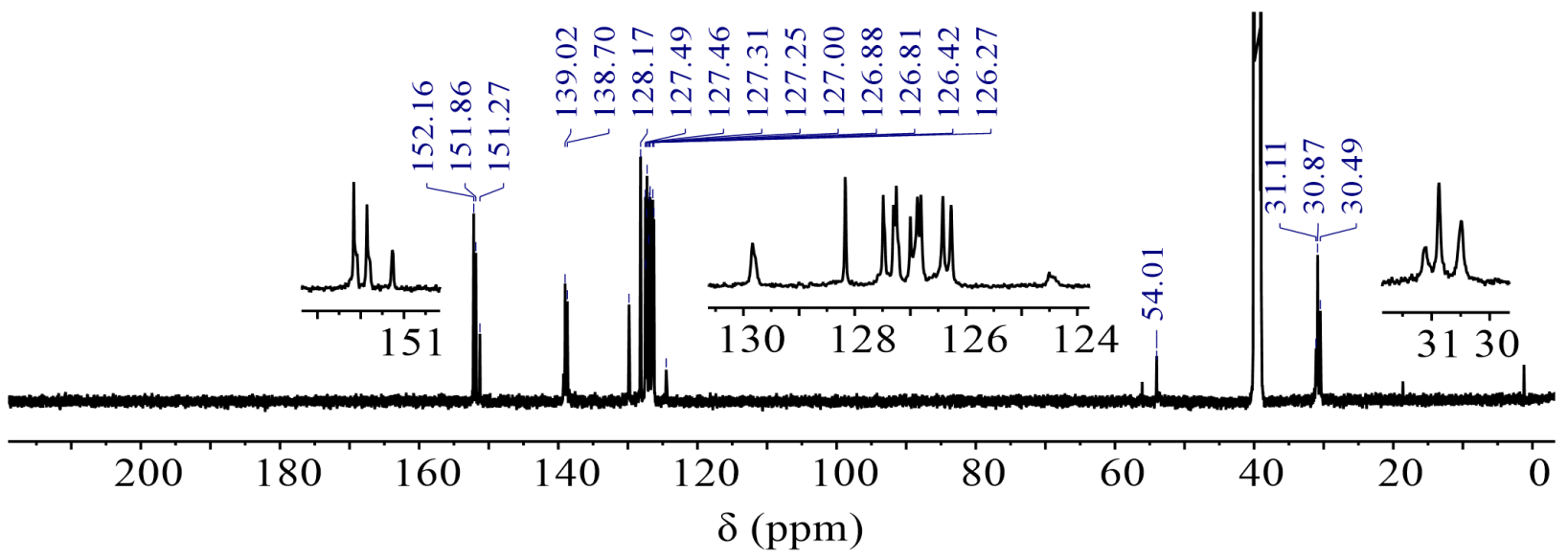

Figure S20. ${ }^{13} \mathrm{C}$ NMR spectrum of monovalent $\mathbf{s} \mathbf{C} \times 5-\mathbf{C H}_{2} \mathrm{NHNH}_{2}\left(125 \mathrm{MHz}, 298 \mathrm{~K}\right.$, in $\left.d_{6}-\mathrm{DMSO}\right)$.

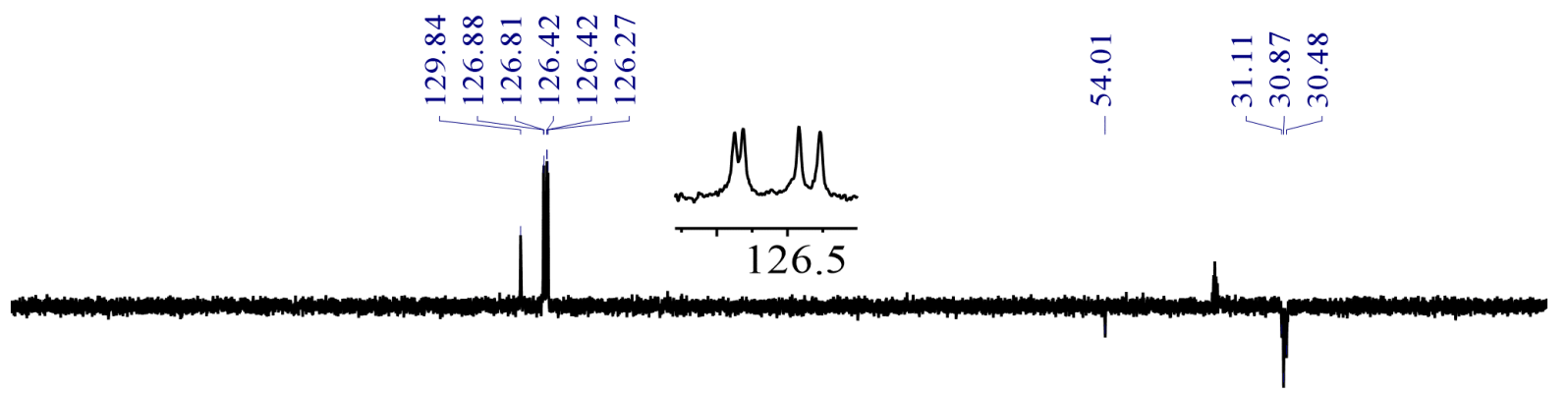

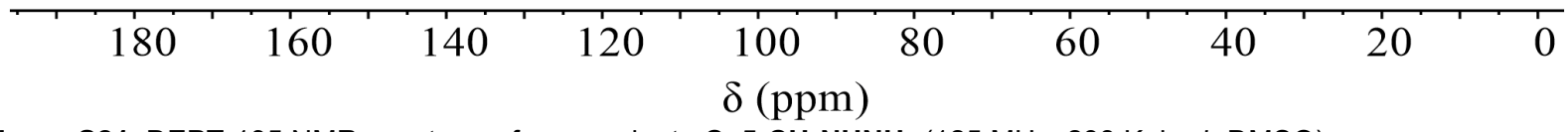

Figure S21. DEPT-135 NMR spectrum of monovalent $\mathbf{s} \mathbf{C} \mathbf{5}-\mathbf{C H}_{2} \mathbf{N H N H}_{\mathbf{2}}\left(125 \mathrm{MHz}, 298 \mathrm{~K}\right.$, in $\left.d_{6}-\mathrm{DMSO}\right)$. 

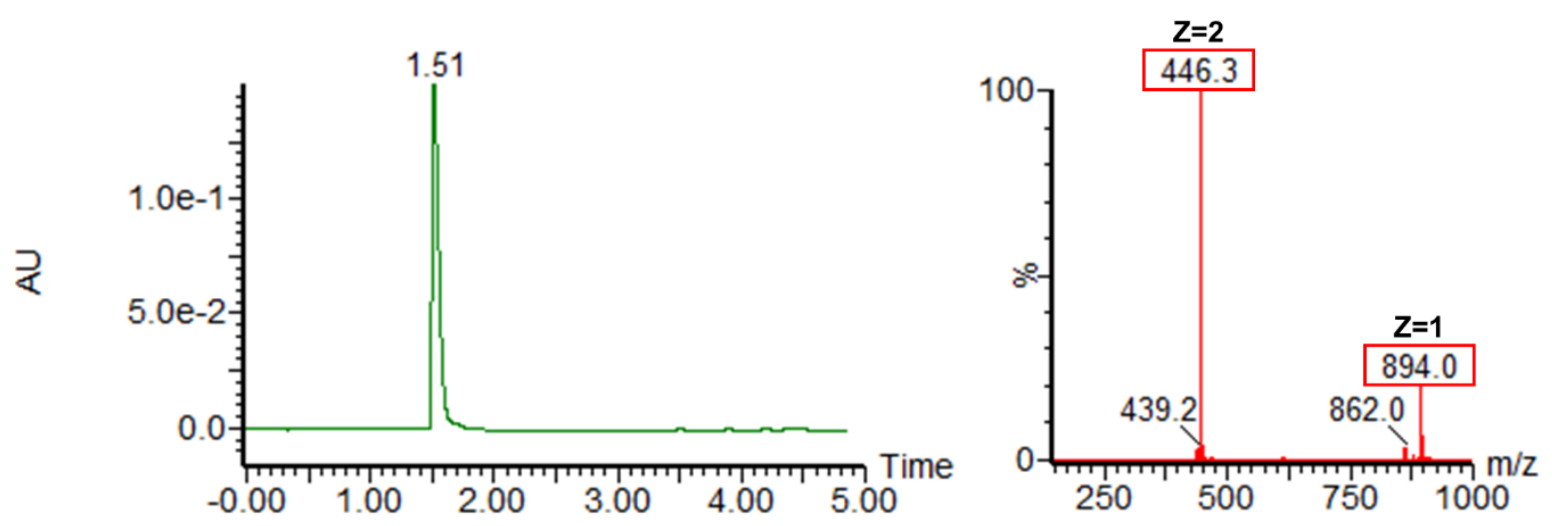

Figure S22. UPLC-MS trace of monovalent $\mathbf{s} \mathbf{C} \times 5-\mathrm{CH}_{2} \mathrm{NHNH}_{2}$ after preparative HPLC purification. 


\subsection{In situ reaction monitoring by ${ }^{1} \mathrm{H}$ NMR and UPLC-MS}

a)
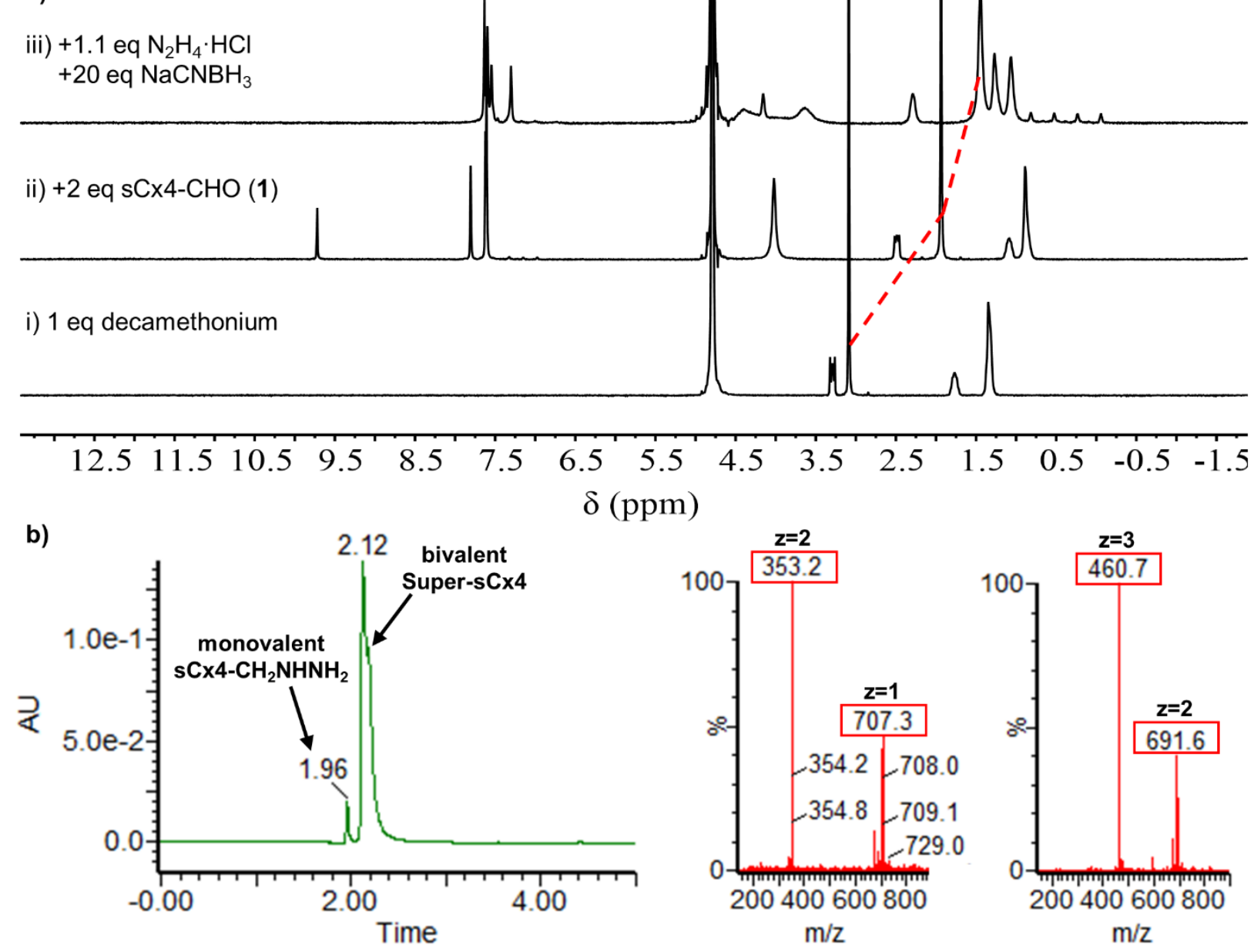

Figure S23. Bivalent calix[4]arene host synthesis is templated by the NMBA decamethonium. a) ${ }^{1} \mathrm{H}$ NMR of i) decamethonium bromide $(5 \mathrm{mM})$ ii) addition of $\mathrm{sCx} 4-\mathrm{CHO}(1)(10 \mathrm{mM})$ iii) crude reaction mixture after condensation and reductive amination. Red dashed line illustrates upfield shift of decamethonium methyl groups, indicating complexation of methyl groups inside the $\mathrm{Cx} 4$ cavity. Reaction in ammonium carbonate $(50 \mathrm{mM}, \mathrm{pD} 6.4)$ in $\mathrm{D}_{2} \mathrm{O}(300 \mathrm{MHz}, 298 \mathrm{~K})$. b) UPLC-MS of crude templated reaction shows minor formation of monovalent sCx4- $\mathbf{C H}_{2} \mathbf{N H N H}_{2}$ (1.96 min peak, left MS trace) and major product formation of bivalent Super-sCx4 (2.12 min peak, right MS trace). 
a)

ii) +1.1 eq $\mathrm{N}_{2} \mathrm{H}_{4} \cdot \mathrm{HCl}$

+20 eq $\mathrm{NaCNBH}_{3}$

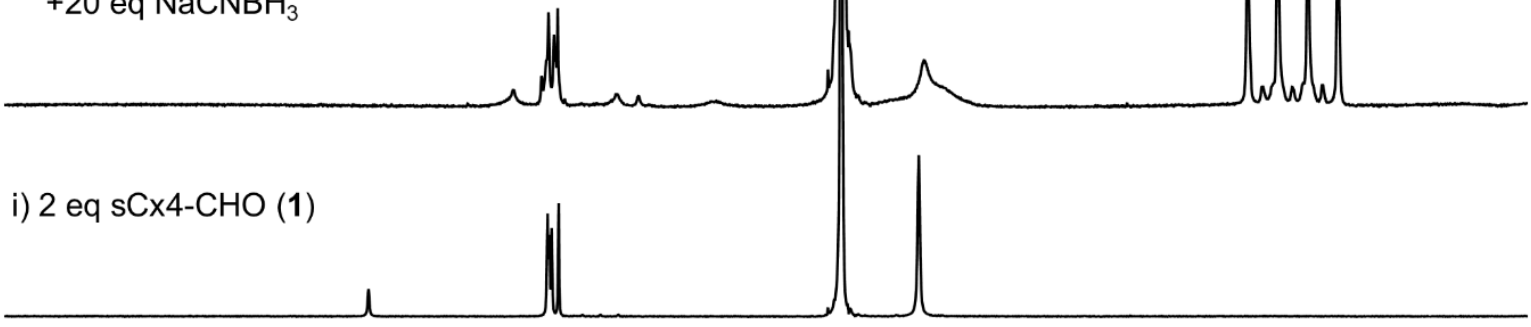

$\begin{array}{llllllllllllllllll}12.5 & 11.5 & 10.5 & 9.5 & 8.5 & 7.5 & 6.5 & 5.5 & 4.5 & 3.5 & 2.5 & 1.5 & 0.5 & -0.5 & -1.5\end{array}$

b)

$\delta(\mathrm{ppm})$
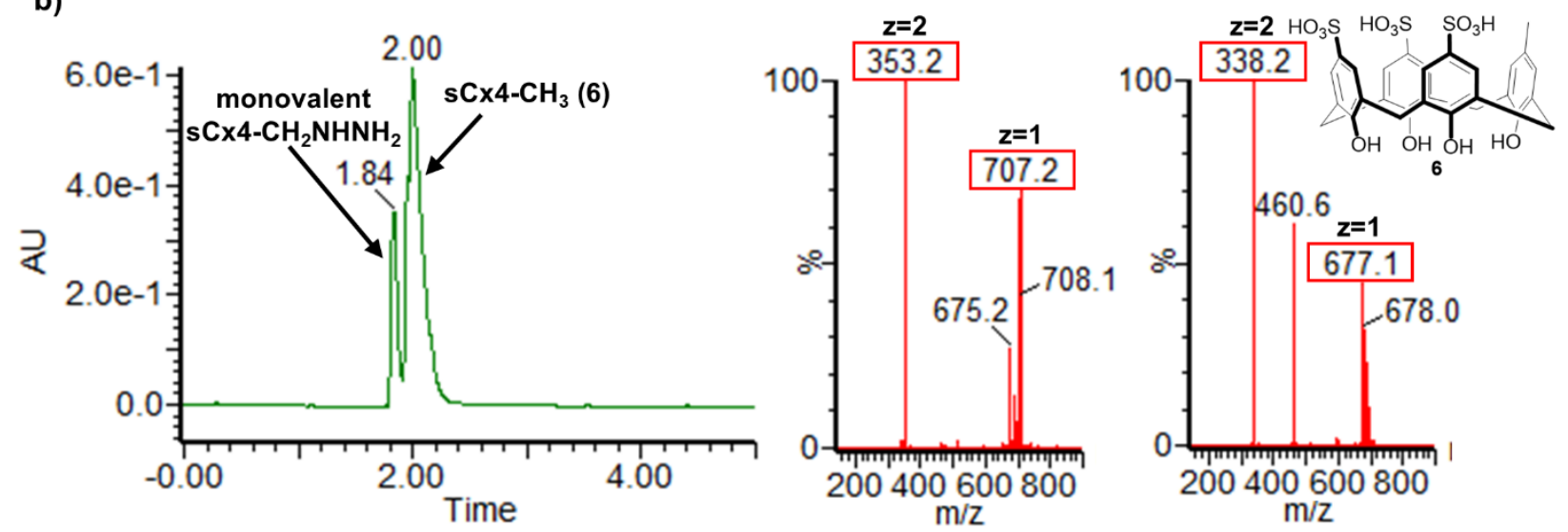

Figure S24. The calix[4]arene untemplated control reaction does not form a bivalent host. a) ${ }^{1} \mathrm{H}$ NMR of i) $\mathrm{sCx} 4-\mathrm{CHO}(1)(10$ $\mathrm{mM})$ ii) crude reaction mixture after condensation and reductive amination. Reaction in ammonium carbonate $(50 \mathrm{mM}, \mathrm{pD}$ $6.4)$ in $\mathrm{D}_{2} \mathrm{O}(300 \mathrm{MHz}, 298 \mathrm{~K})$. b) UPLC-MS of crude untemplated control reaction shows formation of monovalent sCx4$\mathrm{CH}_{2} \mathrm{NHNH}_{2}$ (1.84 min peak, left MS trace) and reduced starting material sCx4- $\mathrm{CH}_{3}(6)$ (2.00 min peak, right MS trace). 
a)

ii) +2 eq $\mathrm{sC} \times 5-\mathrm{CHO}$

$\mid$

i) decamethonium

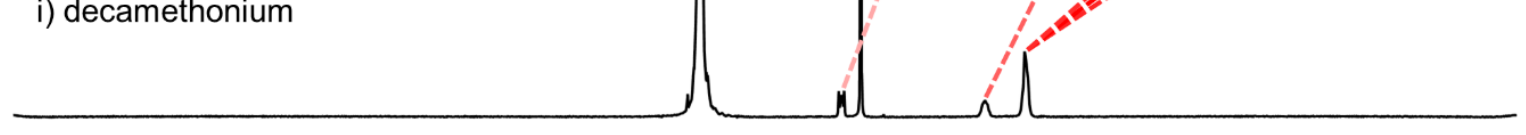

\begin{tabular}{cccccccccccccccc}
\hline 12 & 11 & 10 & 9 & 8 & 7 & 6 & 5 & 4 & 3 & 2 & 1 & 0 & -1 & -2 & -3 \\
$\delta(\mathrm{ppm})$ &
\end{tabular}

b)

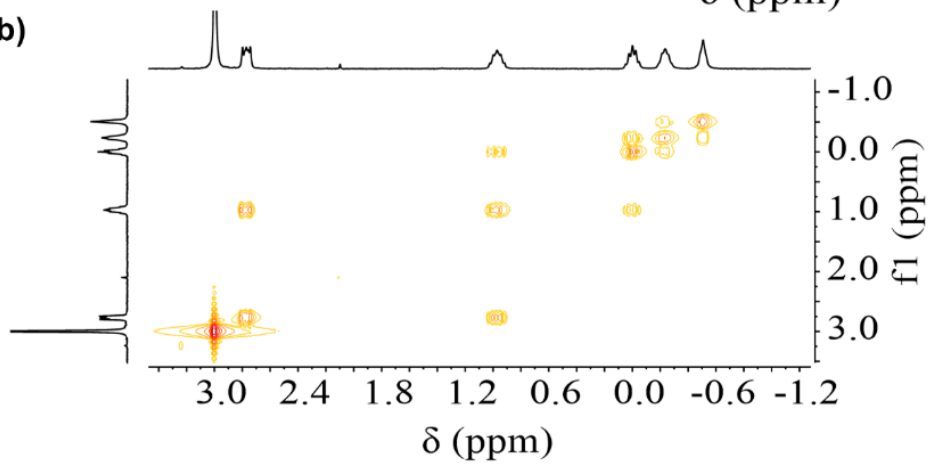

c)

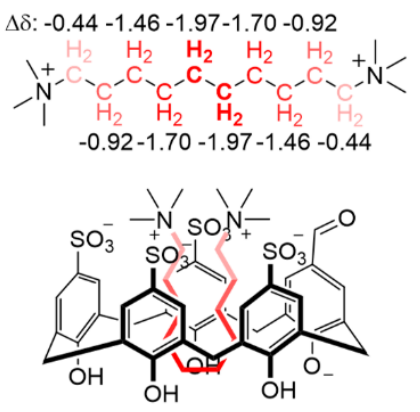

Figure S25. Decamethonium is not suitable for bivalent calix[5]arene host templation. a) ${ }^{1} \mathrm{H}$ NMR of i) decamethonium bromide $(5 \mathrm{mM})$ and ii) addition of 2 eq sCx5-CHO (5) $(10 \mathrm{mM})$. Red dashed lines illustrate upfield chemical shifts of decamethonium methylene peaks. b) COSY c) Change in chemical shifts $(\Delta \delta)$ of decamethonium methylene peaks indicates decamethonium assumes a folded conformation inside the binding pocket of sCx5-CHO. Spectra collected in ammonium carbonate (50 mM, pD 6.4) in $\mathrm{D}_{2} \mathrm{O}(300 \mathrm{MHz}, 298 \mathrm{~K})$. 
a)

iii) +1.1 eq $\mathrm{N}_{2} \mathrm{H}_{4} \cdot \mathrm{HCl}$ +20 eq $\mathrm{NaCNBH}_{3}$

ii) +2 eq $\mathrm{s} \times 55-\mathrm{CHO}(5)$

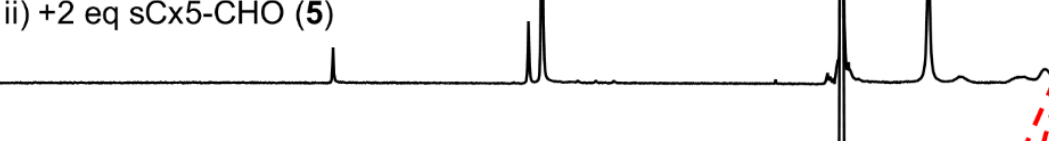

i) 1 eq pancuronium

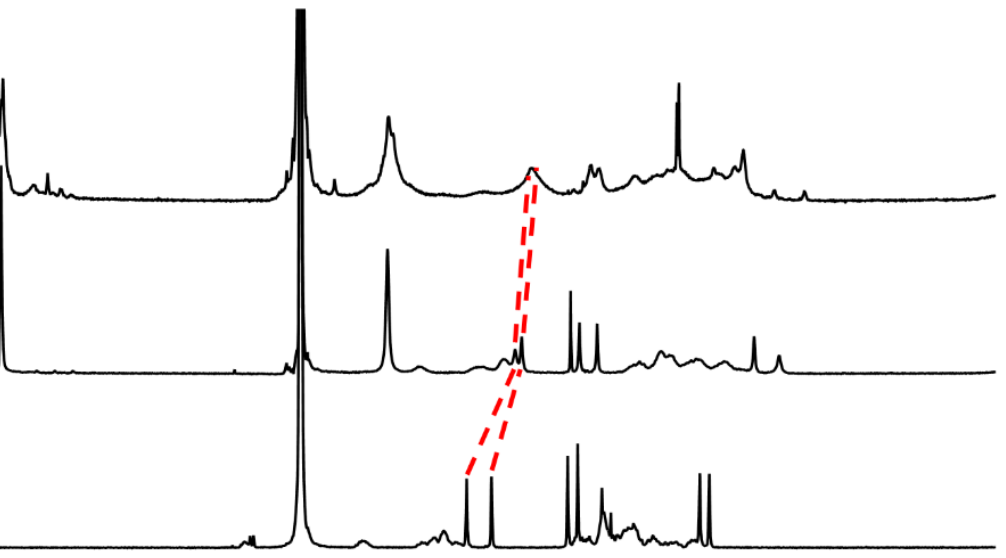

$\begin{array}{ccccccccccccccc}12.5 & 11.5 & 10.5 & 9.5 & 8.5 & 7.5 & 6.5 & 5.5 & 4.5 & 3.5 & 2.5 & 1.5 & 0.5 & -0.5 & -1.5 \\ \delta(\mathrm{ppm}) & & & & & & & \end{array}$

b)
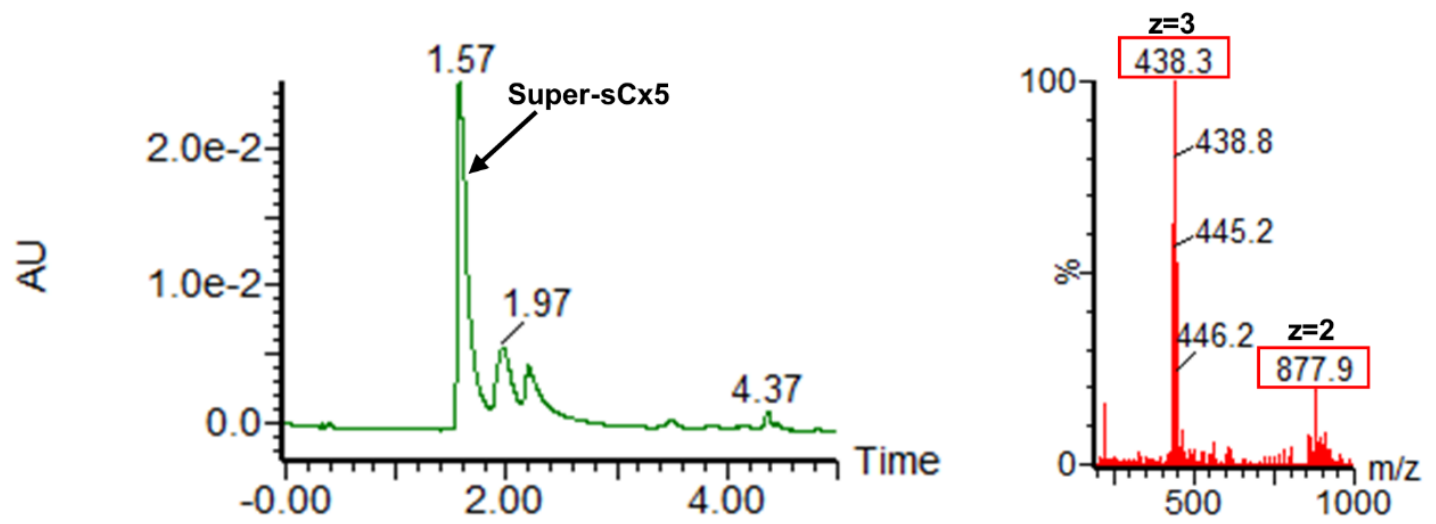

Figure S26. Bivalent calix[5]arene host synthesis is templated by the rigid NMBA pancuronium. a) ${ }^{1} \mathrm{H}$ NMR of i) pancuronium bromide $(5 \mathrm{mM})$ ii) addition of $\mathrm{sCx} 5-\mathrm{CHO}(\mathbf{5})(10 \mathrm{mM})$ iii) crude reaction mixture after condensation and reductive amination. Red dashed line illustrates upfield shifts of the quaternary amine methyl groups on pancuronium, indicating complexation throughout the reaction. Reaction in ammonium carbonate $(50 \mathrm{mM}, \mathrm{pD} 6.4)$ in $\mathrm{D}_{2} \mathrm{O}(300 \mathrm{MHz}, 298$ K). b) UPLC-MS of crude templated reaction shows formation of bivalent Super-sCx5 (1.57 min peak, right MS trace) as the major product. 
a)

ii) +1.1 eq $\mathrm{N}_{2} \mathrm{H}_{4} \cdot \mathrm{HCl}$ +20 eq $\mathrm{NaCNBH}_{3}$

i) 2 eq sCx5-CHO (5)
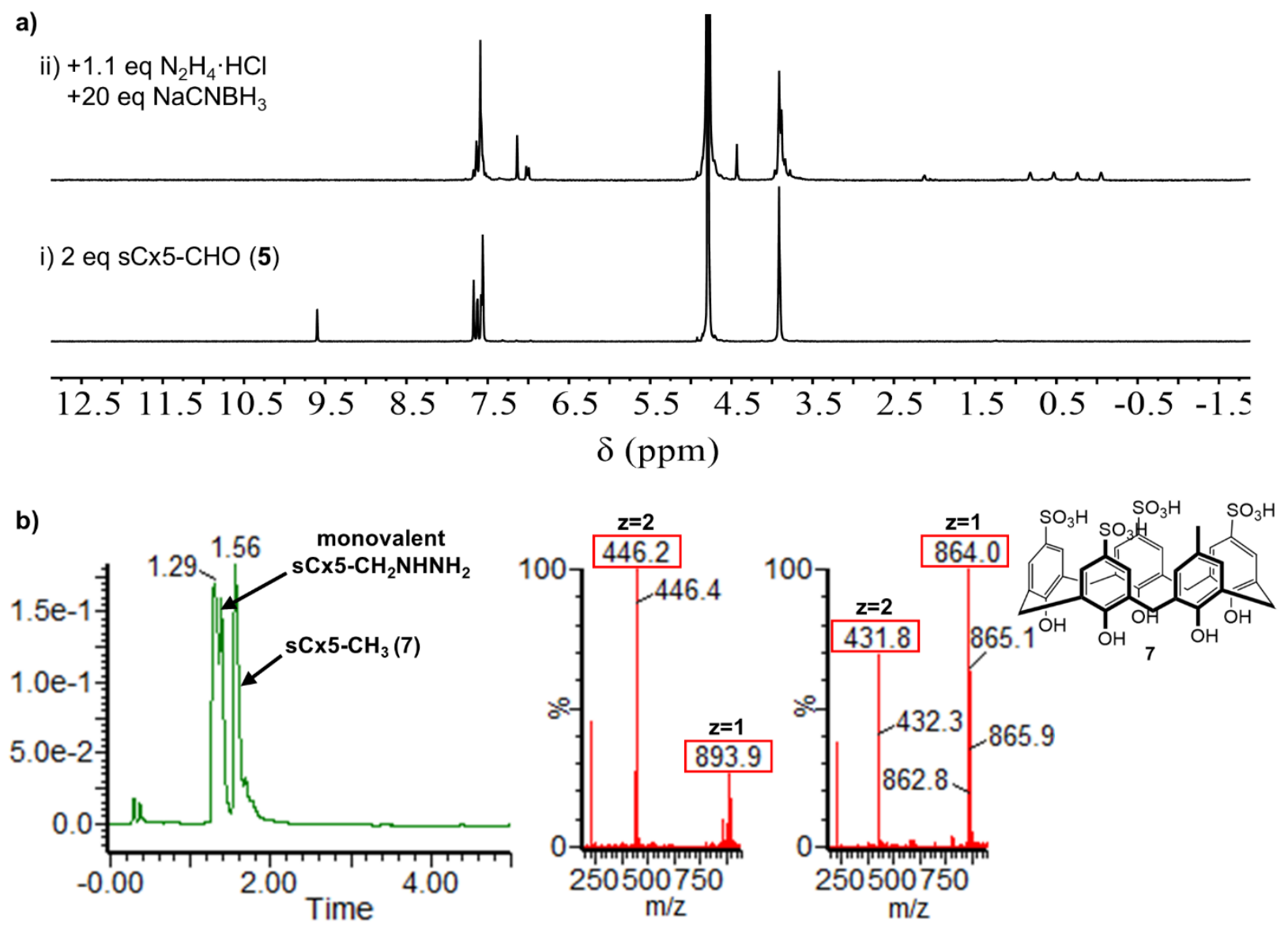

Figure S27. The calix[5]arene untemplated control reaction does not form a bivalent host. a) ${ }^{1} \mathrm{H}$ NMR of i) $\mathrm{sCx} 5-\mathrm{CHO}(\mathbf{5})(10$ $\mathrm{mM})$ ii) crude reaction mixture after condensation and reductive amination. Reaction in ammonium carbonate $(50 \mathrm{mM}, \mathrm{pD}$ $6.4)$ in $\mathrm{D}_{2} \mathrm{O}(300 \mathrm{MHz}, 298 \mathrm{~K})$. b) UPLC-MS of crude untemplated control reaction shows formation of monovalent sCx5$\mathrm{CH}_{2} \mathrm{NHNH}_{2}$ (1.29 min peak, left MS trace) and reduced staring material sCx5- $\mathrm{CH}_{3}$ (7) (1.56 min peak, right MS trace) 


\section{Indicator Displacement Assay}

Direct and competitive titrations were done in NUNC black-walled, optical bottom 96-well plates. Lucigenin was used as the indicator in all titrations and stock concentrations were determined by $\varepsilon_{410 \mathrm{~nm}}=8900 \mathrm{M}^{-1} \mathrm{~cm}^{-1}$. Direct titration solutions were composed of $10 \mathrm{mM}$ phosphate buffer $\left(\mathrm{Na}_{2} \mathrm{HPO}_{4} / \mathrm{NaH}_{2} \mathrm{PO}_{4}\right)$ at $\mathrm{pH} 7.4,0.25 \mu \mathrm{M}$ of lucigenin and varying concentrations of host $(0-40 \mu \mathrm{M})$ made in Milli-Q® ultrapure water. Competitive titration solutions were composed of $10 \mathrm{mM}$ phosphate buffer $\left(\mathrm{Na}_{2} \mathrm{HPO}_{4} / \mathrm{NaH}_{2} \mathrm{PO}_{4}\right)$ at $\mathrm{pH} 7.4,0.25 \mu \mathrm{M}$ of lucigenin, $5 \mu \mathrm{M}$ host and varying concentrations of guest $(0-10 \mathrm{mM})$ made in Milli-Q尺 ultrapure water. Each well had a final volume of $100 \mu \mathrm{L}$. All fluorescence readings were collected on a BioTek Cytation-5, $\lambda_{\mathrm{ex}} 369 \mathrm{~nm}$ and $\lambda_{\mathrm{em}} 485 \mathrm{~nm}$. Three sets of duplicates were performed for each guest on different days with new stock solutions.

A blank containing only the dye and no host $\left(\mathrm{Fl}_{\mathrm{o}}\right)$ was subtracted from each duplicate experiment. The data for each of the duplicates was plotted producing a $K_{d}$ with standard error. The average $K_{d}$ values of the three sets of duplicates was reported along with the propagated standard error for each host•guest interaction.

\subsection{Determining direct and competitive binding affinities}

Direct host•lucigenin affinities were determined by plotting the fluorescence ( $F I-F l o, ~ R F U)$ as a function of host concentration. The data was fitted in GraphPad Prism using a direct one site binding equation:

$$
Y=A \times \frac{\left(D+x+K_{d L C G}\right)-\sqrt{\left(D+x+K_{d L C G}\right)^{2}-(4 D x)}}{2 D}
$$

Where, $\mathrm{A}=$ amplitude of change in fluorescence $(\mathrm{FI}-\mathrm{Fl}$ o $), \mathrm{D}=$ concentration of lucigenin, $\mathrm{x}=$ amount titrated and $K_{\mathrm{d} L \mathrm{LG}}=$ dissociation constant of lucigenin

Direct host $\bullet$ lucigenin fitting was constrained by the concentration of dye $(0.25 \mu \mathrm{M})$. The graphs were plotted with standard deviation and a second plot of $x$ residuals was determined. All graphs met a criterion of $R^{2}>0.95$. The $I C_{90}$ points from the direct titrations were selected as the host concentrations used in competitive titrations, determined to be $5 \mu \mathrm{M}$ for both Super-sCx4 and Super-sCx5.

Competitive host.guest affinities were determined by plotting the logarithm of guest concentration and the fluorescence response from lucigenin displacement ( $\mathrm{Fl}-\mathrm{Fl}$, RFU). The data was analyzed in GraphPad Prism using the competitive one site binding equation:

$$
\left.\log E C_{50}=\log \left(10^{\log K_{\text {dguest }} *\left(1+\frac{D}{K_{d L C G}}\right.}\right)\right)
$$

Where, $K_{\mathrm{d} \text { LCG }}=$ dissociation constant of lucigenin, $\mathrm{D}=$ concentration of lucigenin, $K_{\mathrm{d}}$ guest $=$ dissociation constant of guest of interest

Competitive host•guest fitting was constrained by the direct host•lucigenin dissociation constant $\left(K_{\mathrm{d} \text { LCG }}\right)$ and the concentration of lucigenin $(0.25 \mu \mathrm{M})$. This model fits $K_{d}$ guest directly and does not report the EC50. This analysis also assumes 1:1 host•guest interaction. Graphs were plotted with standard deviation and a second plot of $\mathrm{x}$ residuals were determined. All graphs met a criterion of $\mathrm{R}^{2}>0.95$. 

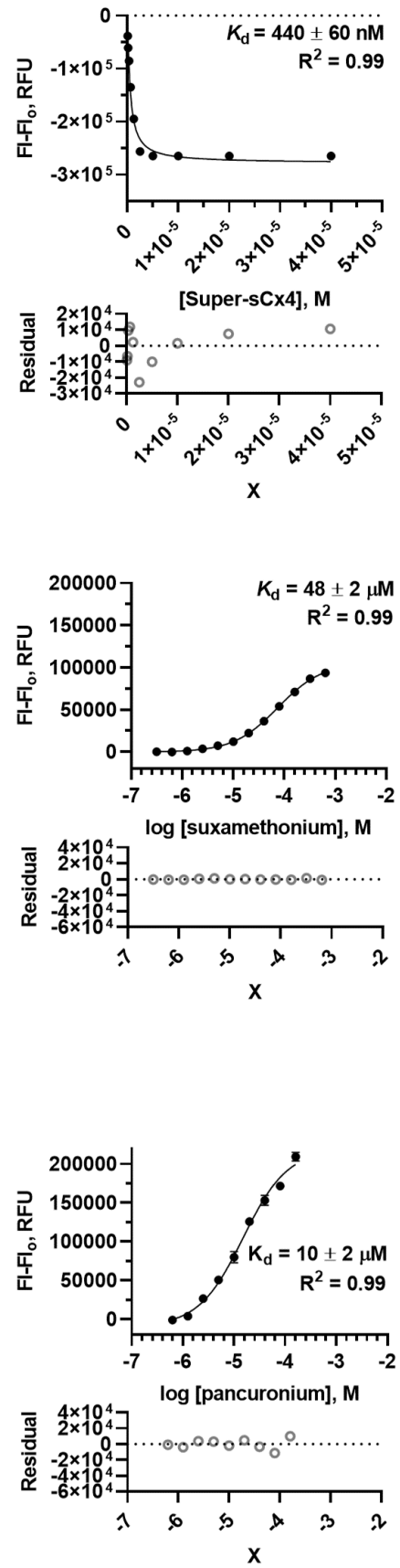
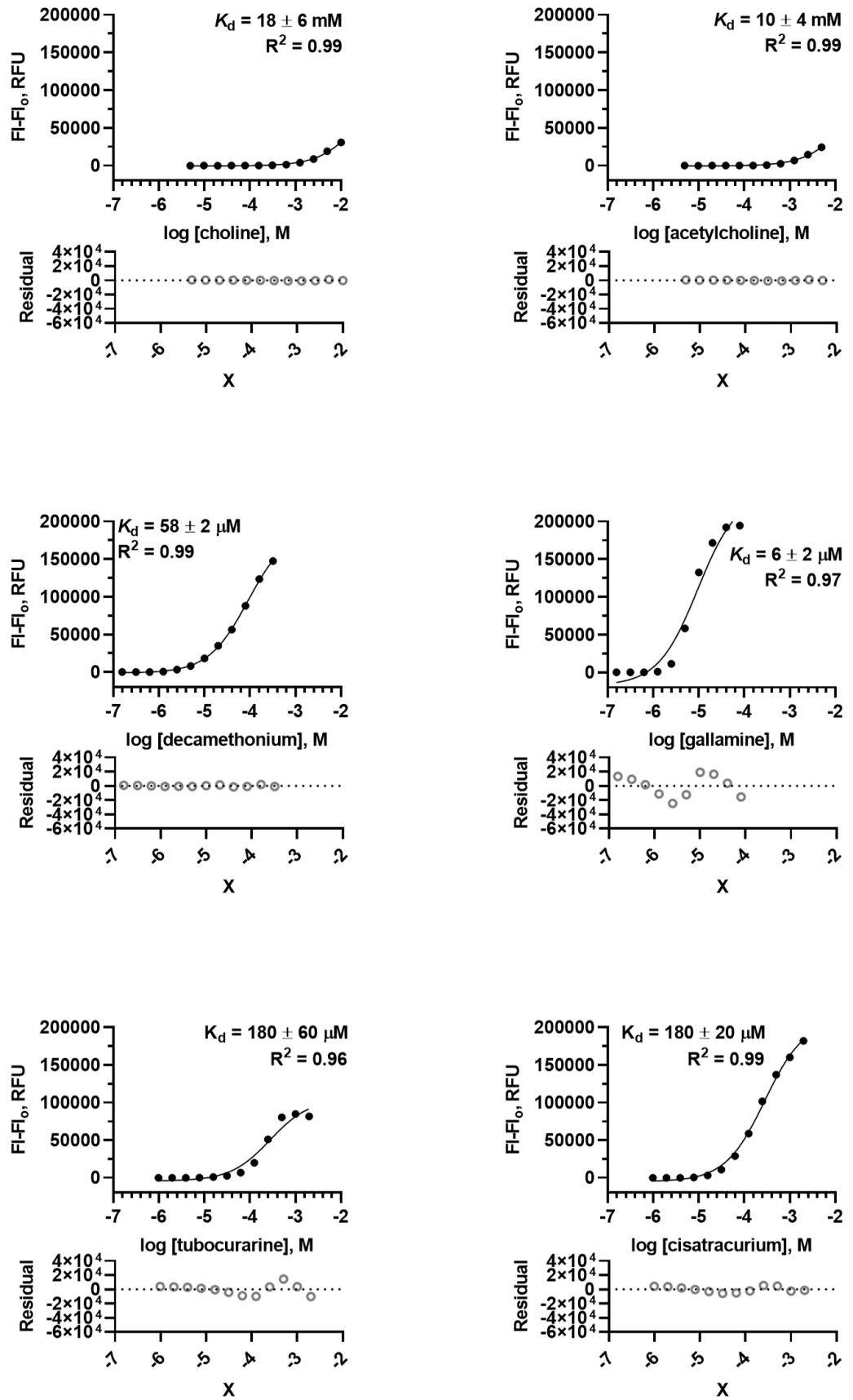
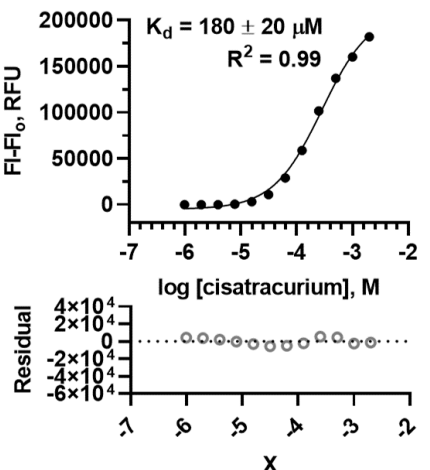

Figure S28. Exemplary duplicate data from direct titrations of Super-sCx4 into lucigenin, and competitive titrations of guest into Super-sCx4 + lucigenin. Error bars were plotted for each duplicate but are not visible in cases where the error is smaller than the plotted point. 


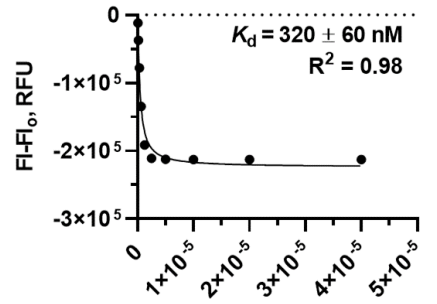

[Super-sCx5], M
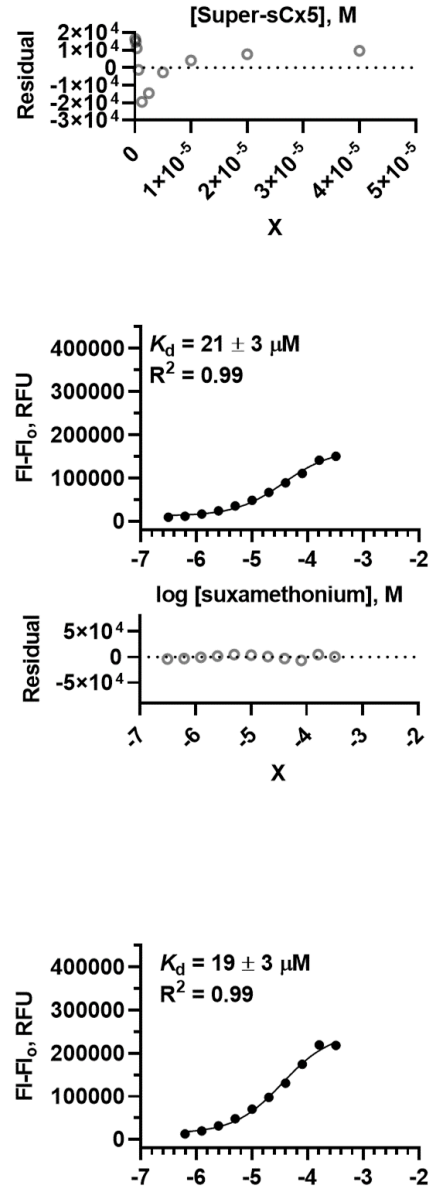

$\log$ [pancuronium], M

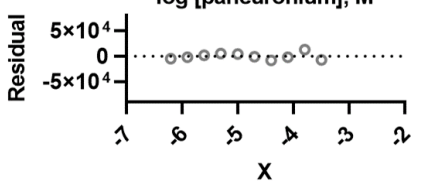

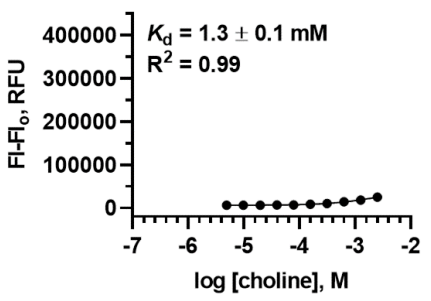
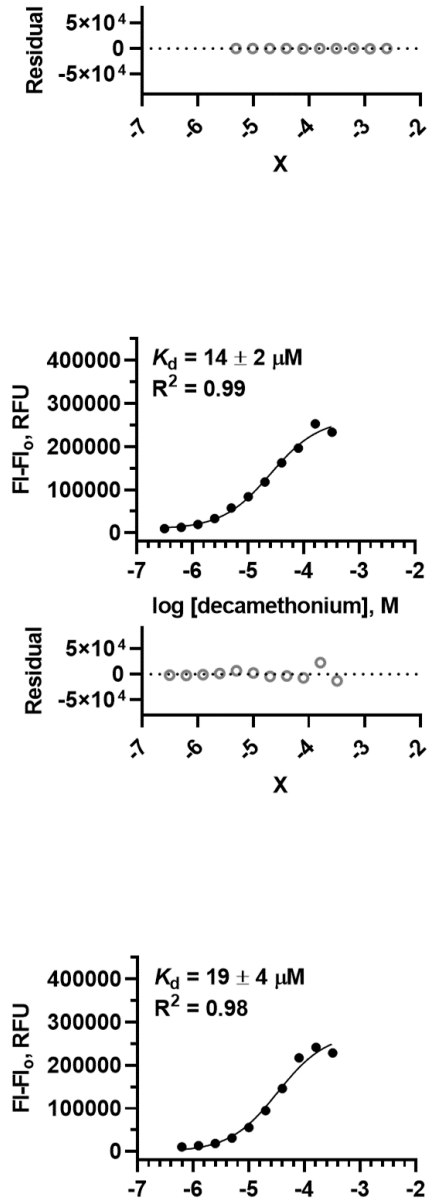

$\log$ [tubocurarine], $\mathrm{M}$

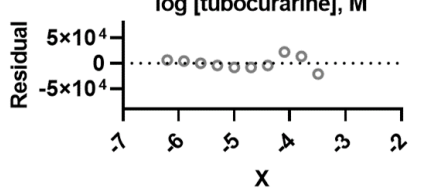

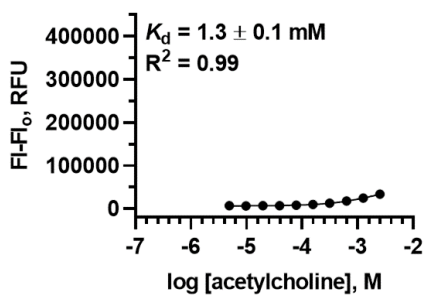
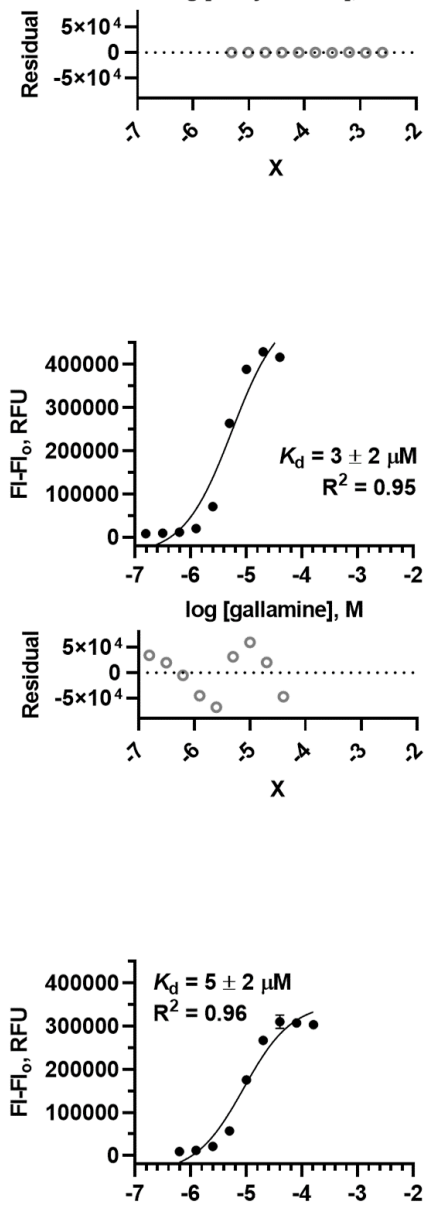

$\log$ [cisatracurium], M

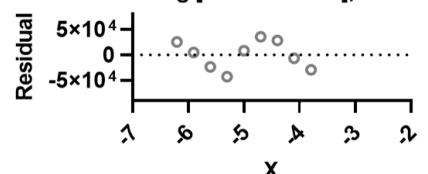

Figure S29. Exemplary duplicate data from direct titrations of Super-sCx5 into lucigenin, and competitive titrations of guest into Super-sCx5 + lucigenin. Error bars were plotted for each duplicate but are not visible in cases where the error is smaller than the plotted point. 


\section{4. ${ }^{1} \mathrm{H}$ NMR titrations}

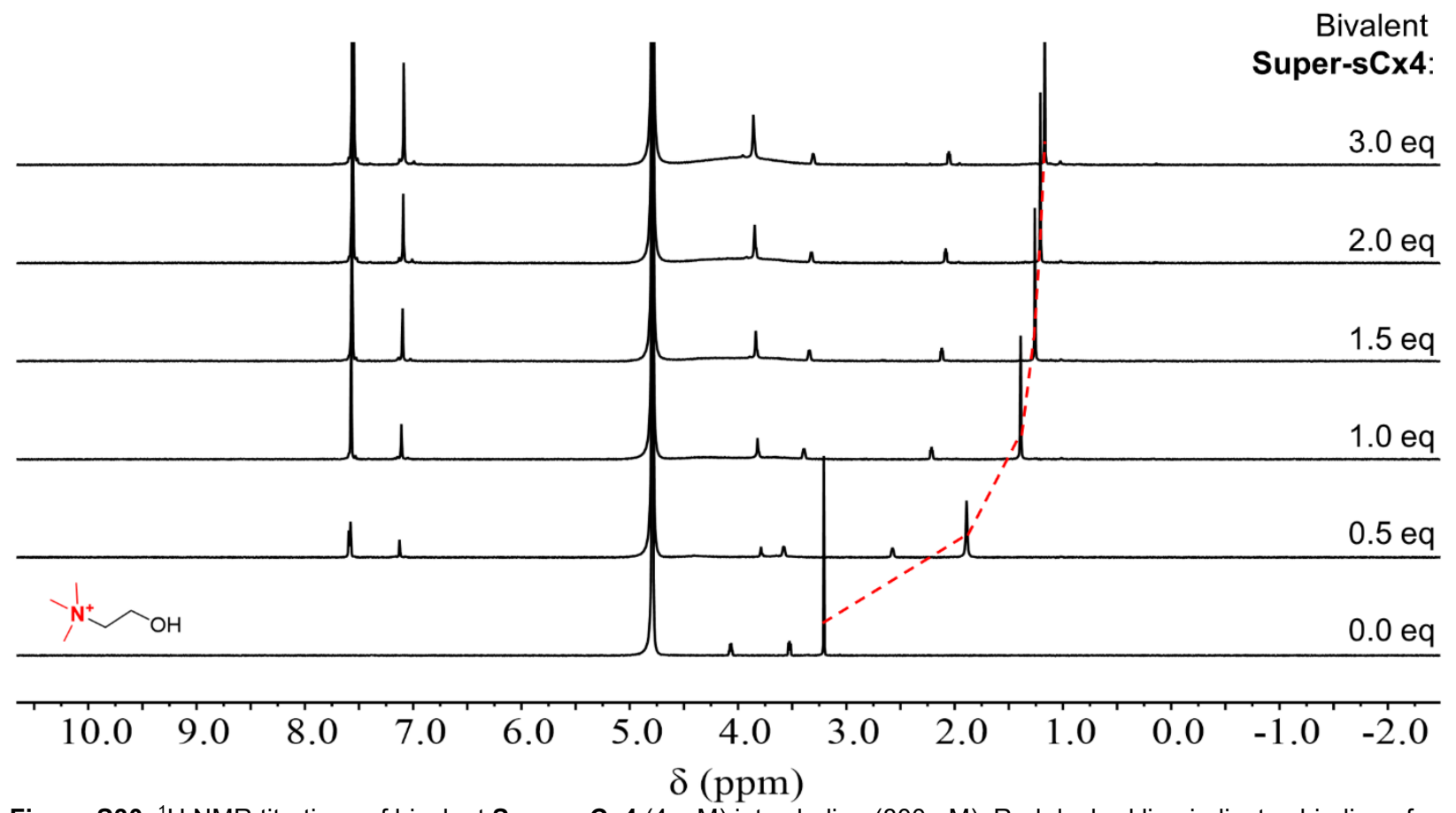

Figure S30. ${ }^{1} \mathrm{H}$ NMR titrations of bivalent Super-sCx4 $(4 \mathrm{mM})$ into choline $(800 \mu \mathrm{M})$. Red dashed line indicates binding of methyl groups. All solutions were in $\mathrm{NaH}_{2} \mathrm{PO}_{4} / \mathrm{Na}_{2} \mathrm{HPO}_{4}(50 \mathrm{mM}, \mathrm{pD} 7.4)$ in $\mathrm{D}_{2} \mathrm{O}(500 \mathrm{MHz}, 297 \mathrm{~K})$.

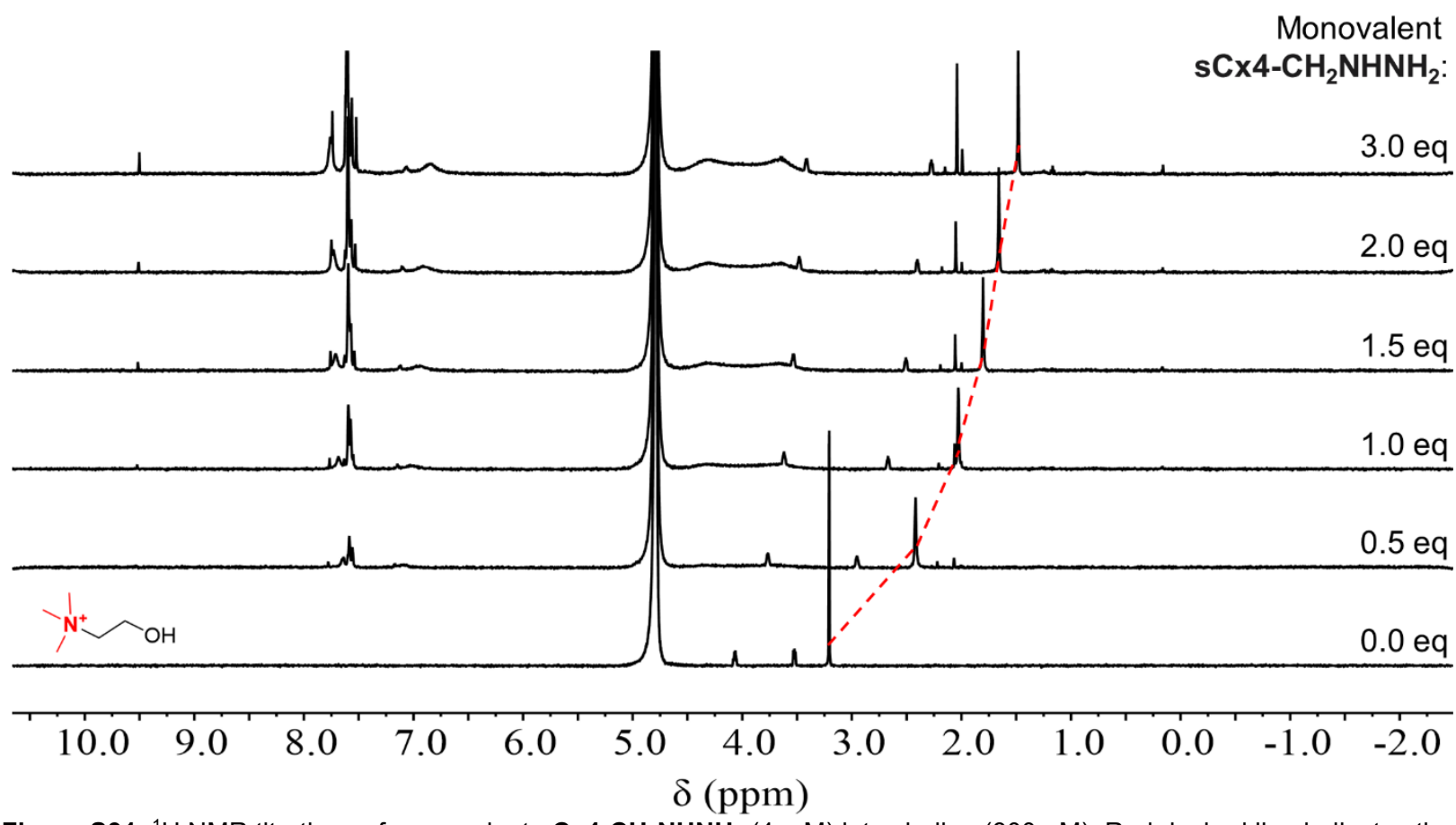

Figure S31. ${ }^{1} \mathrm{H}$ NMR titrations of monovalent $\mathbf{s} \mathbf{C} \mathbf{x} 4-\mathbf{C H}_{2} \mathbf{N H N H}_{2}(4 \mathrm{mM})$ into choline $(800 \mu \mathrm{M})$. Red dashed line indicates the binding of methyl groups. All solutions were in $\mathrm{NaH}_{2} \mathrm{PO}_{4} / \mathrm{Na}_{2} \mathrm{HPO}_{4}(50 \mathrm{mM}, \mathrm{pD} 7.4)$ in $\mathrm{D}_{2} \mathrm{O}(500 \mathrm{MHz}, 297 \mathrm{~K})$. 


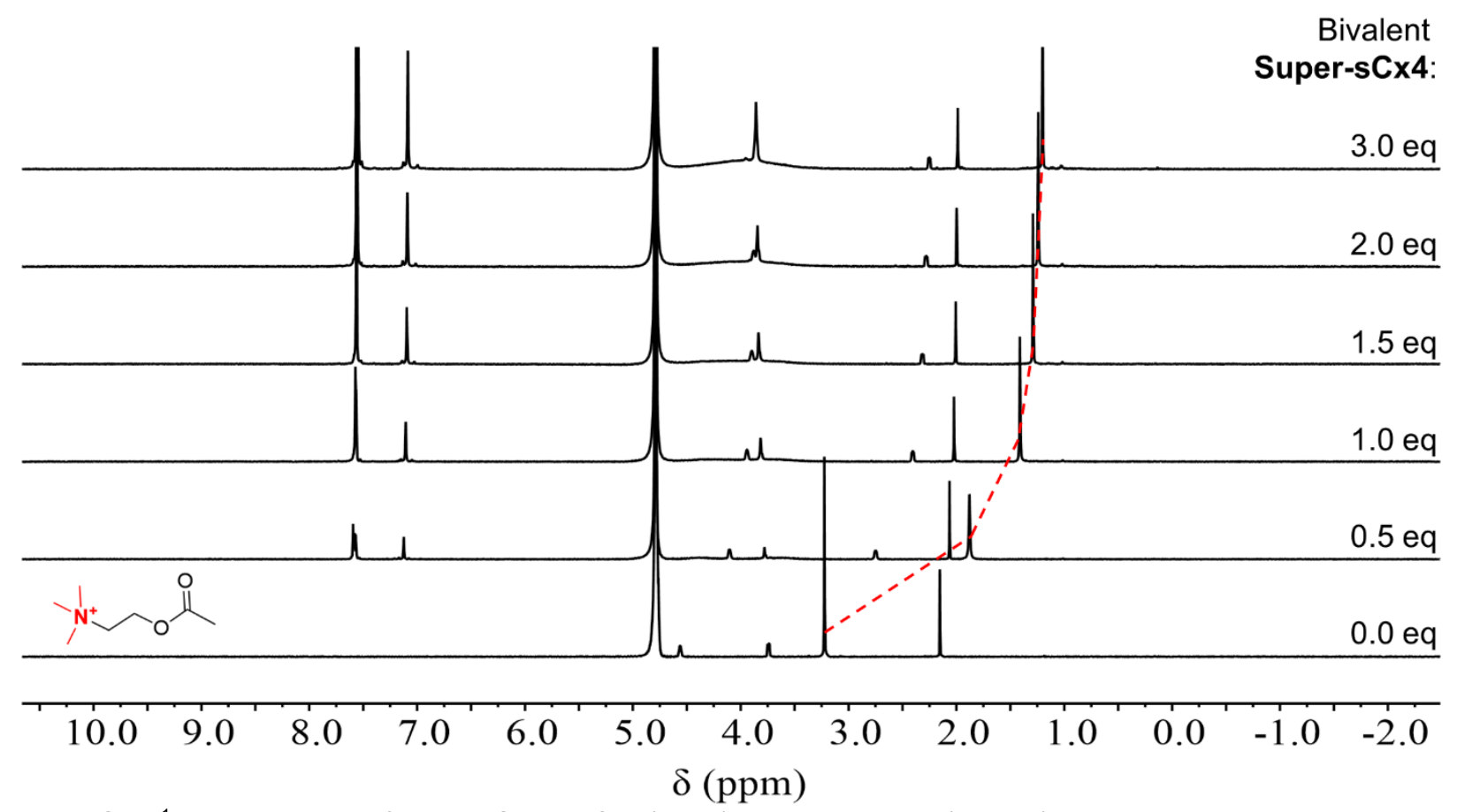

Figure S32. ${ }^{1} \mathrm{H}$ NMR titrations of bivalent Super-sCx4 (4 mM) into acetylcholine $(800 \mu \mathrm{M})$. Red dashed line indicates the binding of methyl groups. All solutions were in $\mathrm{NaH}_{2} \mathrm{PO}_{4} / \mathrm{Na}_{2} \mathrm{HPO}_{4}(50 \mathrm{mM}, \mathrm{pD} 7.4)$ in $\mathrm{D}_{2} \mathrm{O}(500 \mathrm{MHz}, 297 \mathrm{~K})$.

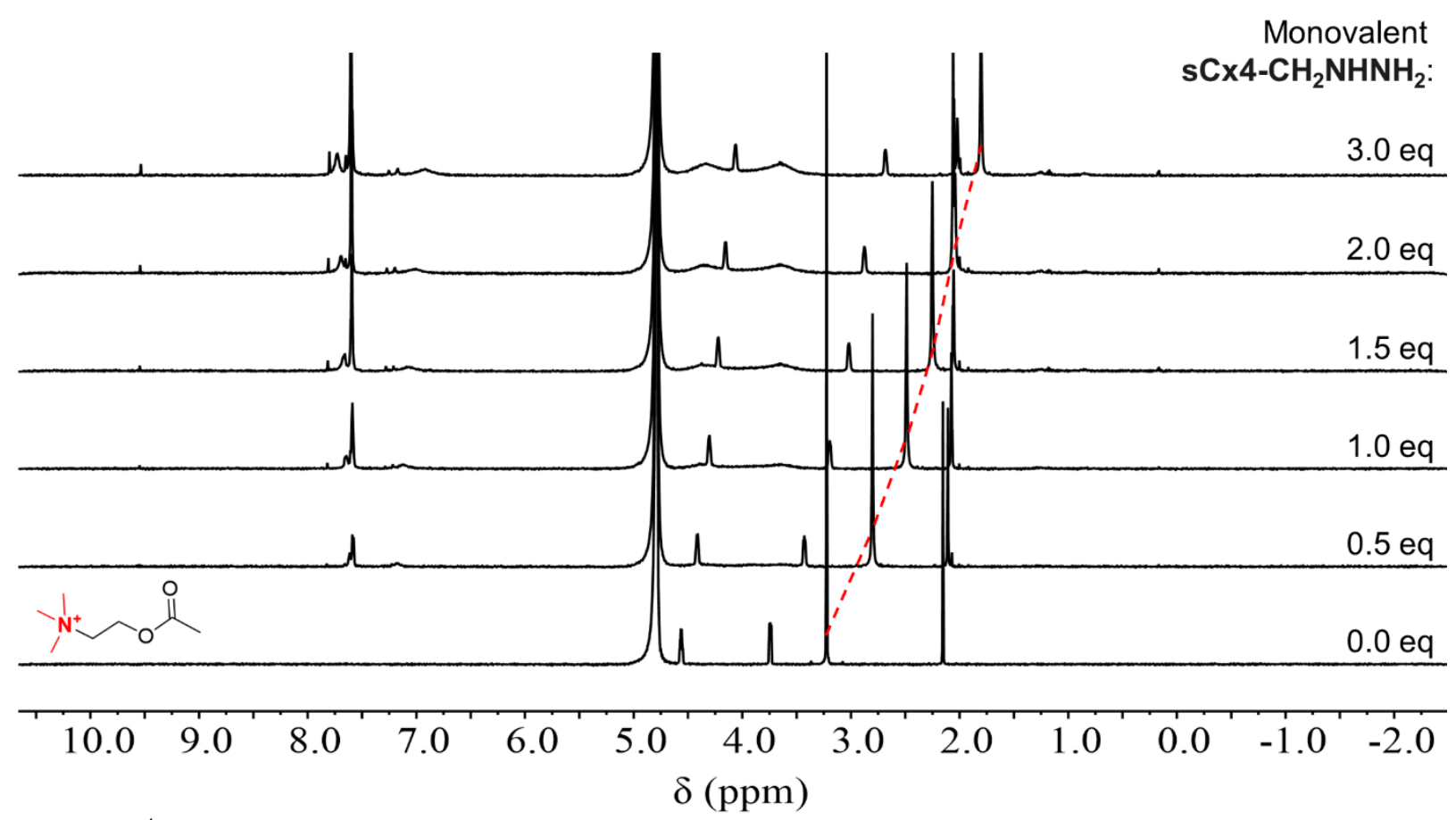

Figure S33. ${ }^{1} \mathrm{H}$ NMR titrations of monovalent $\mathbf{s} \mathbf{C} \times \mathbf{4}-\mathbf{C H}_{2} \mathbf{N H N H}_{2}(4 \mathrm{mM})$ into acetylcholine $(800 \mu \mathrm{M})$. Red dashed line indicates the binding of methyl groups. All solutions were in $\mathrm{NaH}_{2} \mathrm{PO}_{4} / \mathrm{Na}_{2} \mathrm{HPO}_{4}(50 \mathrm{mM}, \mathrm{pD} 7.4)$ in $\mathrm{D}_{2} \mathrm{O}(500 \mathrm{MHz}, 297 \mathrm{~K})$. 


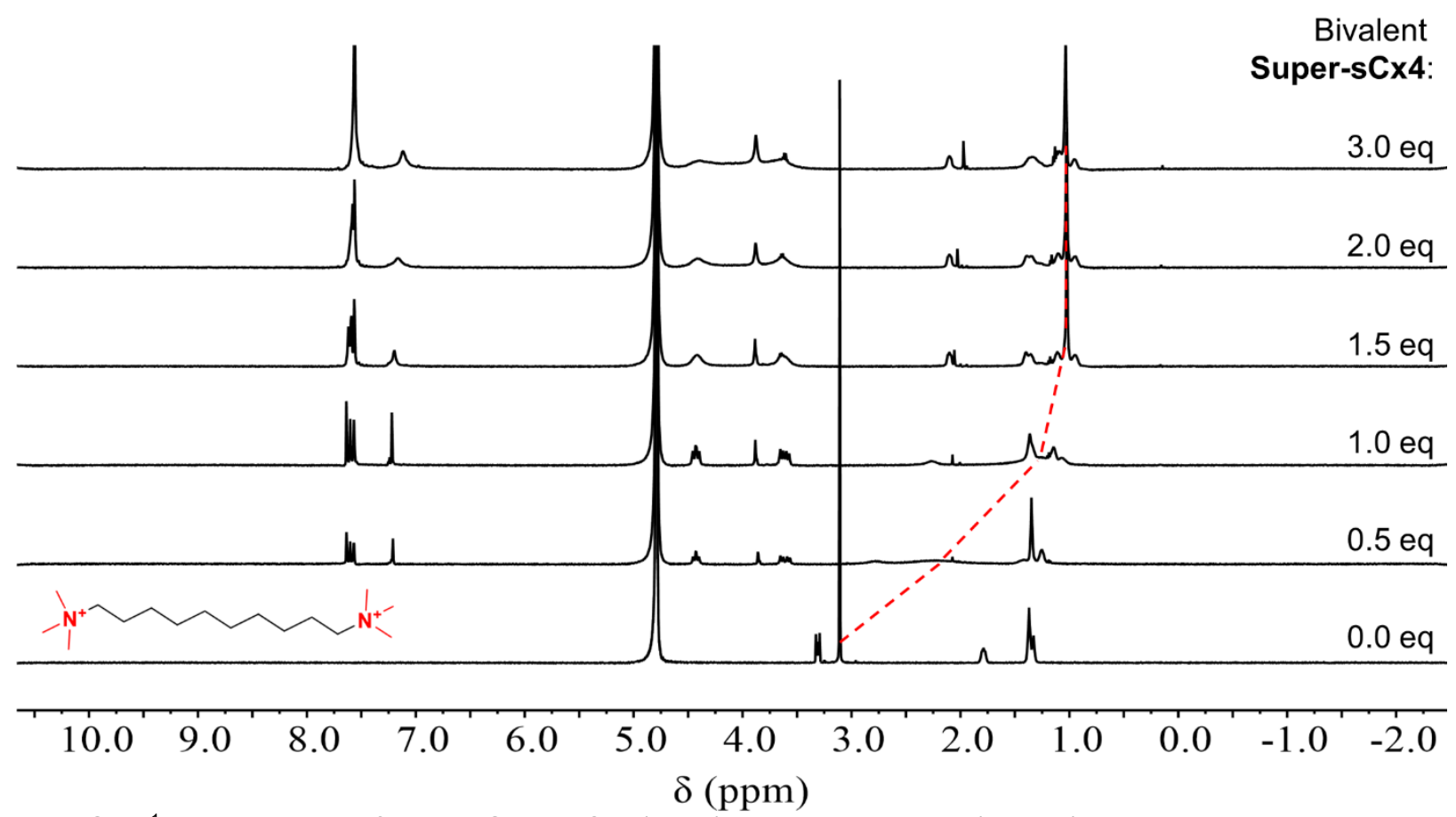

Figure S34. ${ }^{1} \mathrm{H}$ NMR titrations of bivalent Super-sCx4 (4 mM) into decamethonium $(800 \mu \mathrm{M})$. Red dashed line indicates the binding of methyl groups. All solutions were in $\mathrm{NaH}_{2} \mathrm{PO}_{4} / \mathrm{Na}_{2} \mathrm{HPO}_{4}(50 \mathrm{mM}, \mathrm{pD} 7.4)$ in $\mathrm{D}_{2} \mathrm{O}(500 \mathrm{MHz}, 297 \mathrm{~K})$.

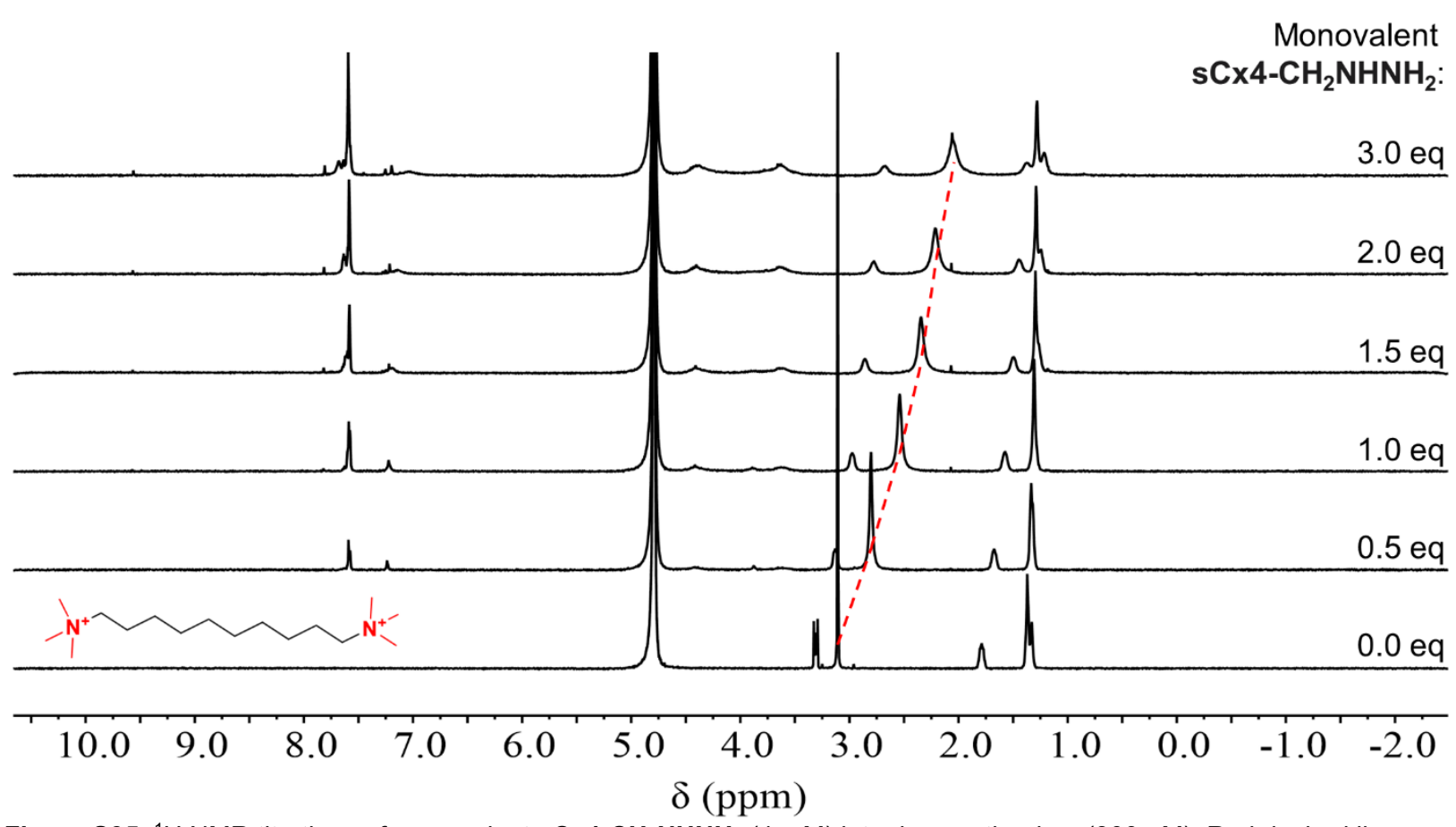

Figure S35. ${ }^{1} \mathrm{H}$ NMR titrations of monovalent $\mathbf{s} \mathbf{C x} 4-\mathrm{CH}_{2} \mathrm{NHNH}_{2}(4 \mathrm{mM})$ into decamethonium $(800 \mu \mathrm{M})$. Red dashed line indicates the binding of methyl groups. All solutions were in $\mathrm{NaH}_{2} \mathrm{PO}_{4} / \mathrm{Na}_{2} \mathrm{HPO}_{4}(50 \mathrm{mM}, \mathrm{pD} 7.4)$ in $\mathrm{D}_{2} \mathrm{O}(500 \mathrm{MHz}, 297 \mathrm{~K})$. 


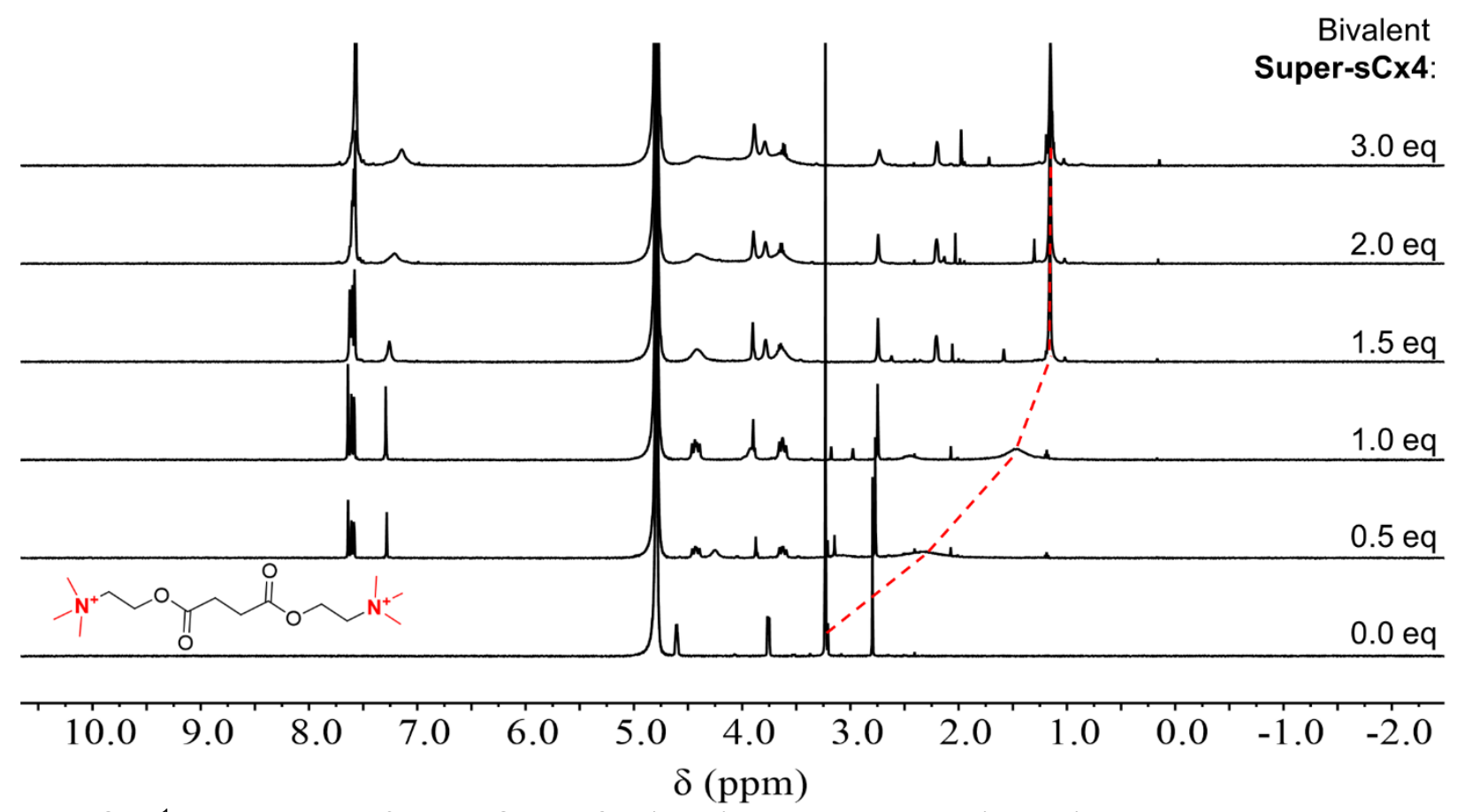

Figure S36. ${ }^{1} \mathrm{H}$ NMR titrations of bivalent Super-sCx4 $(4 \mathrm{mM})$ into suxamethonium $(800 \mu \mathrm{M})$. Red dashed line indicates the binding of methyl groups. All solutions were in $\mathrm{NaH}_{2} \mathrm{PO}_{4} / \mathrm{Na}_{2} \mathrm{HPO}_{4}(50 \mathrm{mM}, \mathrm{pD} 7.4)$ in $\mathrm{D}_{2} \mathrm{O}(500 \mathrm{MHz}, 297 \mathrm{~K})$.

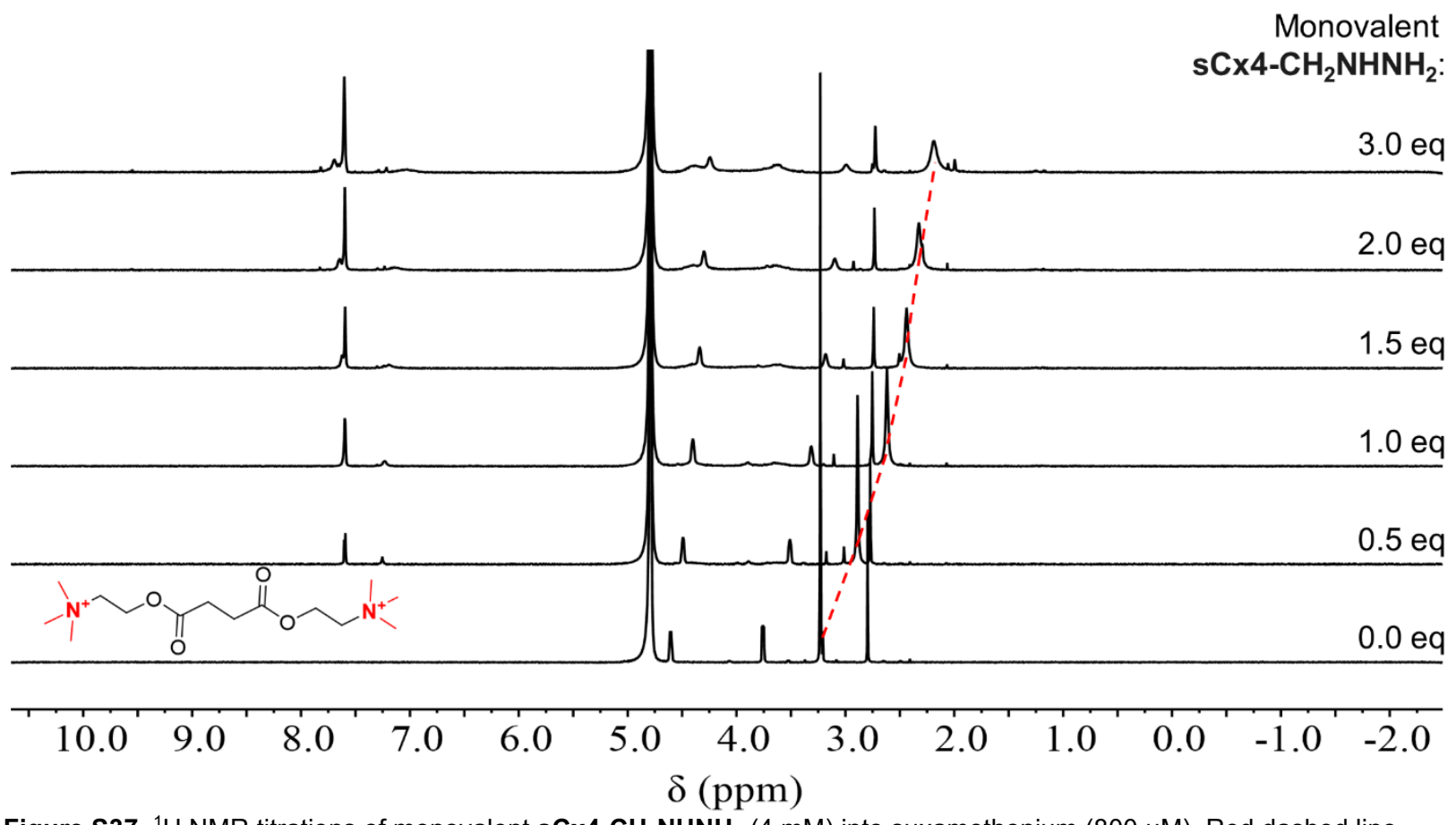

Figure S37. ${ }^{1} \mathrm{H}$ NMR titrations of monovalent $\mathbf{s} \mathbf{C x} 4-\mathrm{CH}_{2} \mathrm{NHNH}_{2}(4 \mathrm{mM})$ into suxamethonium $(800 \mu \mathrm{M})$. Red dashed line indicates the binding of methyl groups. All solutions were in $\mathrm{NaH}_{2} \mathrm{PO}_{4} / \mathrm{Na}_{2} \mathrm{HPO}_{4}(50 \mathrm{mM}, \mathrm{pD} 7.4)$ in $\mathrm{D}_{2} \mathrm{O}(500 \mathrm{MHz}, 297 \mathrm{~K})$. 


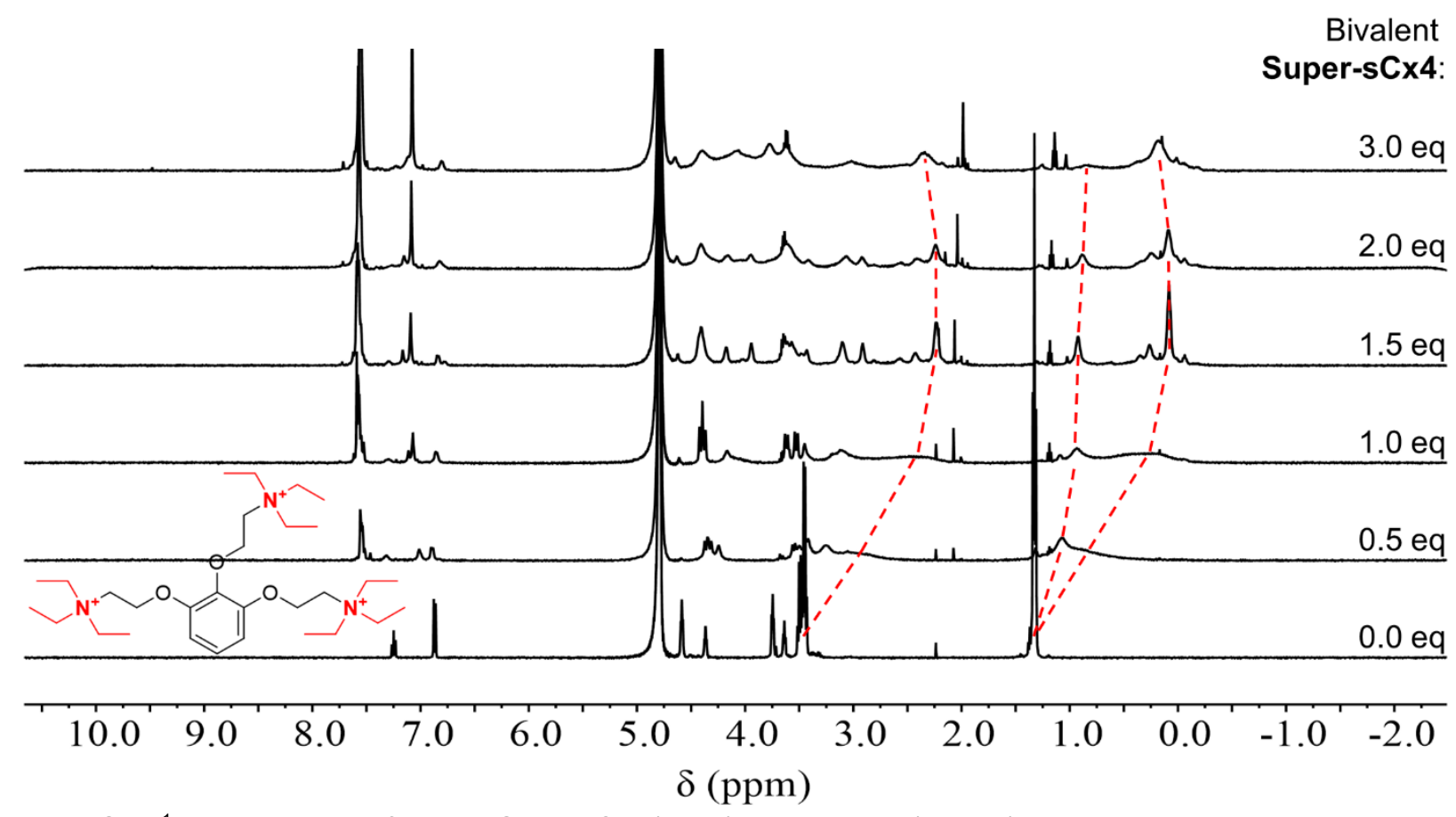

Figure S38. ${ }^{1} \mathrm{H}$ NMR titrations of bivalent Super-sCx4 $(4 \mathrm{mM})$ into gallamine $(800 \mu \mathrm{M})$. Red dashed line indicates the binding of ethyl and methyl groups. All solutions were in $\mathrm{NaH}_{2} \mathrm{PO}_{4} / \mathrm{Na}_{2} \mathrm{HPO}_{4}(50 \mathrm{mM}, \mathrm{pD} 7.4)$ in $\mathrm{D}_{2} \mathrm{O}(500 \mathrm{MHz}, 297 \mathrm{~K})$.

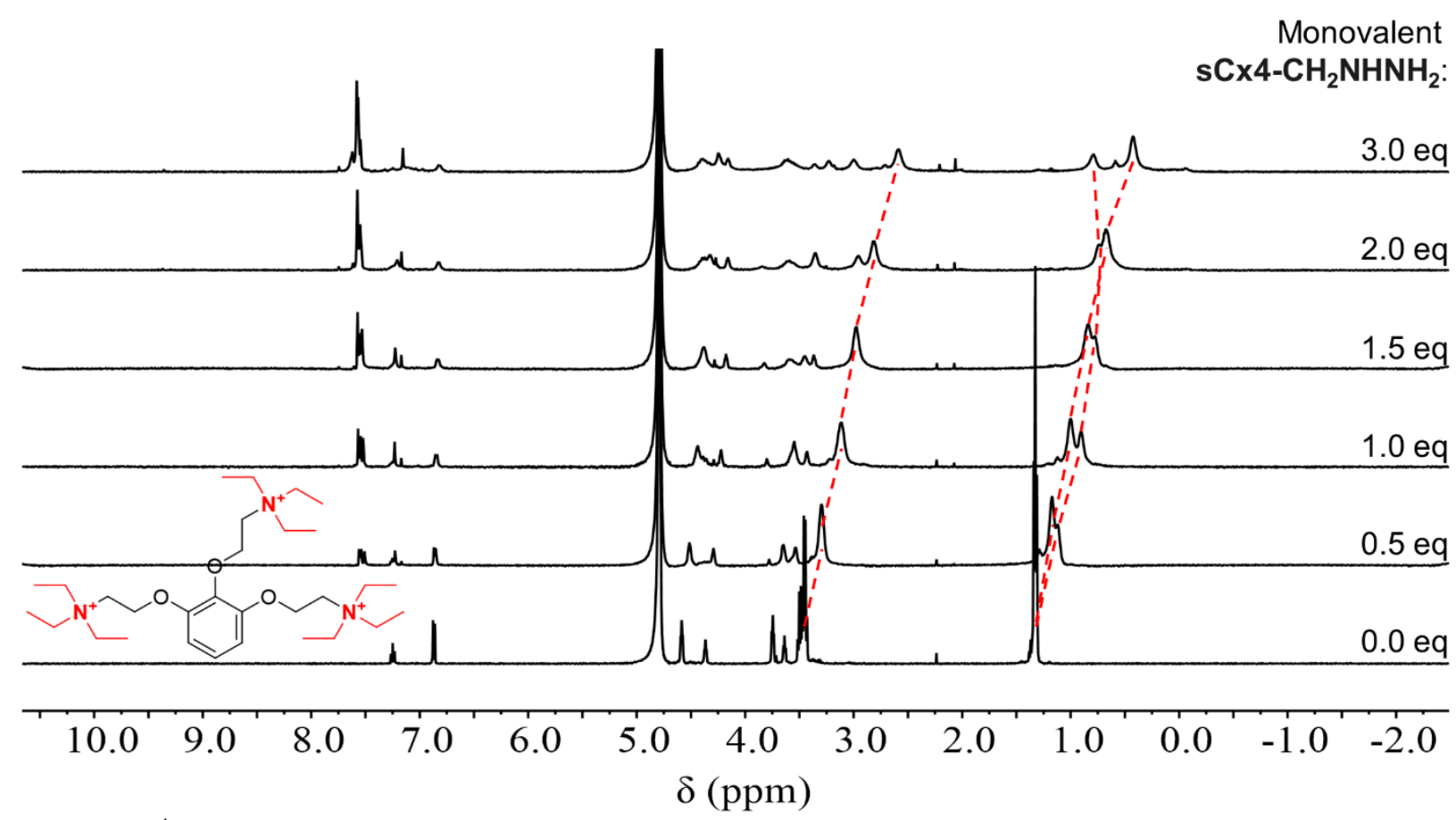

Figure S39. ${ }^{1} \mathrm{H}$ NMR titrations of monovalent $\mathbf{s} \mathbf{C} \times 4-\mathbf{C H}_{2} \mathrm{NHNH}_{2}(4 \mathrm{mM})$ into gallamine $(800 \mu \mathrm{M})$. Red dashed line indicates the binding of ethyl and methyl groups. All solutions were in $\mathrm{NaH}_{2} \mathrm{PO}_{4} / \mathrm{Na}_{2} \mathrm{HPO}_{4}(50 \mathrm{mM}, \mathrm{pD} 7.4)$ in $\mathrm{D}_{2} \mathrm{O}(500 \mathrm{MHz}, 297 \mathrm{~K})$. 


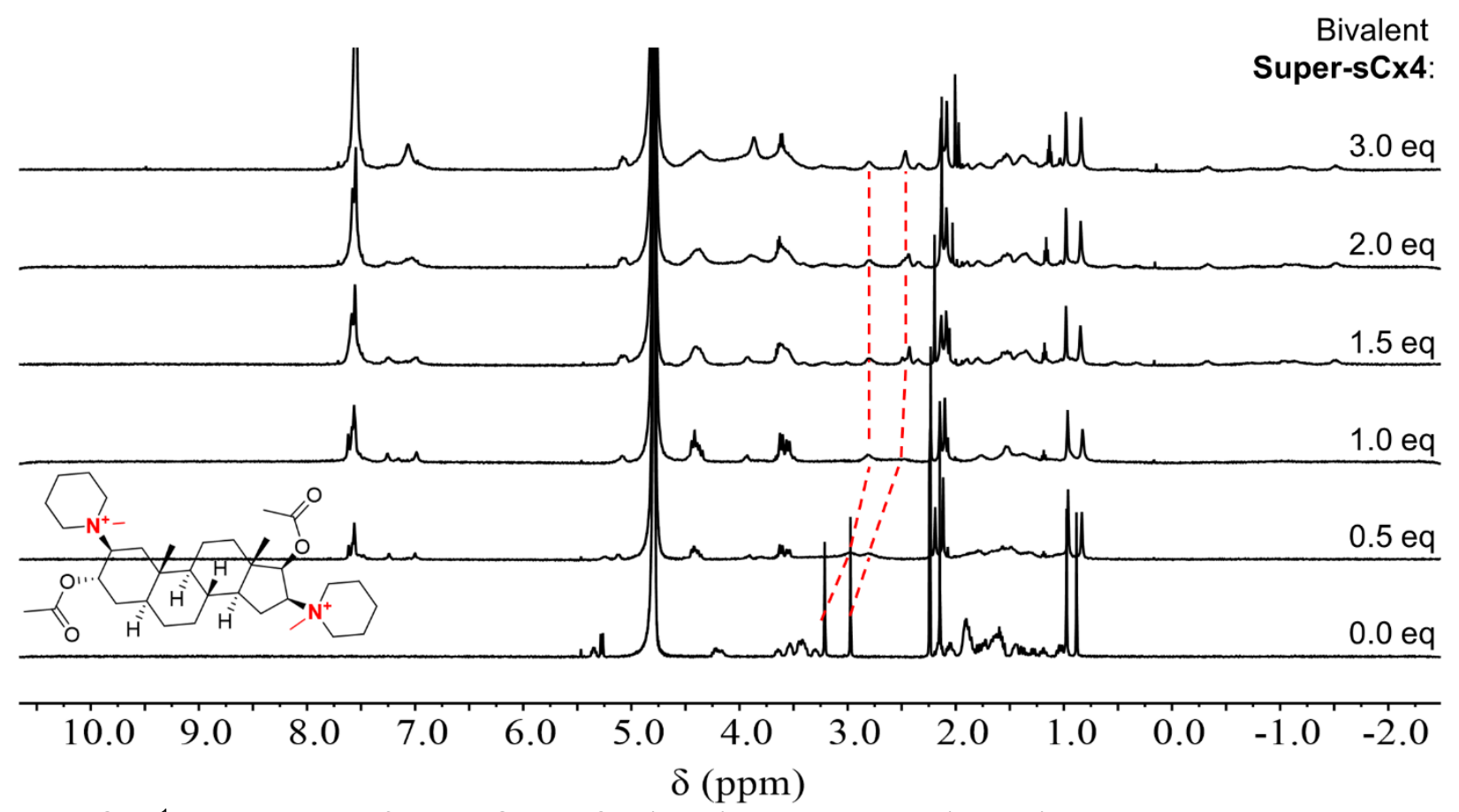

Figure S40. ${ }^{1} \mathrm{H}$ NMR titrations of bivalent Super-sCx4 (4 mM) into pancuronium $(800 \mu \mathrm{M})$. Red dashed line indicates the binding of methyl groups. All solutions were in $\mathrm{NaH}_{2} \mathrm{PO}_{4} / \mathrm{Na}_{2} \mathrm{HPO}_{4}(50 \mathrm{mM}, \mathrm{pD} 7.4)$ in $\mathrm{D}_{2} \mathrm{O}(500 \mathrm{MHz}, 297 \mathrm{~K})$.

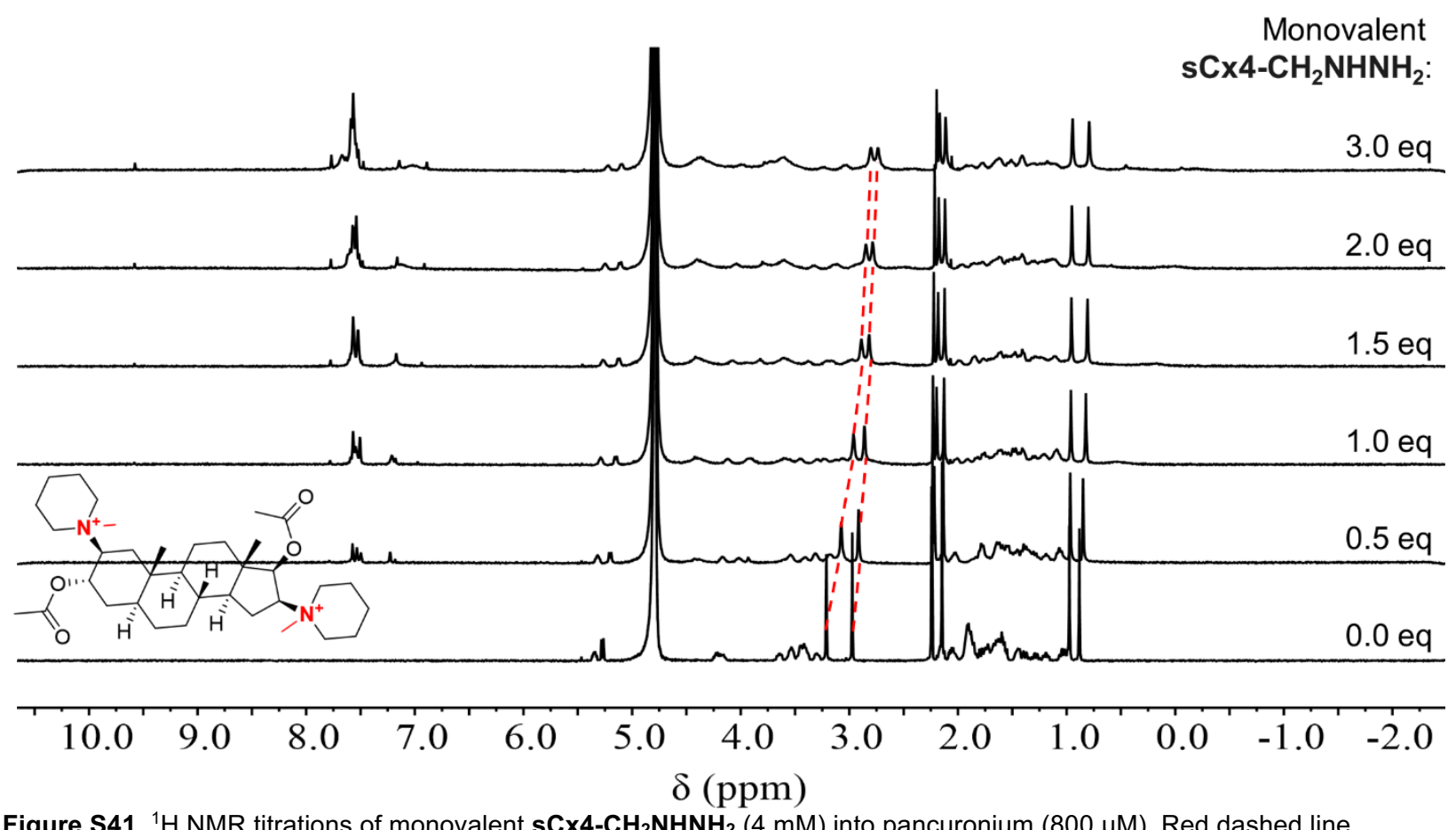

Figure S41. ${ }^{1} \mathrm{H}$ NMR titrations of monovalent $\mathbf{s} \mathbf{C} \mathbf{x}-\mathbf{C H}_{2} \mathbf{N H N H}_{2}(4 \mathrm{mM})$ into pancuronium $(800 \mu \mathrm{M})$. Red dashed line indicates the binding of methyl groups. All solutions were in $\mathrm{NaH}_{2} \mathrm{PO}_{4} / \mathrm{Na}_{2} \mathrm{HPO}_{4}(50 \mathrm{mM}, \mathrm{pD} 7.4)$ in $\mathrm{D}_{2} \mathrm{O}(500 \mathrm{MHz}, 297 \mathrm{~K})$. 


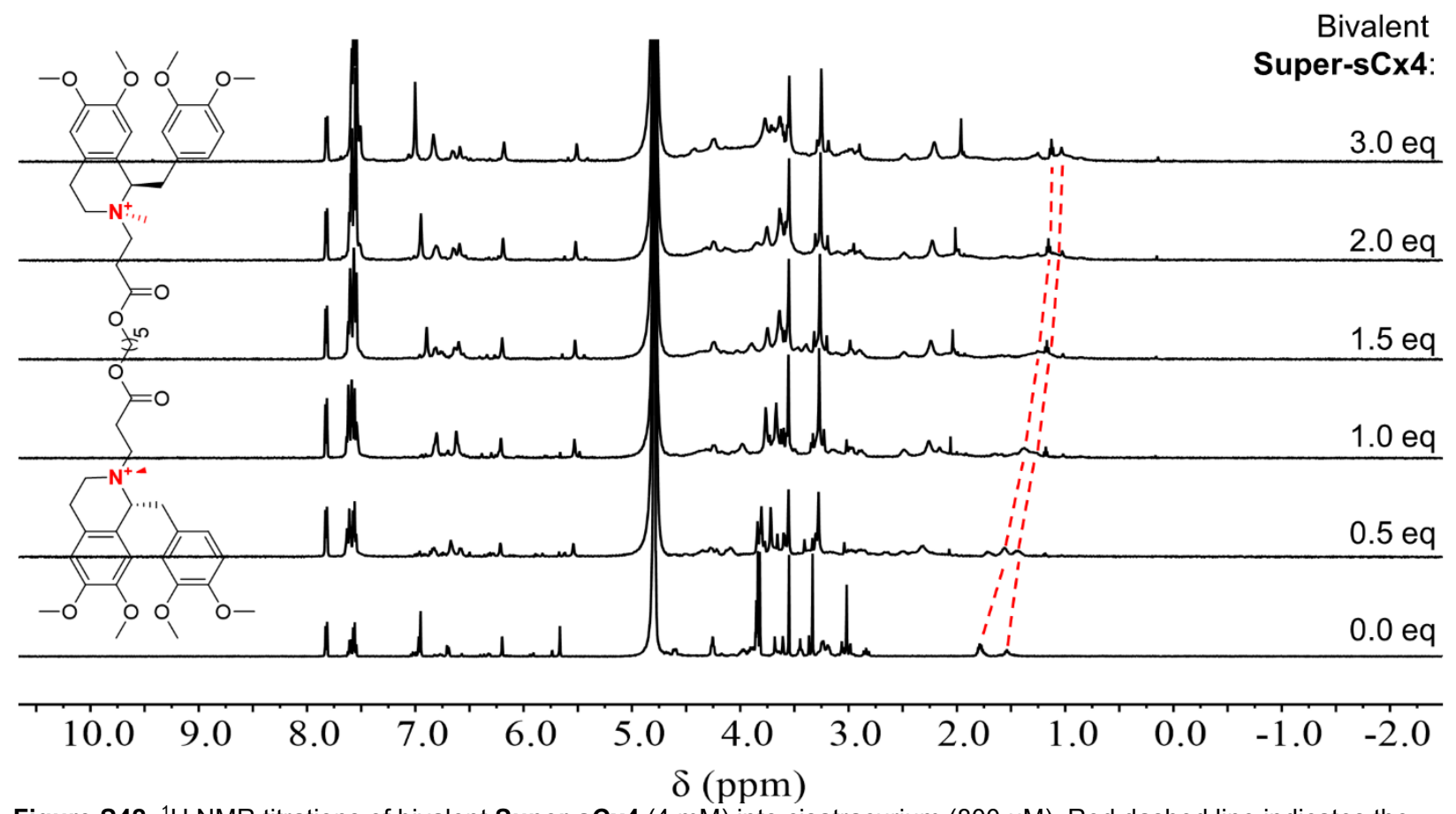

Figure S42. ${ }^{1} \mathrm{H}$ NMR titrations of bivalent Super-sCx4 (4 mM) into cisatracurium $(800 \mu \mathrm{M})$. Red dashed line indicates the binding of methyl groups. All solutions were in $\mathrm{NaH}_{2} \mathrm{PO}_{4} / \mathrm{Na}_{2} \mathrm{HPO}_{4}(50 \mathrm{mM}, \mathrm{pD} 7.4)$ in $\mathrm{D}_{2} \mathrm{O}(500 \mathrm{MHz}, 297 \mathrm{~K})$.
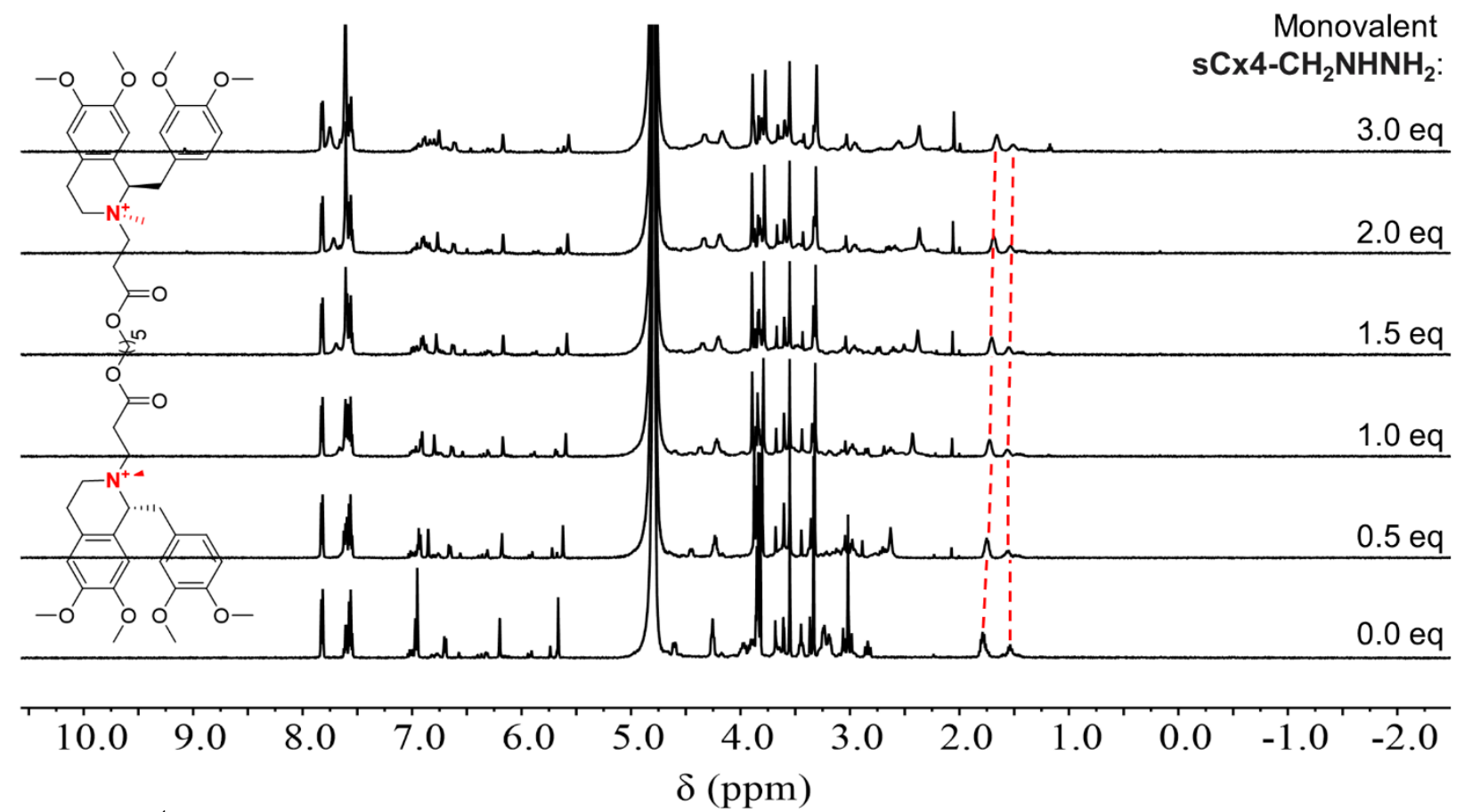

Figure S43. ${ }^{1} \mathrm{H}$ NMR titrations of monovalent $\mathbf{s} \mathbf{C} \mathbf{4}-\mathbf{C H}_{2} \mathbf{N H N H}_{2}(4 \mathrm{mM})$ into cisatracurium $(800 \mu \mathrm{M})$. Red dashed line indicates the binding of methyl groups. All solutions were in $\mathrm{NaH}_{2} \mathrm{PO}_{4} / \mathrm{Na}_{2} \mathrm{HPO}_{4}(50 \mathrm{mM}, \mathrm{pD} 7.4)$ in $\mathrm{D}_{2} \mathrm{O}(500 \mathrm{MHz}, 297 \mathrm{~K})$. 


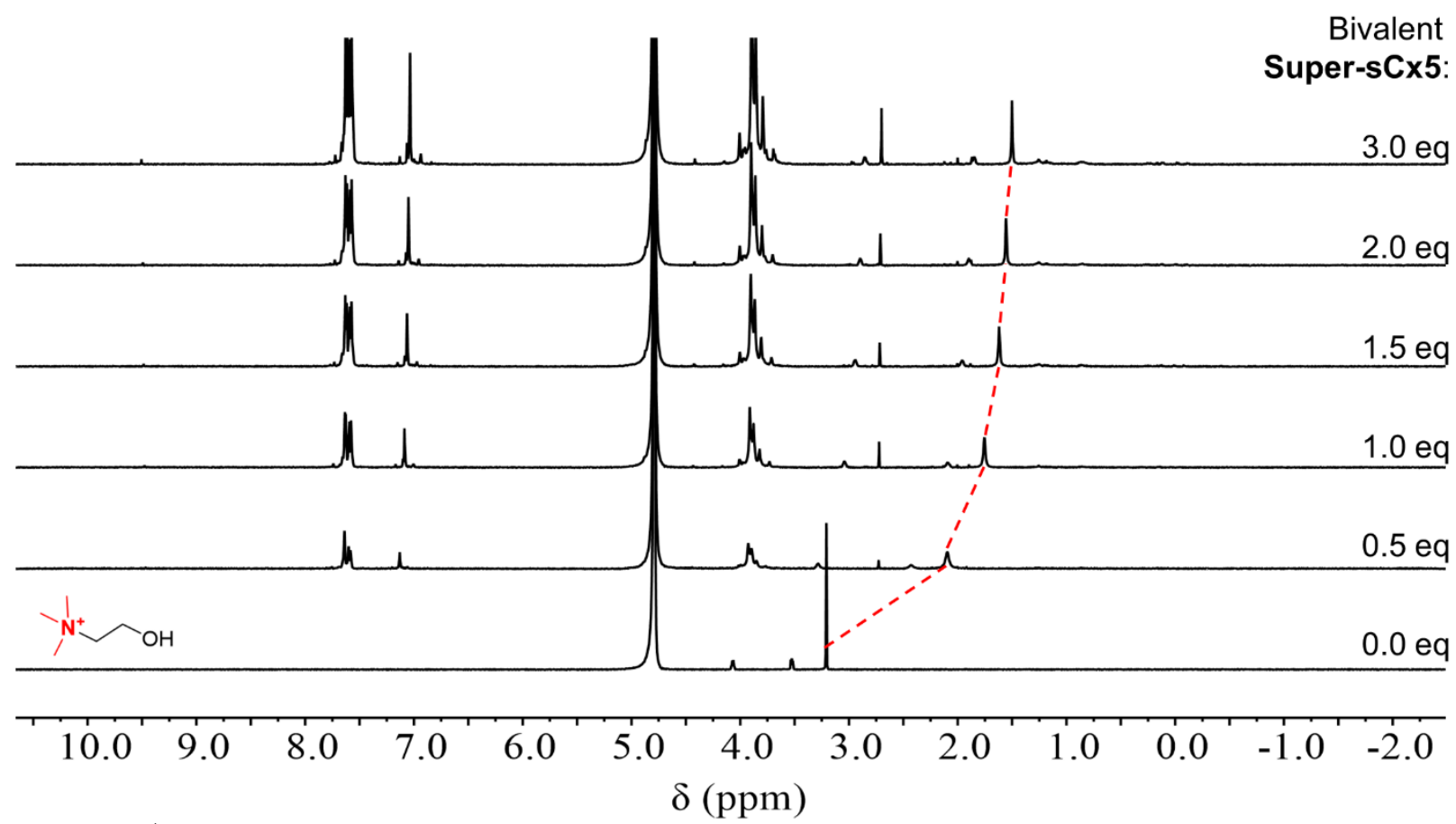

Figure S44. ${ }^{1} \mathrm{H}$ NMR titrations of bivalent Super-sCx5 (4 mM) into choline $(800 \mu \mathrm{M})$. Red dashed line indicates binding of methyl groups. All solutions were in $\mathrm{NaH}_{2} \mathrm{PO}_{4} / \mathrm{Na}_{2} \mathrm{HPO}_{4}(50 \mathrm{mM}, \mathrm{pD} 7.4)$ in $\mathrm{D}_{2} \mathrm{O}(500 \mathrm{MHz}, 297 \mathrm{~K})$.

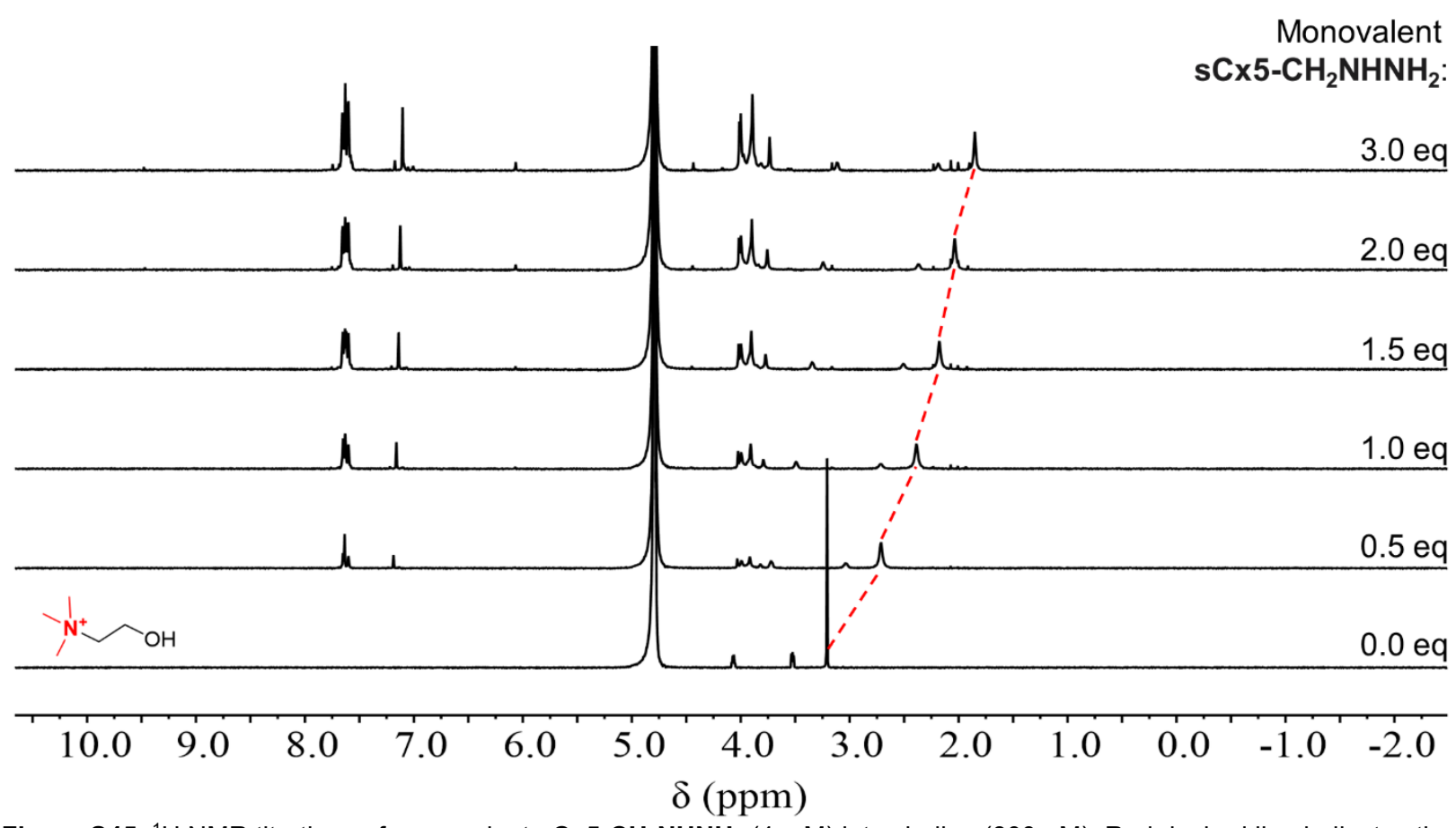

Figure S45. ${ }^{1} \mathrm{H}$ NMR titrations of monovalent $\mathbf{s} \mathbf{C} \times 5-\mathbf{C H}_{2} \mathbf{N H N H}_{2}(4 \mathrm{mM})$ into choline $(800 \mu \mathrm{M})$. Red dashed line indicates the binding of methyl groups. All solutions were in $\mathrm{NaH}_{2} \mathrm{PO}_{4} / \mathrm{Na}_{2} \mathrm{HPO}_{4}(50 \mathrm{mM}, \mathrm{pD} 7.4)$ in $\mathrm{D}_{2} \mathrm{O}(500 \mathrm{MHz}, 297 \mathrm{~K})$. 


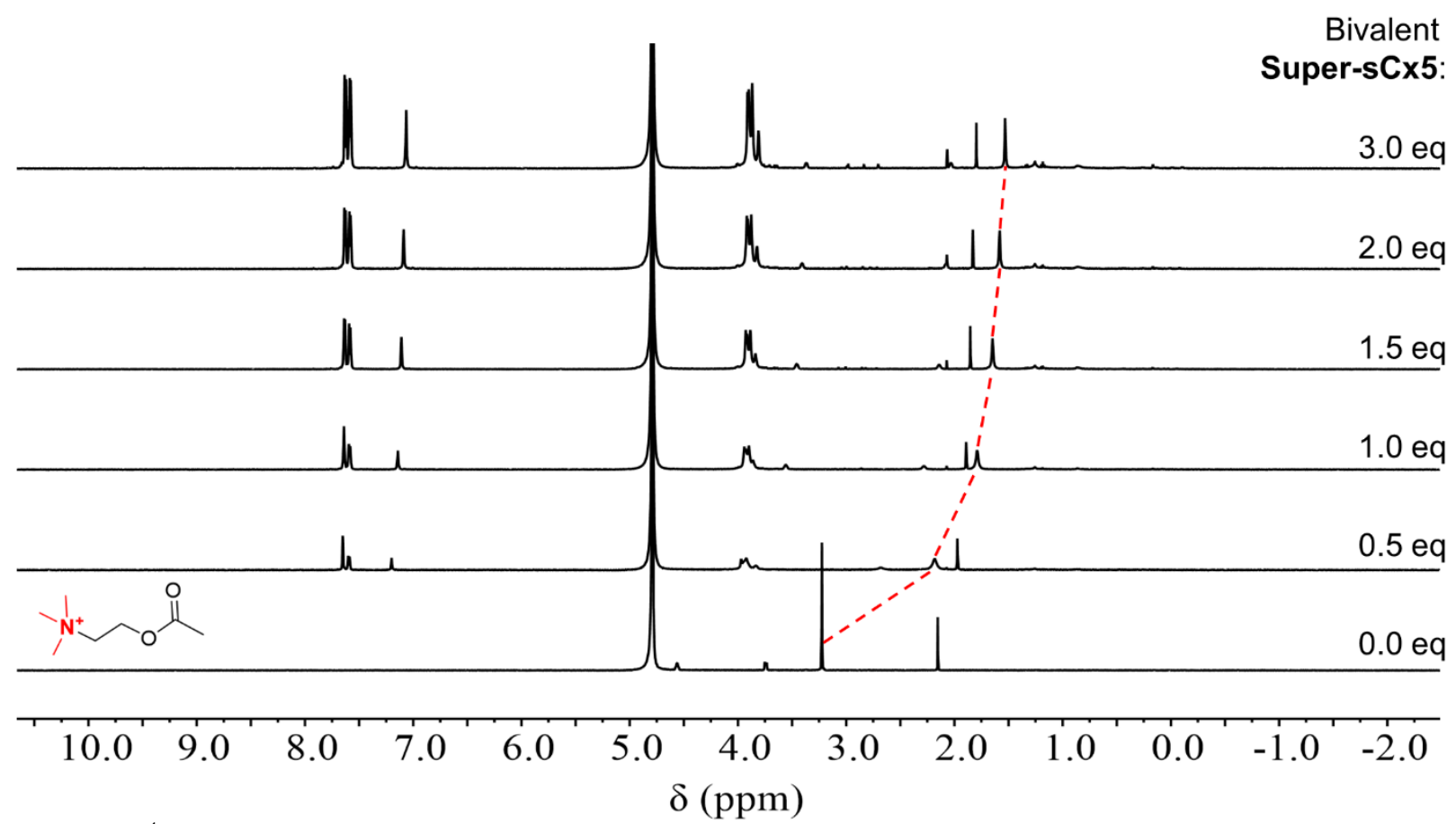

Figure S46. ${ }^{1} \mathrm{H}$ NMR titrations of bivalent Super-sCx5 (4 mM) into acetylcholine $(800 \mu \mathrm{M})$. Red dashed line indicates the binding of methyl groups. All solutions were in $\mathrm{NaH}_{2} \mathrm{PO}_{4} / \mathrm{Na}_{2} \mathrm{HPO}_{4}(50 \mathrm{mM}, \mathrm{pD} 7.4)$ in $\mathrm{D}_{2} \mathrm{O}(500 \mathrm{MHz}, 297 \mathrm{~K})$.

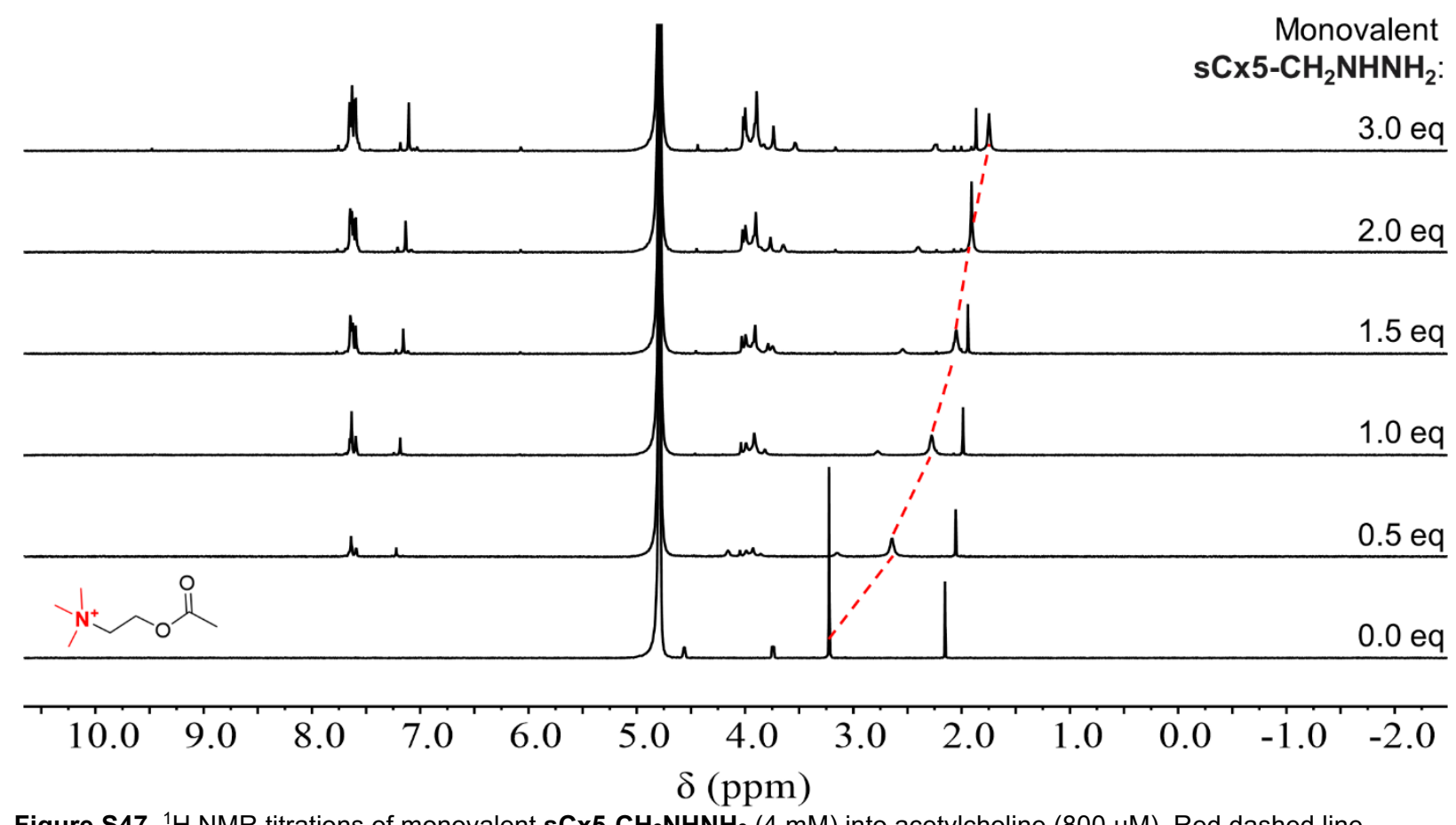

Figure S47. ${ }^{1} \mathrm{H}$ NMR titrations of monovalent $\mathbf{s} \mathbf{C} \times \mathbf{5}-\mathbf{C H}_{2} \mathbf{N H N H}_{2}(4 \mathrm{mM})$ into acetylcholine $(800 \mu \mathrm{M})$. Red dashed line indicates the binding of methyl groups. All solutions were in $\mathrm{NaH}_{2} \mathrm{PO}_{4} / \mathrm{Na}_{2} \mathrm{HPO}_{4}(50 \mathrm{mM}, \mathrm{pD} 7.4)$ in $\mathrm{D}_{2} \mathrm{O}(500 \mathrm{MHz}, 297 \mathrm{~K})$. 

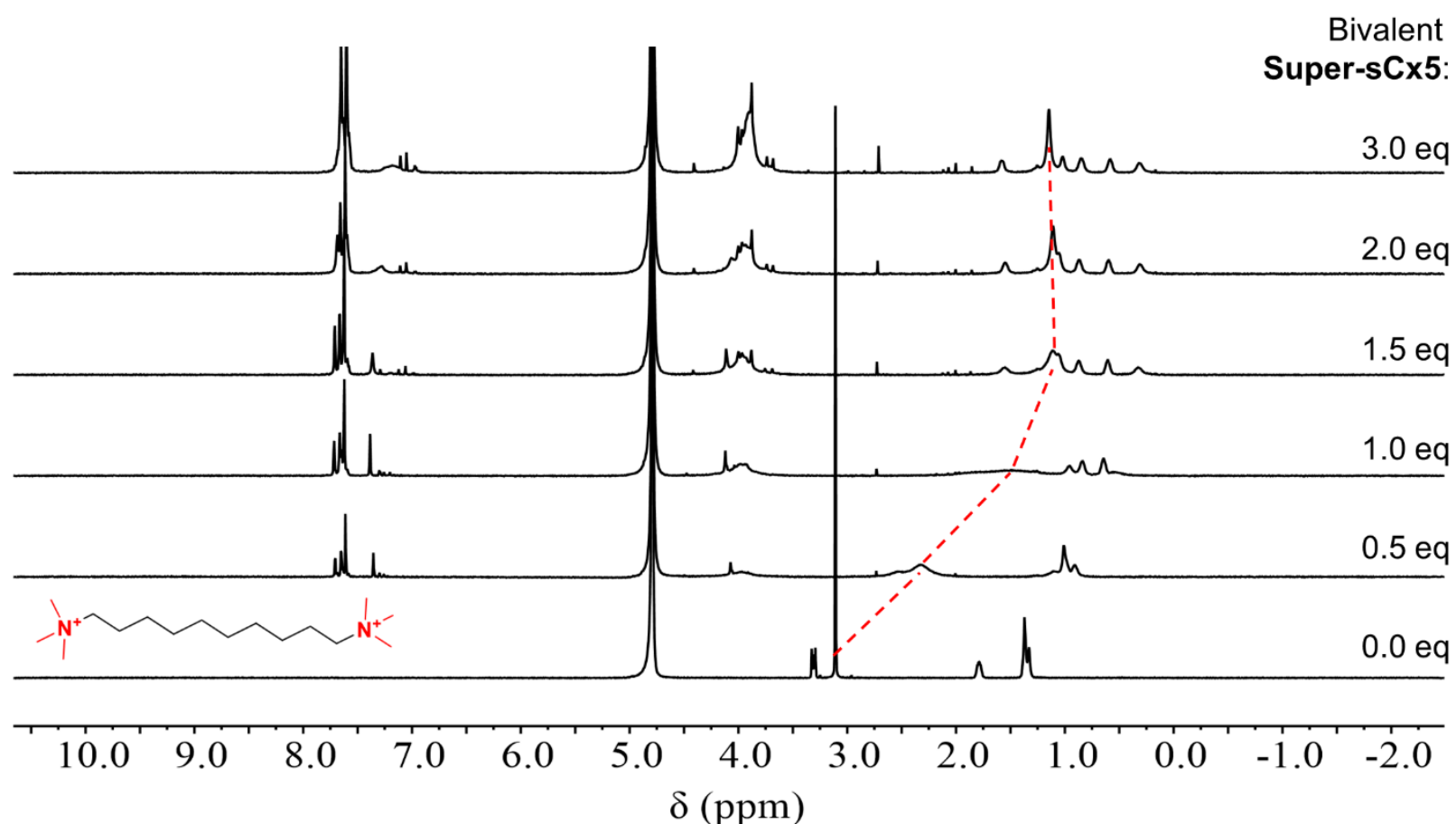

Figure S48. ${ }^{1} \mathrm{H}$ NMR titrations of bivalent Super-sCx5 (4 mM) into decamethonium ( $\left.800 \mu \mathrm{M}\right)$. Red dashed line indicates the binding of methyl groups. All solutions were in $\mathrm{NaH}_{2} \mathrm{PO}_{4} / \mathrm{Na}_{2} \mathrm{HPO}_{4}(50 \mathrm{mM}, \mathrm{pD} 7.4)$ in $\mathrm{D}_{2} \mathrm{O}(500 \mathrm{MHz}, 297 \mathrm{~K})$.

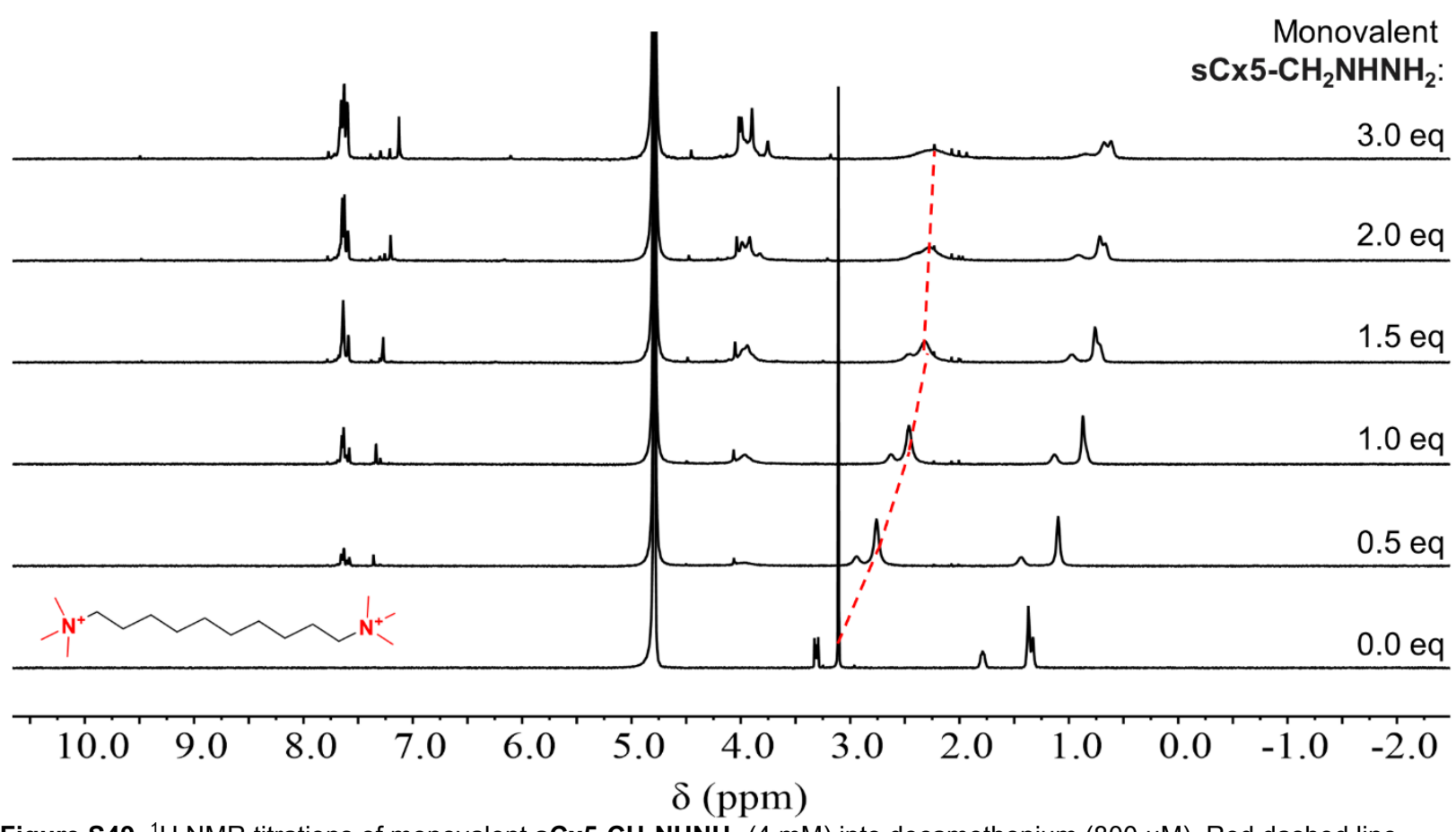

Figure S49. ${ }^{1} \mathrm{H}$ NMR titrations of monovalent $\mathbf{s} \mathbf{C} \times 5-\mathbf{C H}_{2} \mathbf{N H N H}_{2}(4 \mathrm{mM})$ into decamethonium $(800 \mu \mathrm{M})$. Red dashed line indicates the binding of methyl groups. All solutions were in $\mathrm{NaH}_{2} \mathrm{PO}_{4} / \mathrm{Na}_{2} \mathrm{HPO}_{4}(50 \mathrm{mM}, \mathrm{pD} 7.4)$ in $\mathrm{D}_{2} \mathrm{O}(500 \mathrm{MHz}, 297 \mathrm{~K})$. 


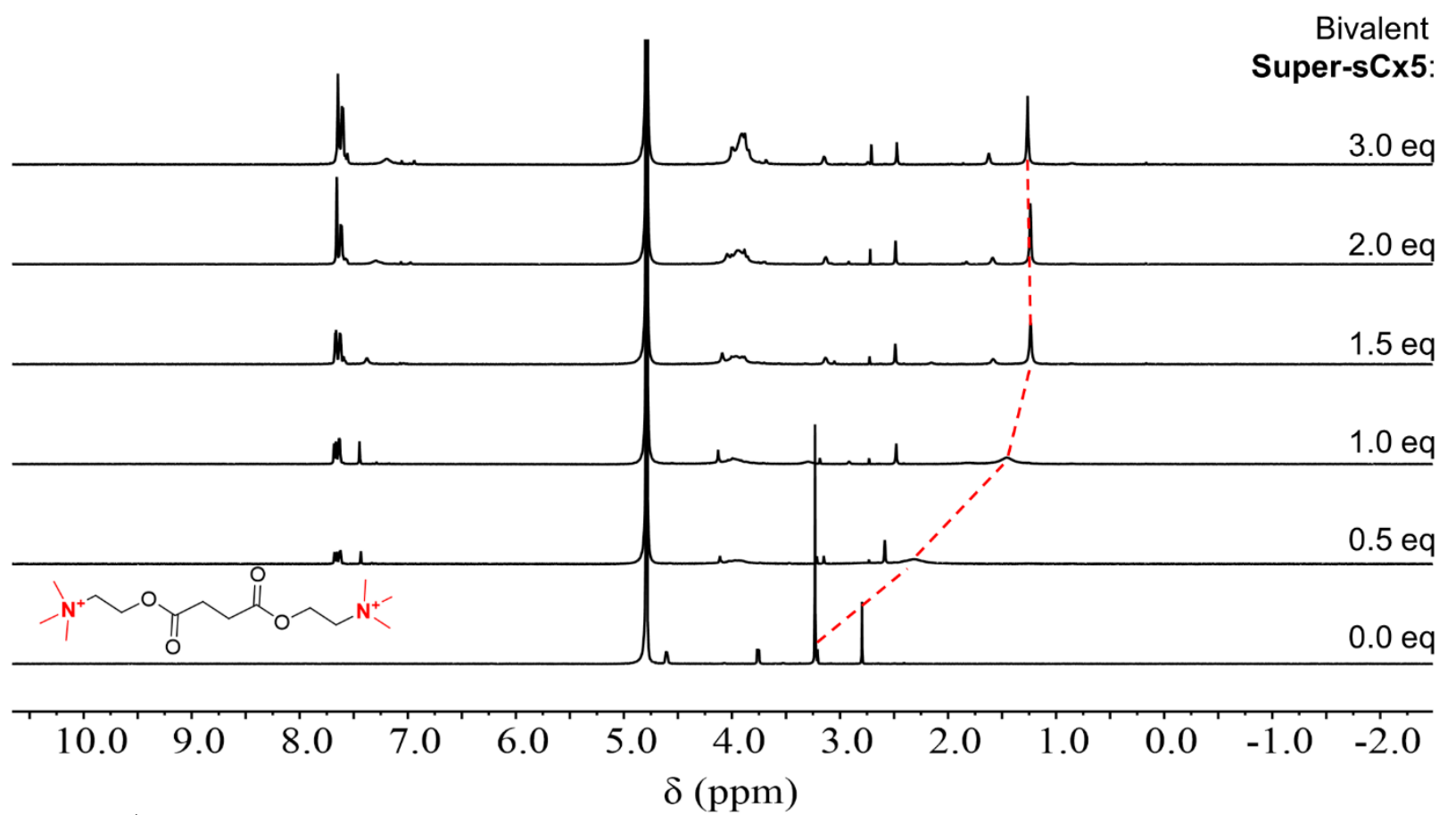

Figure 50. ${ }^{1} \mathrm{H}$ NMR titrations of bivalent Super-sCx5 (4 mM) into suxamethonium $(800 \mu \mathrm{M})$. Red dashed line indicates the binding of methyl groups. All solutions were in $\mathrm{NaH}_{2} \mathrm{PO}_{4} / \mathrm{Na}_{2} \mathrm{HPO}_{4}(50 \mathrm{mM}, \mathrm{pD} 7.4)$ in $\mathrm{D}_{2} \mathrm{O}(500 \mathrm{MHz}, 297 \mathrm{~K})$.

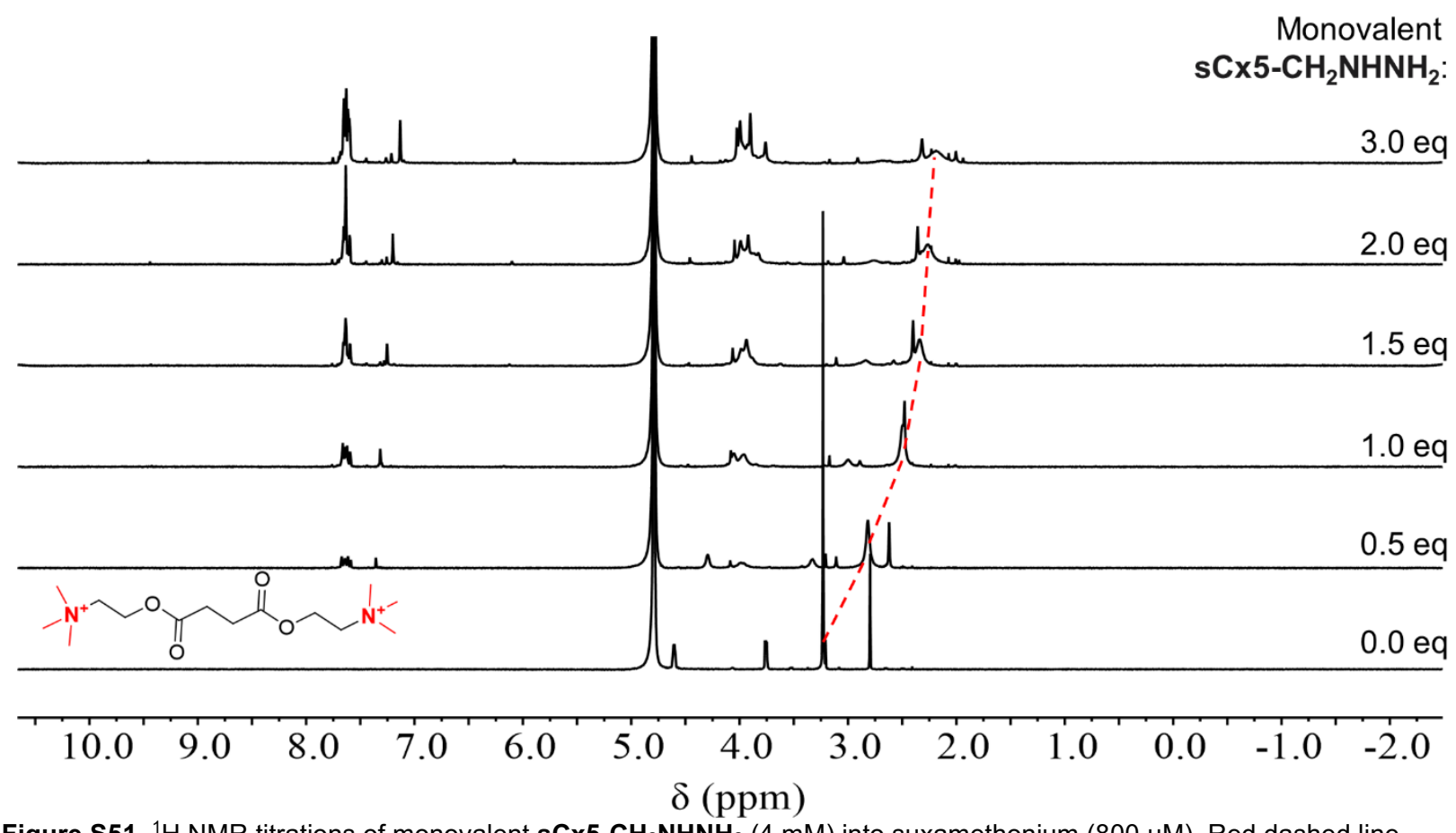

Figure S51. ${ }^{1} \mathrm{H}$ NMR titrations of monovalent $\mathbf{s} \mathbf{C} \times 5-\mathbf{C H}_{2} \mathbf{N H N H}_{2}(4 \mathrm{mM})$ into suxamethonium $(800 \mu \mathrm{M})$. Red dashed line indicates the binding of methyl groups. All solutions were in $\mathrm{NaH}_{2} \mathrm{PO}_{4} / \mathrm{Na}_{2} \mathrm{HPO}_{4}(50 \mathrm{mM}, \mathrm{pD} 7.4)$ in $\mathrm{D}_{2} \mathrm{O}(500 \mathrm{MHz}, 297 \mathrm{~K})$. 


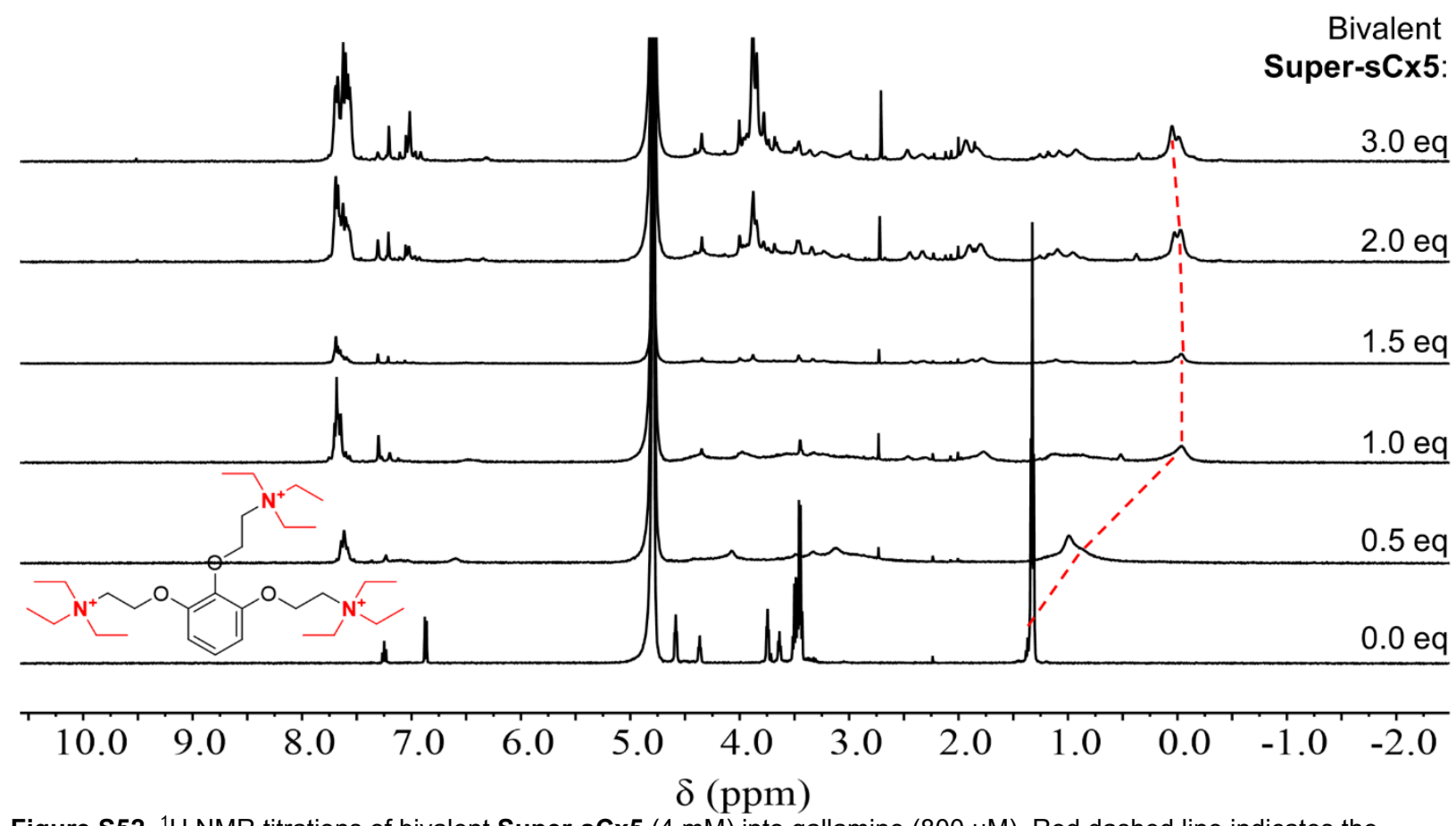

Figure S52. ${ }^{1} \mathrm{H}$ NMR titrations of bivalent Super-sCx5 (4 mM) into gallamine (800 $\left.\mu \mathrm{M}\right)$. Red dashed line indicates the binding of ethyl and methyl groups. All solutions were in $\mathrm{NaH}_{2} \mathrm{PO}_{4} / \mathrm{Na}_{2} \mathrm{HPO}_{4}(50 \mathrm{mM}, \mathrm{pD} 7.4)$ in $\mathrm{D}_{2} \mathrm{O}(500 \mathrm{MHz}, 297 \mathrm{~K})$.

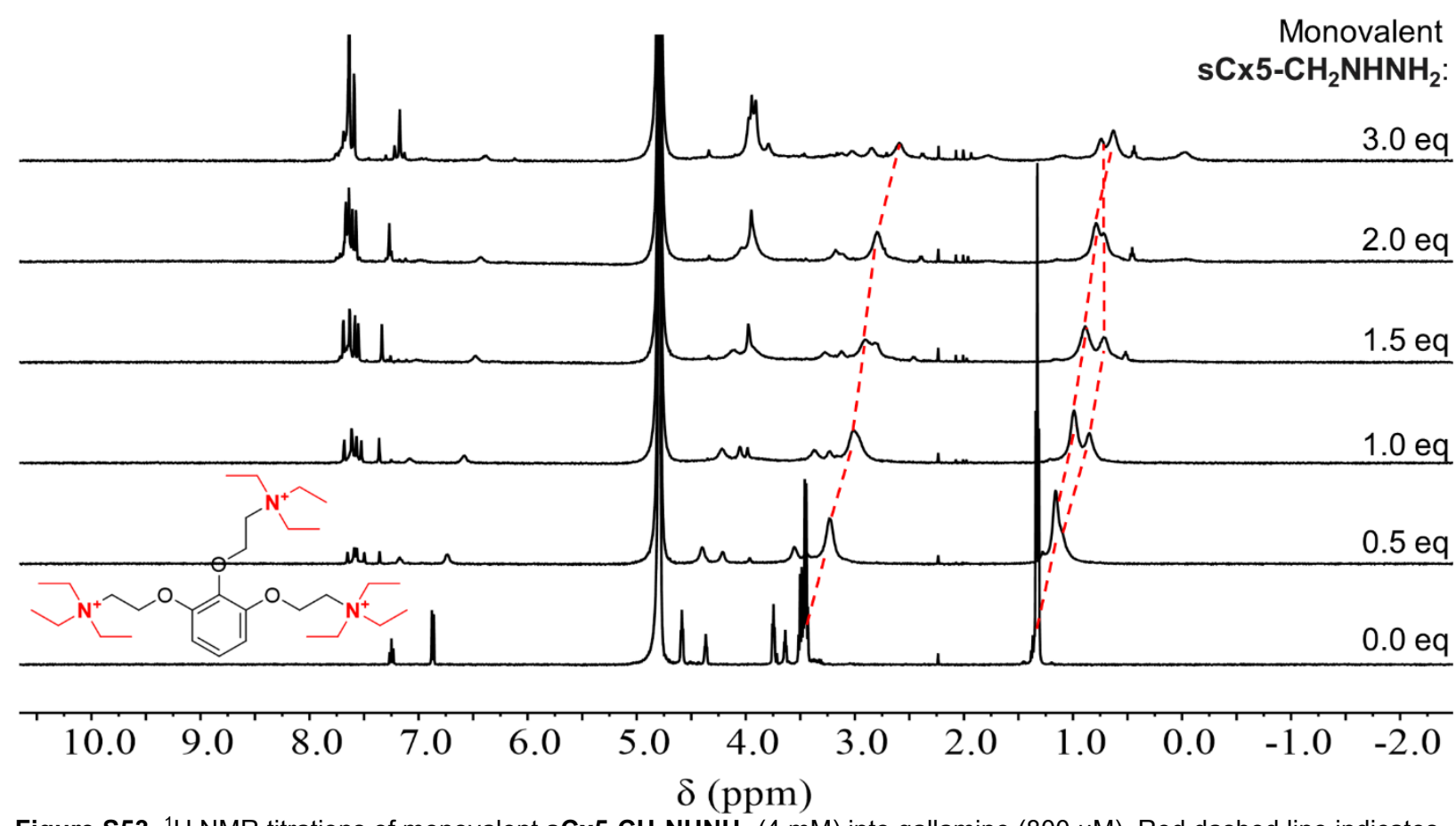

Figure S53. ${ }^{1} \mathrm{H}$ NMR titrations of monovalent $\mathbf{s} \mathbf{C} \times 5-\mathbf{C H}_{2} \mathbf{N H N H}_{2}(4 \mathrm{mM})$ into gallamine $(800 \mu \mathrm{M})$. Red dashed line indicates the binding of ethyl and methyl groups. All solutions were in $\mathrm{NaH}_{2} \mathrm{PO}_{4} / \mathrm{Na}_{2} \mathrm{HPO}_{4}(50 \mathrm{mM}, \mathrm{pD} 7.4)$ in $\mathrm{D}_{2} \mathrm{O}(500 \mathrm{MHz}, 297 \mathrm{~K})$. 


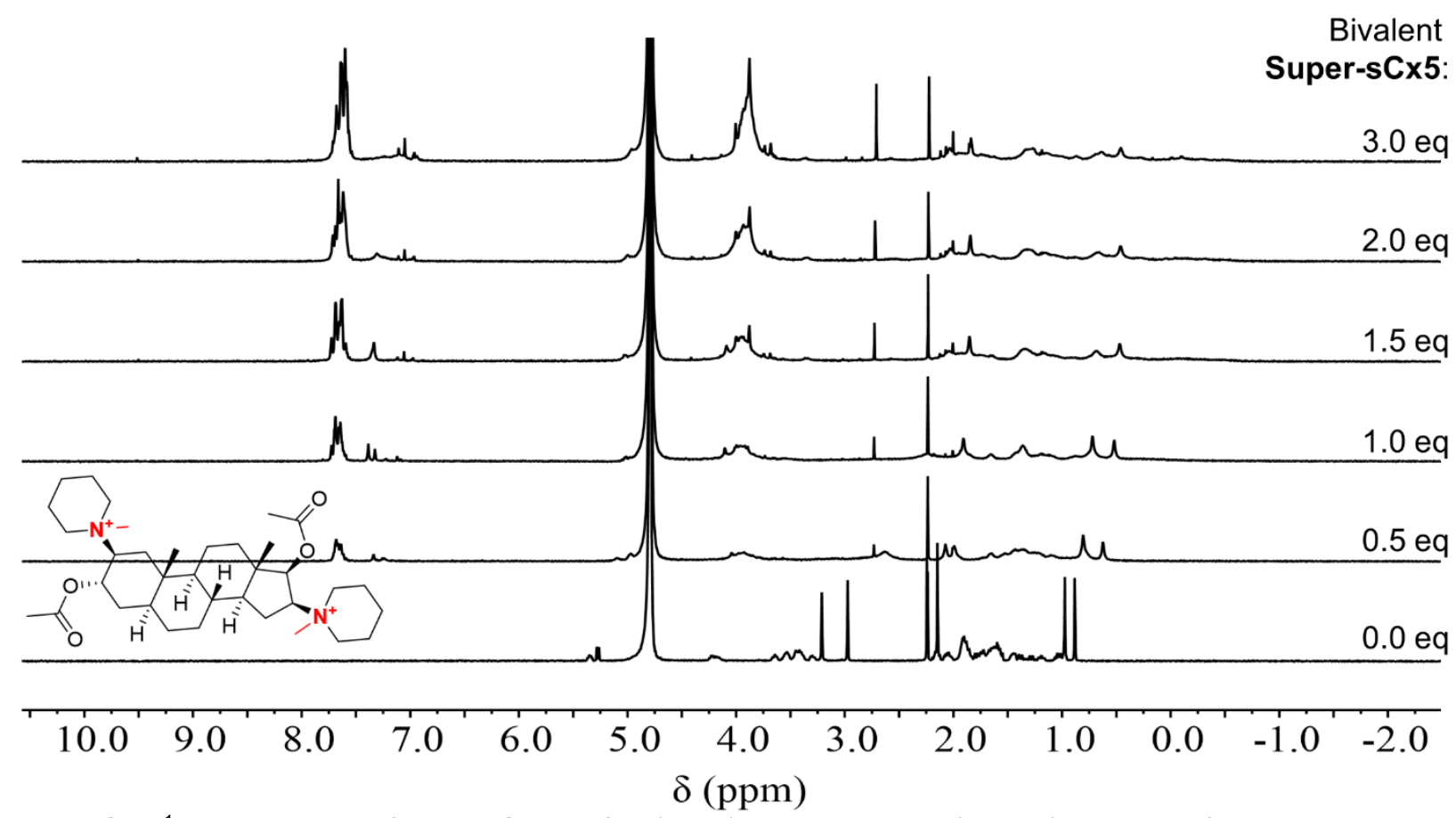

Figure S54. ${ }^{1} \mathrm{H}$ NMR titrations of bivalent Super-sCx5 (4 mM) into pancuronium $(800 \mu \mathrm{M})$. Migration of quaternary amine methyl groups were not distinguishable. All solutions were in $\mathrm{NaH}_{2} \mathrm{PO}_{4} / \mathrm{Na}_{2} \mathrm{HPO}_{4}(50 \mathrm{mM}, \mathrm{pD} 7.4)$ in $\mathrm{D}_{2} \mathrm{O}(500 \mathrm{MHz}, 297 \mathrm{~K})$.

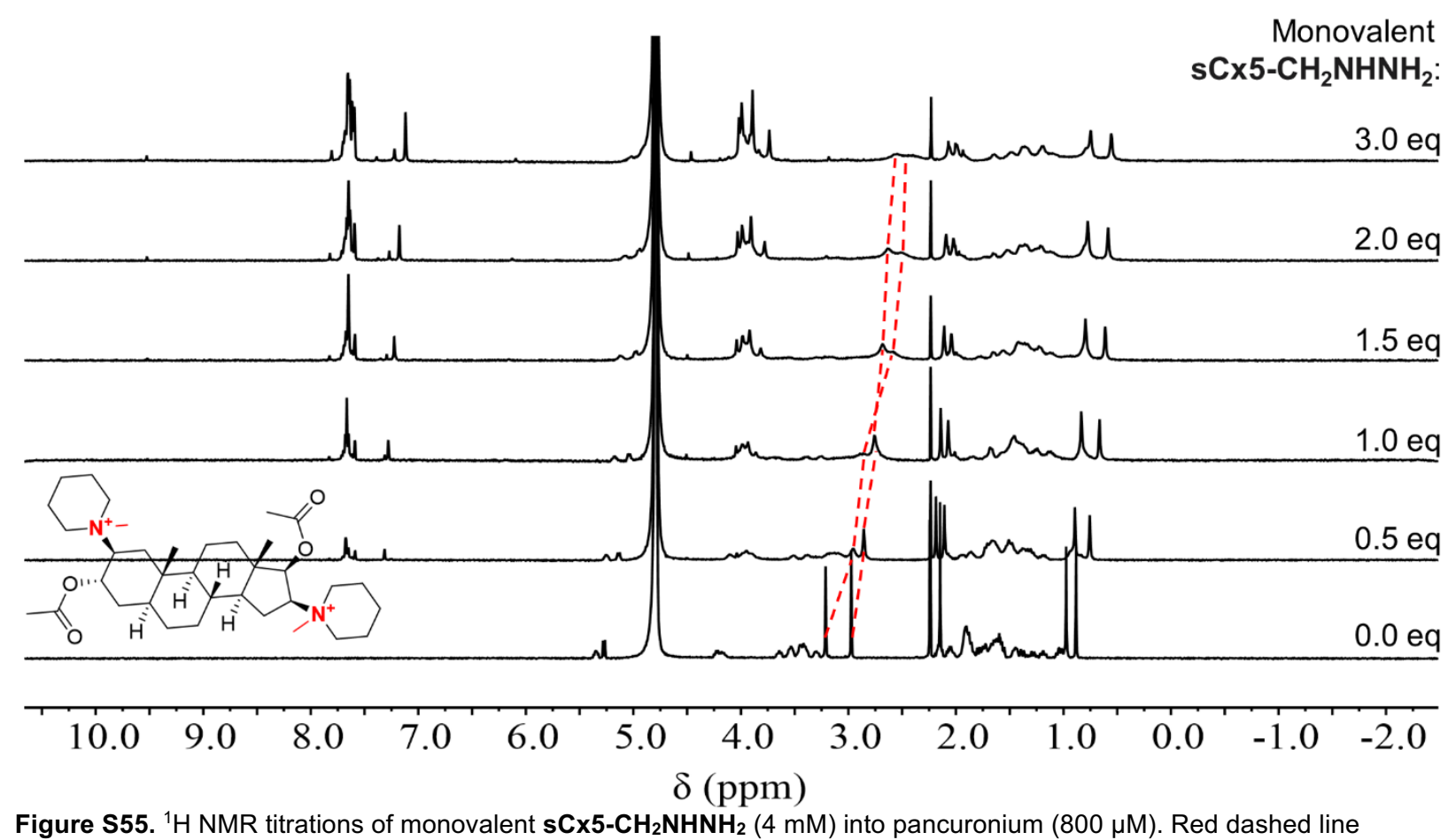

Figure S55. ${ }^{1} \mathrm{H}$ NMR titrations of monovalent $\mathbf{s} \mathbf{C} 5 \mathbf{-}-\mathrm{CH}_{2} \mathrm{NHNH}_{2}(4 \mathrm{mM})$ into pancuronium $(800 \mu \mathrm{M})$. Red dashed line
indicates the binding of methyl groups. All solutions were in $\mathrm{NaH}_{2} \mathrm{PO}_{4} / \mathrm{Na}_{2} \mathrm{HPO}_{4}(50 \mathrm{mM}, \mathrm{pD} 7.4)$ in $\mathrm{D}_{2} \mathrm{O}(500 \mathrm{MHz}, 297 \mathrm{~K})$. 


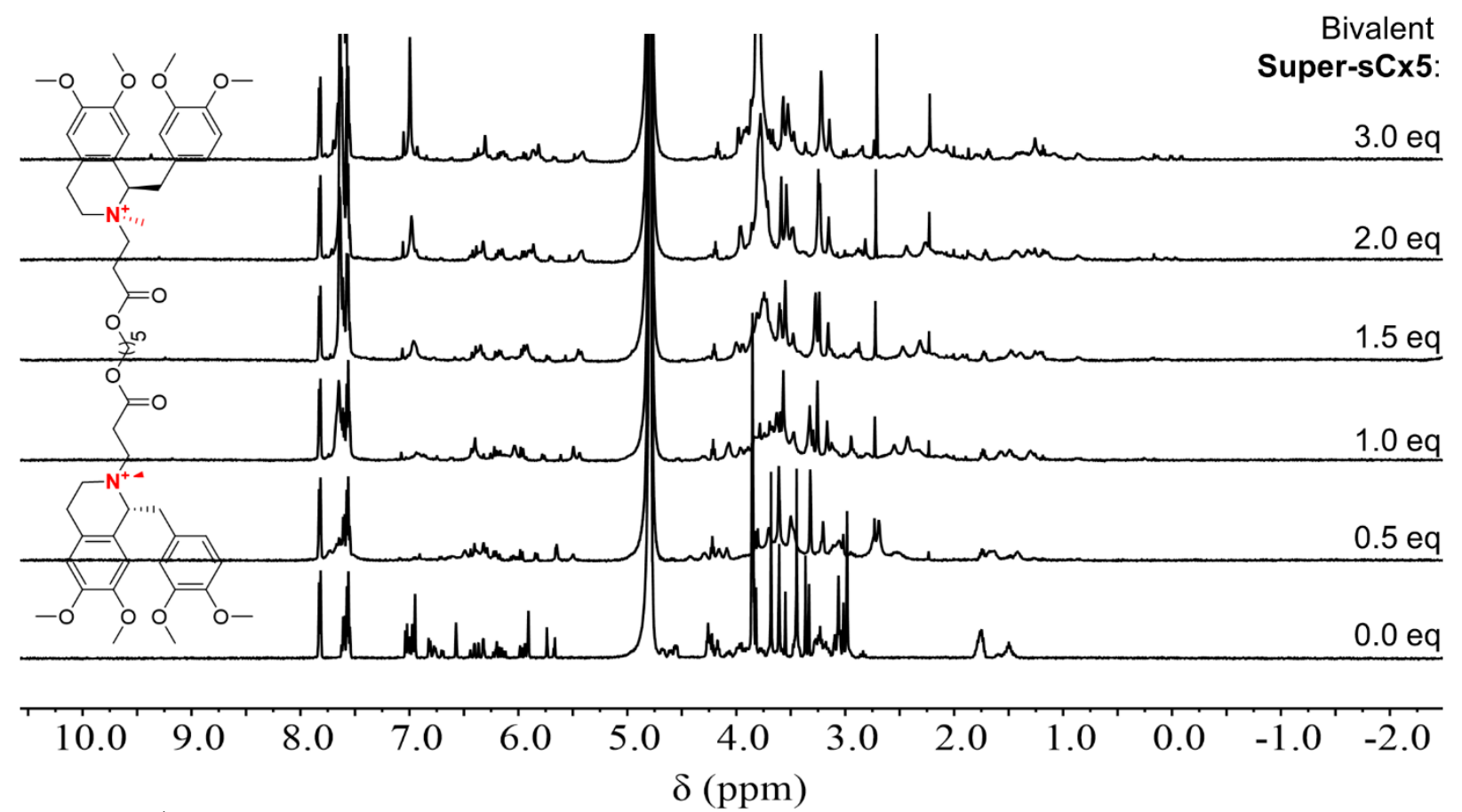

Figure S56. ${ }^{1} \mathrm{H}$ NMR titrations of bivalent Super-sCx5 (4 mM) into cisatracurium $(800 \mu \mathrm{M})$. Migration of quaternary amine methyl groups were not distinguishable. All solutions were in $\mathrm{NaH}_{2} \mathrm{PO}_{4} / \mathrm{Na}_{2} \mathrm{HPO}_{4}(50 \mathrm{mM}, \mathrm{pD} 7.4)$ in $\mathrm{D}_{2} \mathrm{O}(500 \mathrm{MHz}, 297 \mathrm{~K})$.

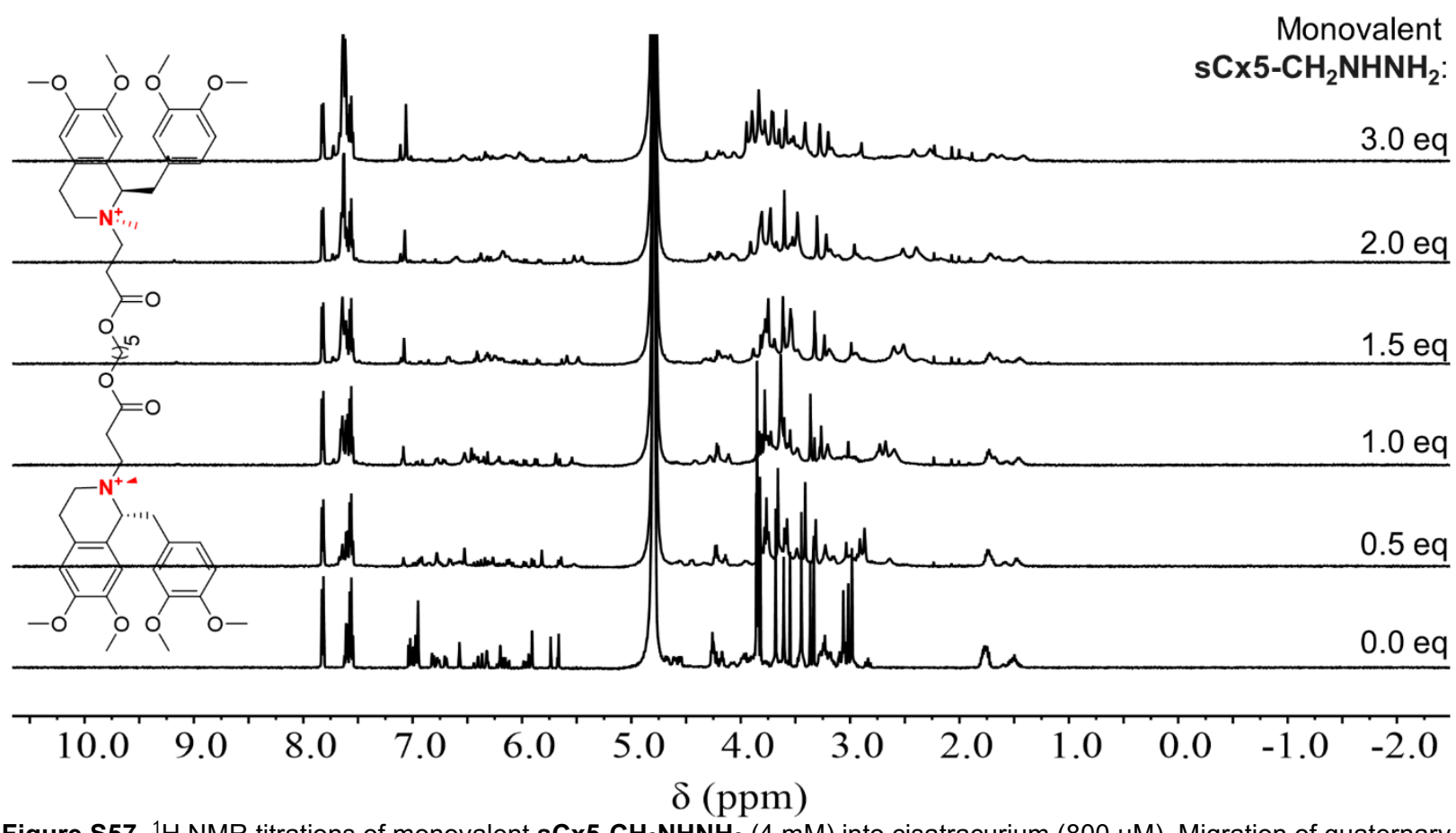

Figure S57. ${ }^{1} \mathrm{H}$ NMR titrations of monovalent $\mathbf{s} \mathbf{C x} 5-\mathbf{C H}_{2} \mathbf{N H N H}_{2}(4 \mathrm{mM})$ into cisatracurium $(800 \mu \mathrm{M})$. Migration of quaternary amine methyl groups were not distinguishable. All solutions were in $\mathrm{NaH}_{2} \mathrm{PO}_{4} / \mathrm{Na}_{2} \mathrm{HPO}_{4}(50 \mathrm{mM}, \mathrm{pD} 7.4)$ in $\mathrm{D}_{2} \mathrm{O}(500 \mathrm{MHz}$, $297 \mathrm{~K})$.

${ }^{*}$ Note: ${ }^{1} \mathrm{H}$ NMR titrations were not completed for tubocurarine due to solubility issues at the concentrations required for NMR. 


\section{DOSY}

For each DOSY experiment the $90^{\circ}$ pulse was determined, T1 was estimated, $\Delta$ and $\delta$ were determined. The $90^{\circ}$ pulse was determined by measuring the null pulse length at $360^{\circ}$ and dividing by four using a zg pulse sequence. The T1 relaxation was estimated through an inversion recovery pulse sequence, $\mathrm{t} 1 \mathrm{ir} 1 \mathrm{~d}$. The relaxation time for each experiment was set to be $5 x$ the estimated T1. For each experiment, the $\Delta$ and $\delta$ were determined by finding a $90-95 \%$ intensity difference between the first and last spectra in the power array. The $\delta$ was set to $2500 \mu \mathrm{s}$ and $\Delta$ was initially set to $0.1 \mathrm{~ms}$, then increased if needed. A stebpgp1s1d pulse sequence was used in all DOSY experiments with an FID size of 32. The data was preprocessed and phased in TopSpin. Then the diffusion coefficients were calculated with Bruker Dynamic Center. Peak integrals were user defined. The data was fit using the following diffusion fit function with a variable gradient strength and $95 \%$ confidence level:

$$
f(x)=I_{o} \exp ^{\left(-\gamma^{2} G^{2} \delta^{2}\left(\Delta-\frac{\delta}{3}\right) D\right)}
$$

The data was plotted as a function of the field gradient strength $(G)$ with a residuals plot. For each DOSY experiment the average diffusion coefficient was calculated with standard error. Then the Stokes-Einstein equation was used to calculate the hydrodynamic radius $\left(\mathrm{r}_{\mathrm{H}}\right)$ assuming the molecules were spherical in shape.

$$
r_{H}=\frac{k_{B} T}{6 \pi \eta D}
$$

Where, $\mathrm{k}_{\mathrm{B}}=$ boltzmann constant, $\mathrm{T}=297 \pm 1 \mathrm{~K}$ and $\eta=$ viscosity of water, $8.94 \times 10^{-4} \pm 2.78 \times 10^{-5} \mathrm{~Pa} \cdot \mathrm{s}^{[3]}$ 
Table S1. Parameters used in diffusion analysis of templated starting material sCx4-CHO (1)•decamethonium (2:1).

\section{Used Y}

Used $\delta$

Used $\Delta$

\section{$26752 \mathrm{rad} /\left(\mathrm{s}^{*}\right.$ Gauss $)$}

$0.0025000 \mathrm{~s}$

$0.13990 \mathrm{~s}$

Table S2. Dynamics Center calculated diffusion coefficients output from user defined integrals for template starting material sCx4-CHO (1) • decamethonium (2:1).

\begin{tabular}{llll}
\hline Peak name & F2 $[\mathbf{p p m}]$ & $\mathbf{D}\left[\mathbf{m}^{2} / \mathbf{s}\right]$ & error \\
\hline 1 & 9.66 & $2.21 \times 10^{-10}$ & $7.230 \times 10^{-13}$ \\
2 & 7.56 & $2.20 \times 10^{-10}$ & $2.301 \times 10^{-13}$ \\
3 & 3.97 & $2.18 \times 10^{-10}$ & $1.149 \times 10^{-12}$ \\
4 & 1.97 & $2.12 \times 10^{-10}$ & $1.248 \times 10^{-13}$ \\
5 & 0.81 & $2.11 \times 10^{-10}$ & $1.493 \times 10^{-13}$ \\
\hline
\end{tabular}

a)

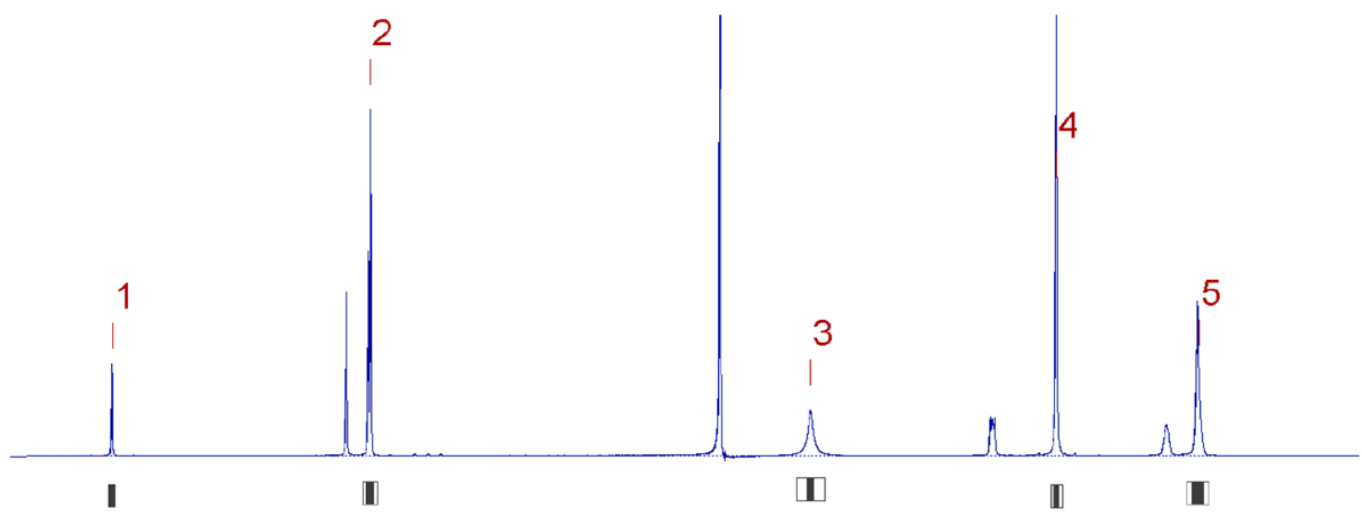

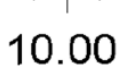

b)

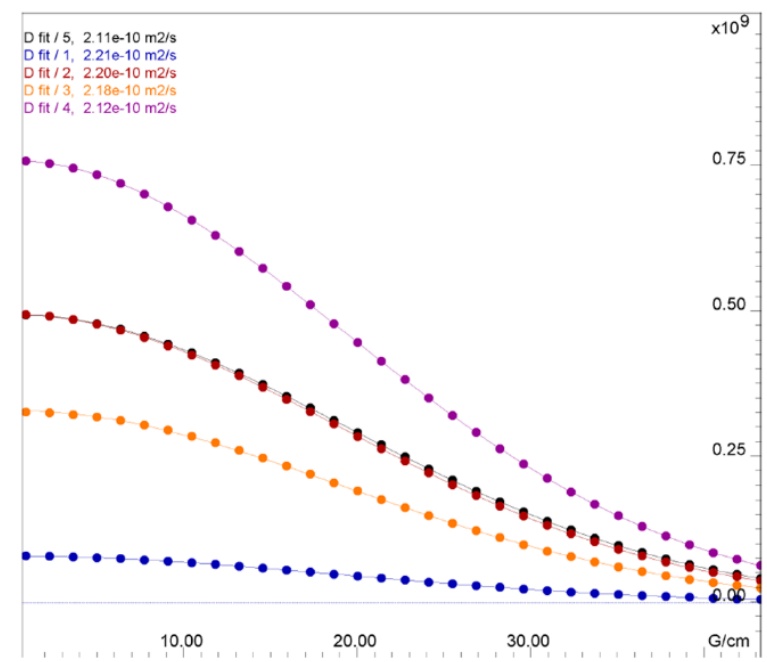

c)

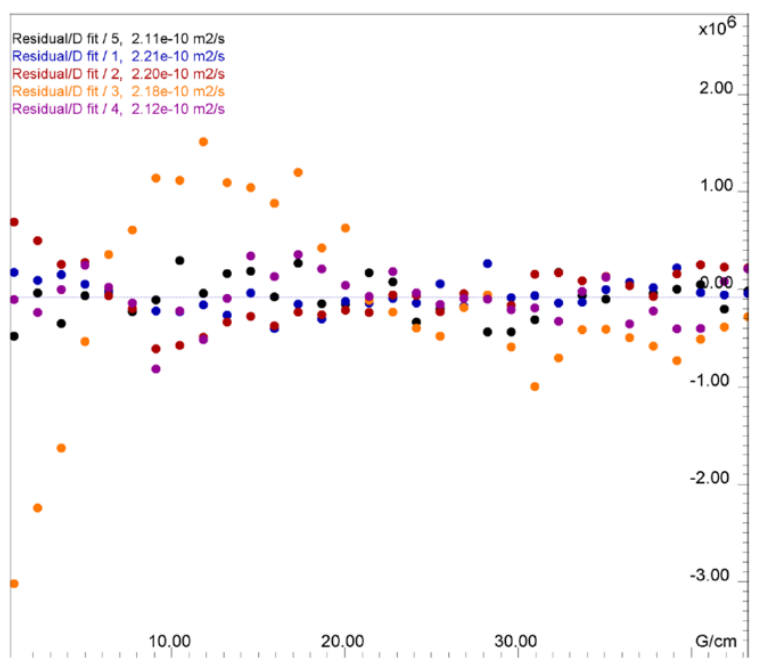

Figure S58. a) ${ }^{1} \mathrm{H}$ NMR of templated starting material $\mathrm{sCx} 4-\mathrm{CHO}(1) \cdot d e c a m e t h o n i u m ~(2: 1)$, the peak area integrals highlighted in grey were used to calculate diffusion coefficients b) 1D DOSY plots for each integral and c) the corresponding $1 \mathrm{D}$ residuals plot. Solution was in ammonium carbonate $(50 \mathrm{mM}, \mathrm{pD} 6.4)$ in $\mathrm{D}_{2} \mathrm{O}(500 \mathrm{MHz}, 297 \mathrm{~K})$. 
Table S3. Parameters used in diffusion analysis of bivalent Super-sCx4.

\begin{tabular}{|c|c|c|c|}
\hline $\begin{array}{l}\text { Used } \mathrm{Y} \\
\text { Used } \delta \\
\text { Used } \Delta\end{array}$ & & $\begin{array}{l}26752 \mathrm{rad} /(\mathrm{s} \\
0.0025000 \mathrm{~s} \\
0.13990 \mathrm{~s}\end{array}$ & \\
\hline Peak name & F2 [ppm] & $\mathrm{D}\left[\mathrm{m}^{2} / \mathrm{s}\right]$ & error \\
\hline 1 & 7.47 & $2.24 \times 10^{-10}$ & $3.563 \times 10^{-13}$ \\
\hline 2 & 6.99 & $2.20 \times 10^{-10}$ & $3.790 \times 10^{-13}$ \\
\hline 3 & 3.78 & $2.21 \times 10^{-10}$ & $6.865 \times 10^{-13}$ \\
\hline
\end{tabular}

a)

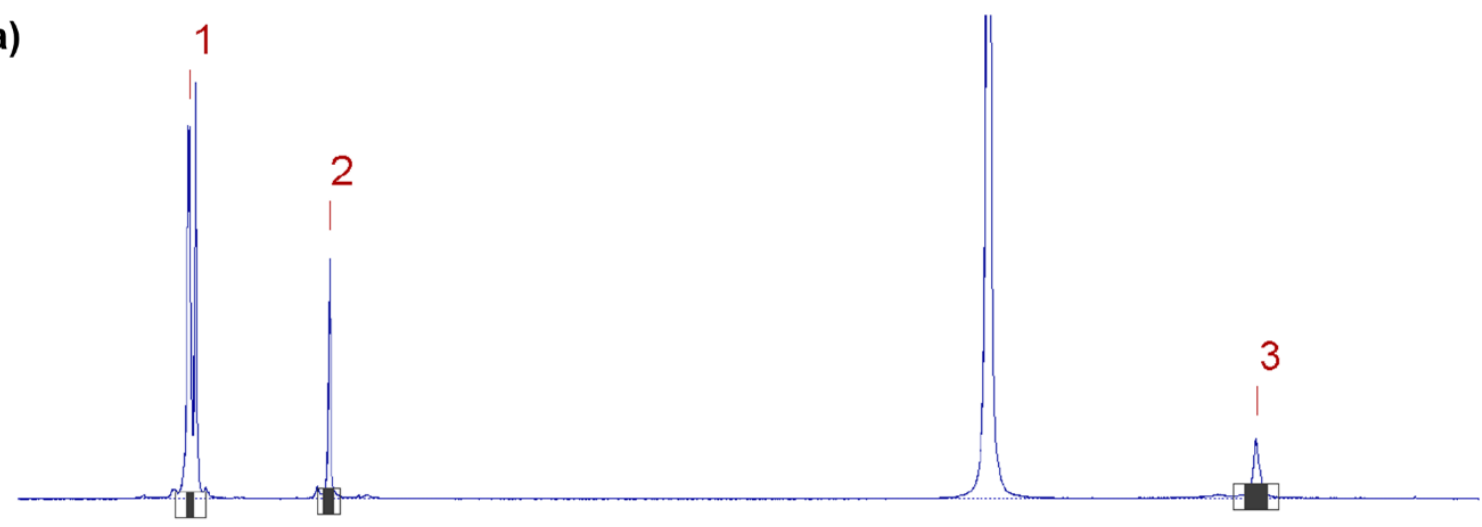

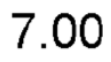

b)

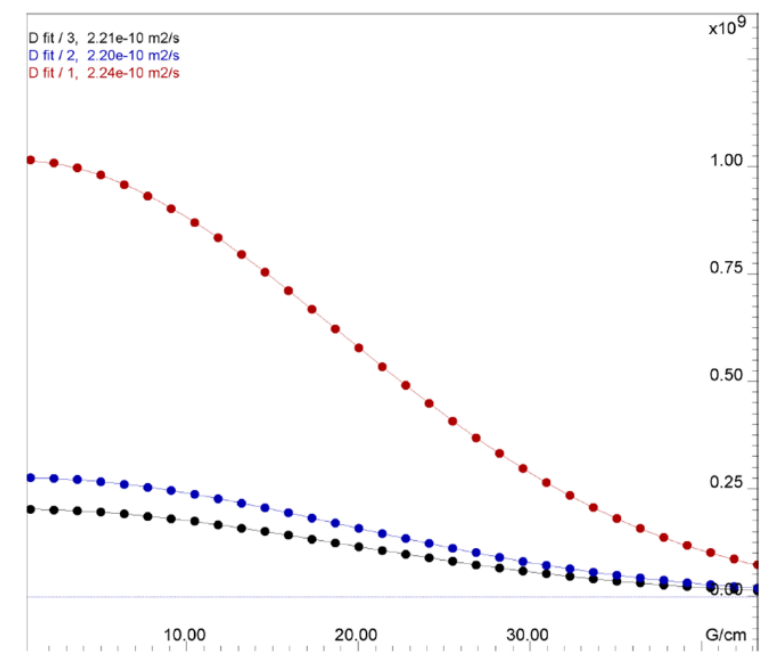

c)

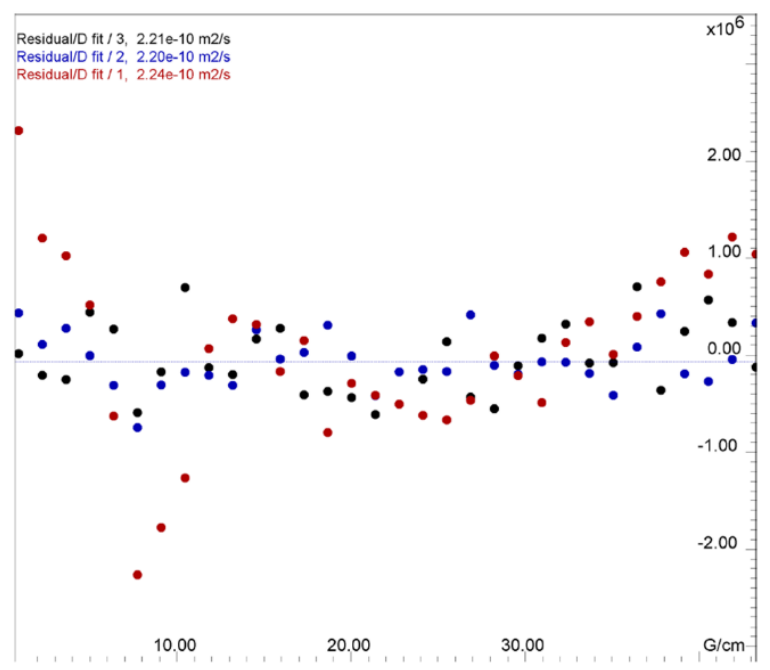

Figure S59. a) ${ }^{1} \mathrm{H}$ NMR of bivalent SuperPSC-sCx4, the peak area integrals highlighted in grey were used to calculate diffusion coefficients b) 1D DOSY plots for each integral and c) the corresponding 1D residuals plot. Solution was in phosphate buffer (50 mM, pD 7.4) in $\mathrm{D}_{2} \mathrm{O}(500 \mathrm{MHz}, 297 \mathrm{~K})$. 
Table S5. Parameters used in diffusion analysis of monovalent $\mathbf{s} \mathbf{C} \mathbf{x}-\mathbf{C H}_{2} \mathbf{N H N H}_{2}$.

\begin{tabular}{|c|c|c|c|}
\hline $\begin{array}{l}\text { Used } \mathrm{Y} \\
\text { Used } \delta \\
\text { Used } \Delta\end{array}$ & & $\begin{array}{l}26752 \mathrm{rad} /(\mathrm{s} \\
0.0025000 \mathrm{~s} \\
0.099900 \mathrm{~s}\end{array}$ & \\
\hline Peak name & F2 [ppm] & $\mathrm{D}\left[\mathrm{m}^{2} / \mathrm{s}\right]$ & error \\
\hline 1 & 7.73 & $2.82 \times 10^{-10}$ & $2.072 \times 10^{-12}$ \\
\hline 2 & 7.55 & $2.76 \times 10^{-10}$ & $5.263 \times 10^{-13}$ \\
\hline 3 & 6.64 & $2.73 \times 10^{-10}$ & 3.568. $\times 10^{-12}$ \\
\hline
\end{tabular}

a)
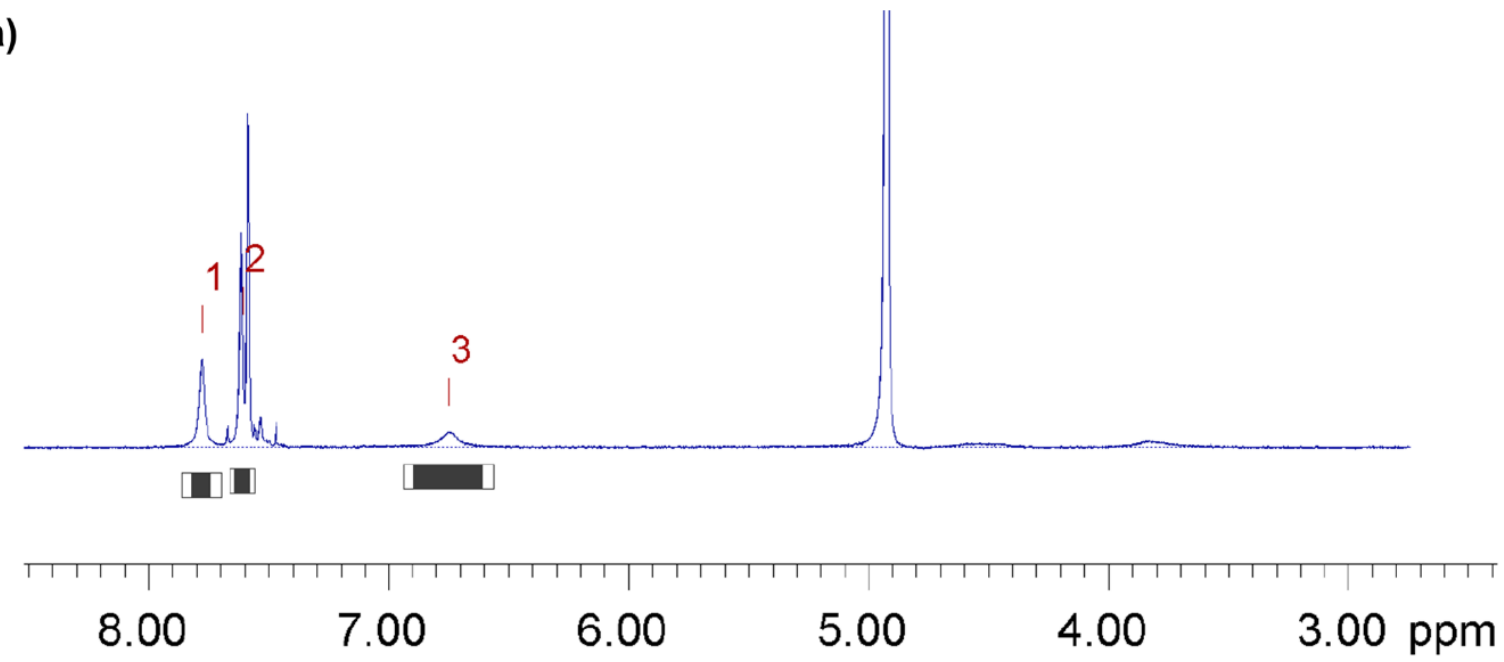

b)

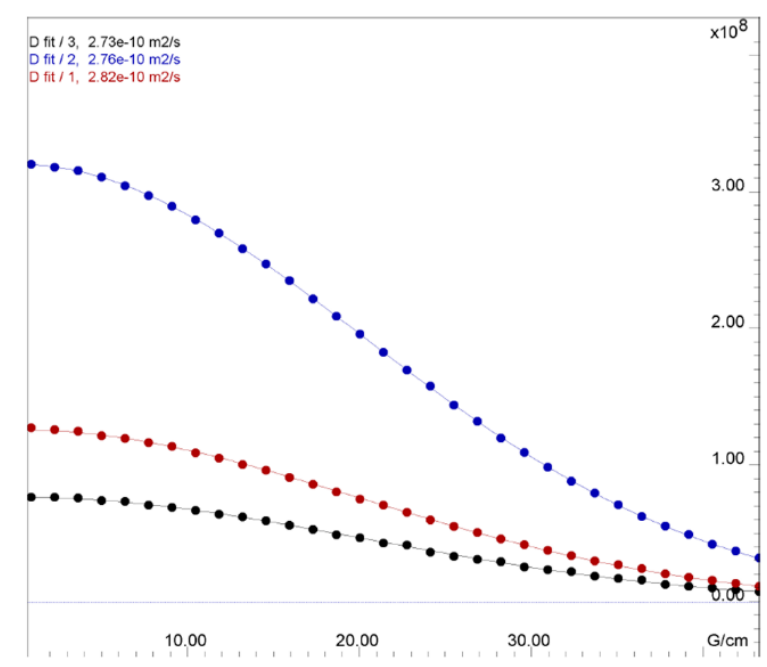

c)

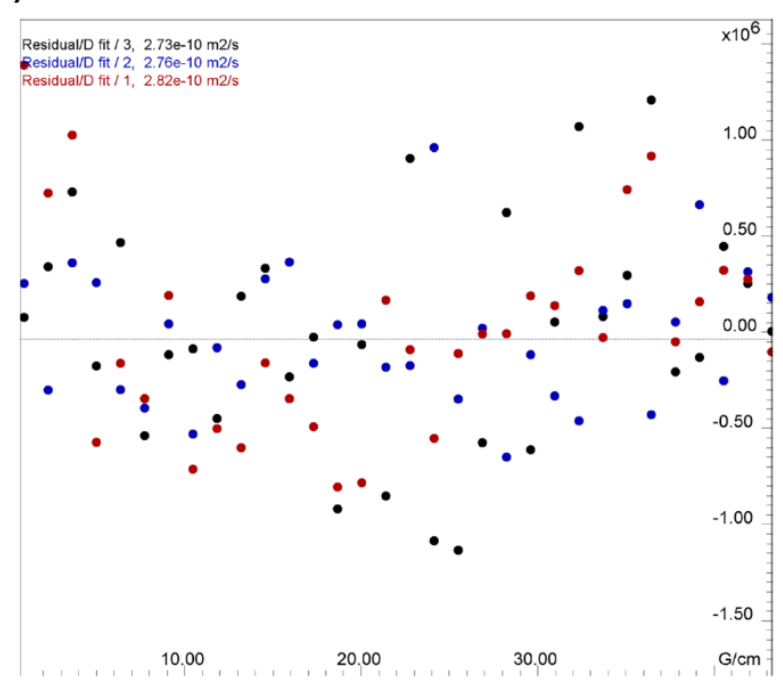

Figure S60. a) ${ }^{1} \mathrm{H}$ NMR of monovalent $\mathbf{S} \mathbf{C} \times 4-\mathrm{CH}_{2} \mathbf{N H N H}_{2}$, the peak area integrals highlighted in grey were used to calculate diffusion coefficients b) 1D DOSY plots for each integral and c) the corresponding 1D residuals plot. Solution was in phosphate buffer (50 mM, pD 7.4) in $\mathrm{D}_{2} \mathrm{O}(500 \mathrm{MHz}, 297 \mathrm{~K})$. 
Table S7. Parameters used in diffusion analysis of Super-sCx4·Suxamethonium (1:1).

\begin{tabular}{ll}
\hline Used $\mathrm{Y}$ & $26752 \mathrm{rad} /\left(\mathrm{s}^{\star}\right.$ Gauss $)$ \\
Used $\delta$ & $0.0025000 \mathrm{~s}$
\end{tabular}

0.0025000

Used $\Delta$

$0.13990 \mathrm{~s}$

Table S8. Dynamics Center calculated diffusion coefficients output from user defined integrals for SupersCx4•Suxamethonium (1:1).

\begin{tabular}{llll}
\hline Peak name & F2 [ppm] & D [m²] & error \\
\hline 1 & 7.52 & $2.20 \times 10^{-10}$ & $1.703 \times 10^{-13}$ \\
2 & 7.25 & $2.15 \times 10^{-10}$ & $5.150 \times 10^{-13}$ \\
3 & 3.85 & $2.33 \times 10^{-10}$ & $2.292 \times 10^{-12}$ \\
4 & 3.54 & $2.15 \times 10^{-10}$ & $1.544 \times 10^{-12}$ \\
5 & 2.65 & $2.39 \times 10^{-10}$ & $4.716 \times 10^{-13}$ \\
6 & 1.45 & $2.38 \times 10^{-10}$ & $1.961 \times 10^{-13}$ \\
\hline
\end{tabular}

\section{a)}
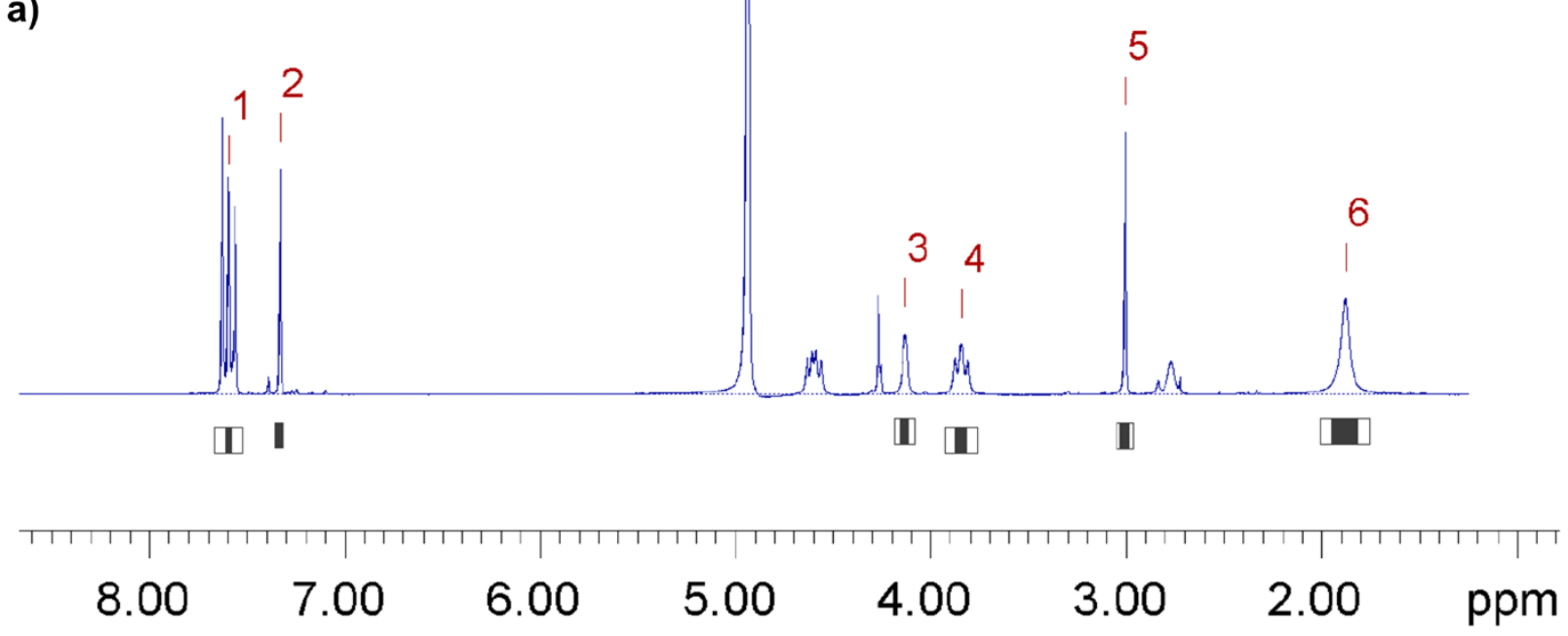

b)

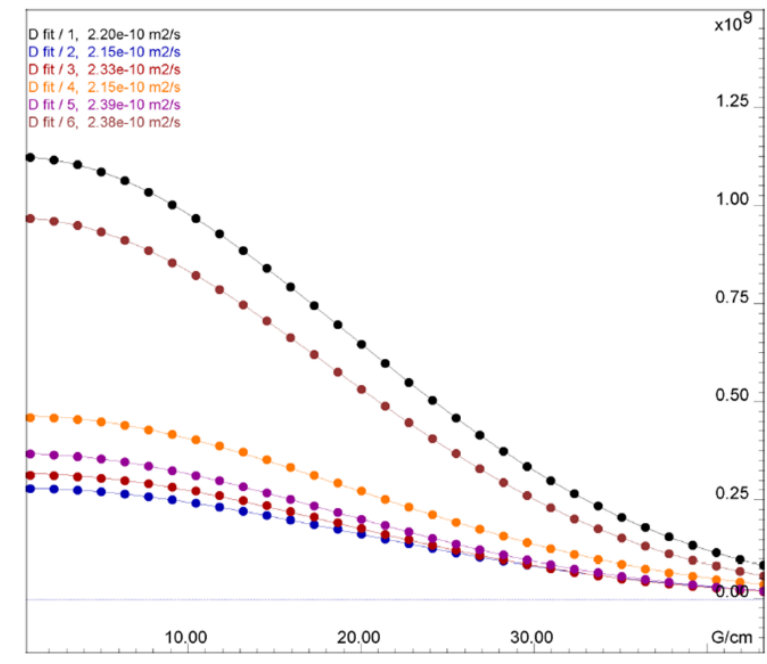

C)

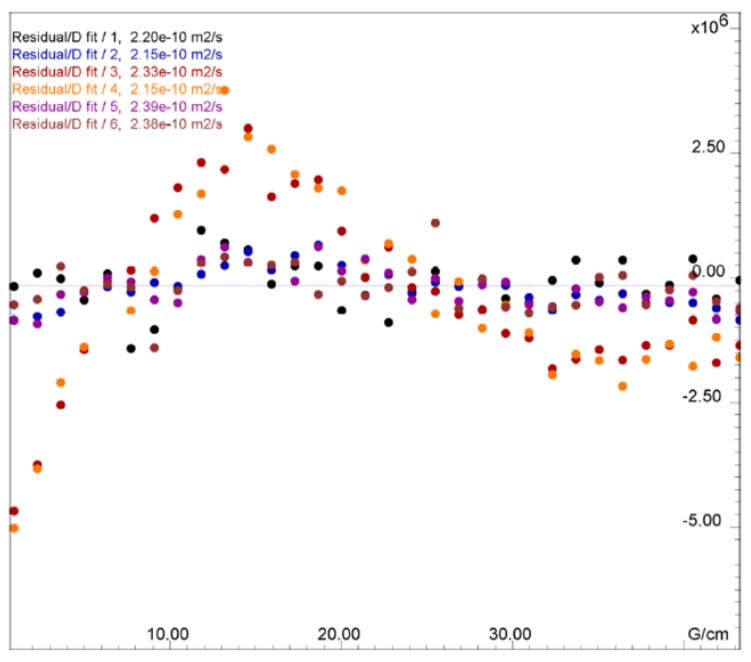

Figure S61. a) ${ }^{1} \mathrm{H}$ NMR of Super-sCx4·Suxamethonium (1:1), the peak area integrals highlighted in grey were used to calculate diffusion coefficients b) 1D DOSY plots for each integral and c) the corresponding 1D residuals plot. Solution was in phosphate buffer (50 mM, pD 7.4) in $\mathrm{D}_{2} \mathrm{O}(500 \mathrm{MHz}, 297 \mathrm{~K})$. 
Table S9. Parameters used in diffusion analysis of $\mathrm{sCx} 5-\mathrm{CHO}(5)$.

\begin{tabular}{|c|c|c|c|}
\hline $\begin{array}{l}\text { Used } \mathrm{Y} \\
\text { Used } \delta \\
\text { Used } \Delta\end{array}$ & & $\begin{array}{l}26752 \mathrm{rad} /(\mathrm{s} \\
0.0025000 \mathrm{~s} \\
0.10990 \mathrm{~s}\end{array}$ & \\
\hline Peak name & F2 [ppm] & $D\left[\mathrm{~m}^{2} / \mathrm{s}\right]$ & error \\
\hline 1 & 9.43 & $2.80 \times 10^{-10}$ & $1.350 \times 10^{-12}$ \\
\hline 2 & 7.45 & $2.75 \times 10^{-10}$ & $1.427 \times 10^{-12}$ \\
\hline 3 & 7.49 & $2.77 \times 10^{-10}$ & $7.515 \times 10^{-13}$ \\
\hline 4 & 7.56 & $2.80 \times 10^{-10}$ & $3.358 \times 10^{-13}$ \\
\hline 5 & 7.61 & $2.84 \times 10^{-10}$ & $1.183 \times 10^{-12}$ \\
\hline 6 & 3.81 & $2.78 \times 10^{-10}$ & $7.702 \times 10^{-13}$ \\
\hline
\end{tabular}

a)
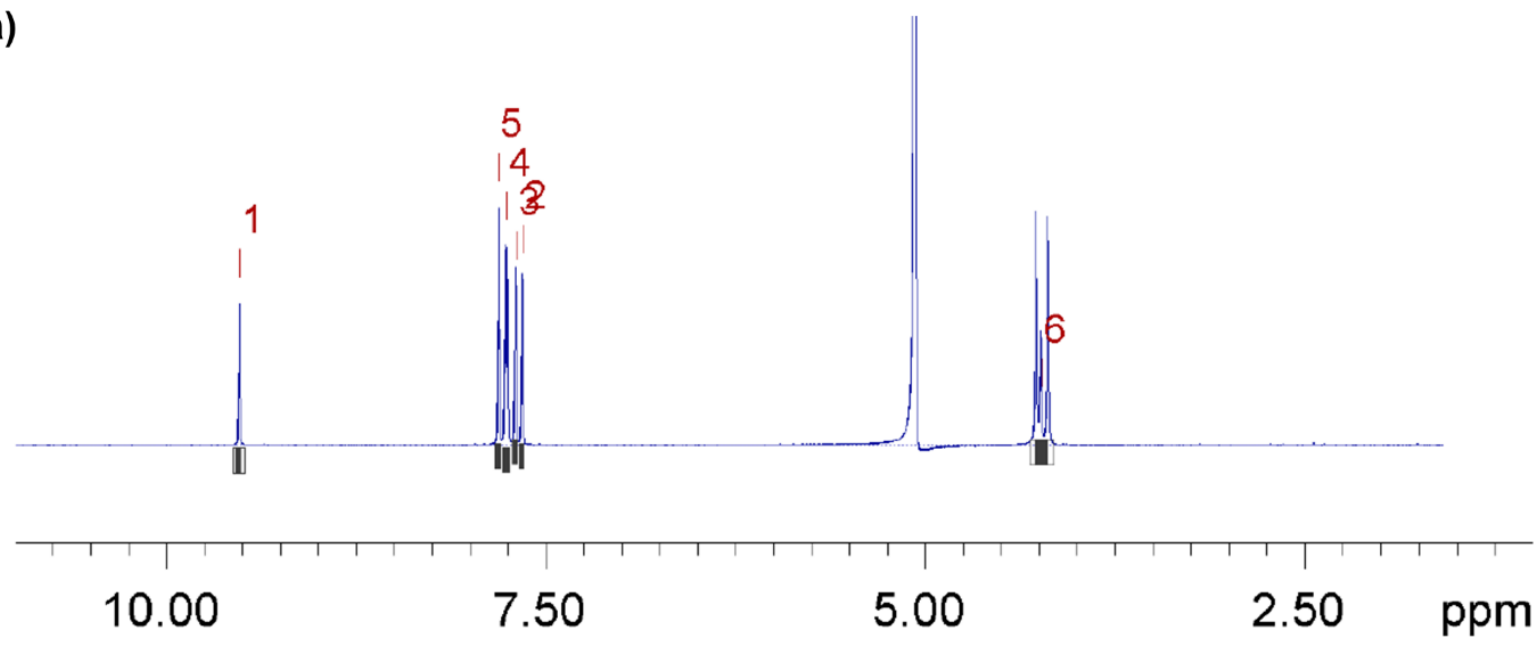

b)

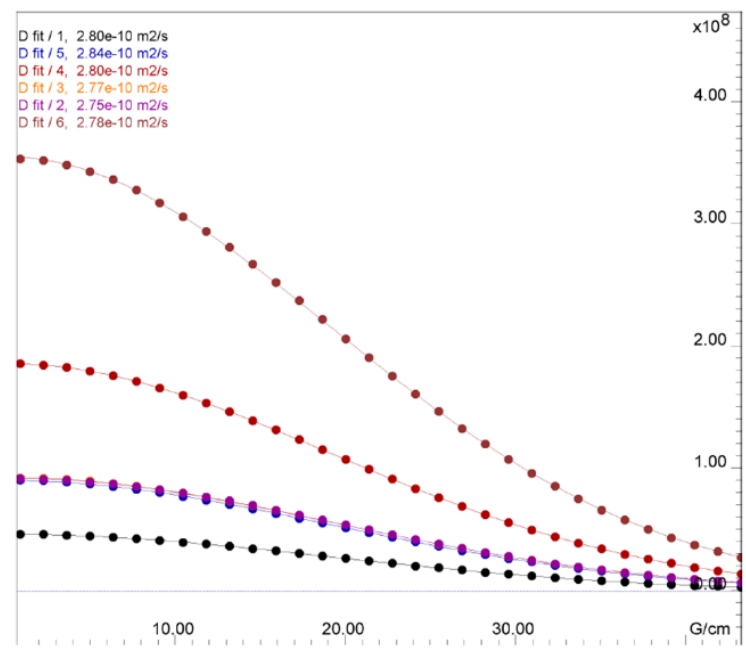

c)

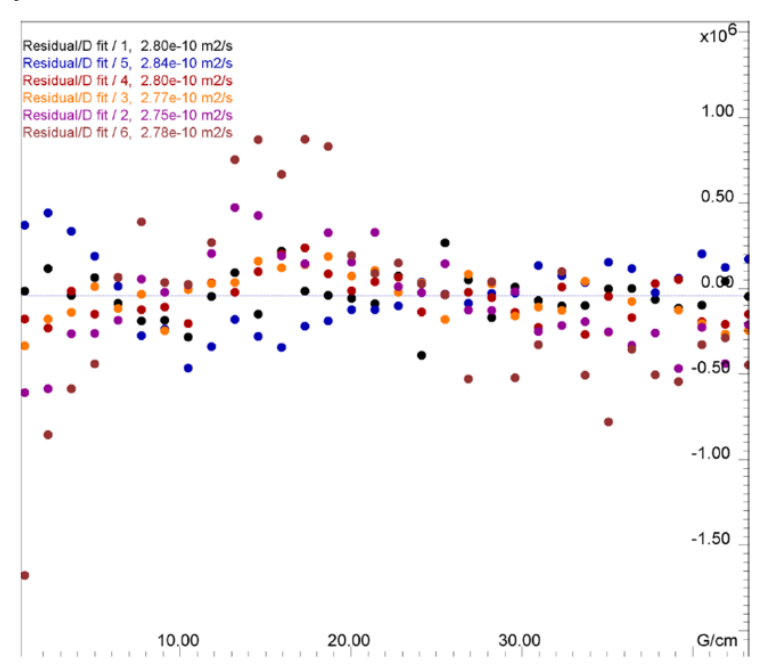

Figure S62. a) ${ }^{1} \mathrm{H}$ NMR of $\mathrm{SC} \times 5-\mathrm{CHO}(5)$, the peak area integrals highlighted in grey were used to calculate diffusion coefficients b) 1D DOSY plots for each integral and c) the corresponding 1D residuals plot. Solution was in phosphate buffer (50 mM, pD 7.4) in $\mathrm{D}_{2} \mathrm{O}(500 \mathrm{MHz}, 297 \mathrm{~K})$. 
Table S11. Parameters used in diffusion analysis of templated starting material sCx5-CHO (1)•pancuronium (2:1).

$\begin{array}{ll}\text { Used } Y & 26752 \mathrm{rad} /\left(\mathrm{s}^{*} \mathrm{Gauss}\right) \\ \text { Used } \delta & 0.0025000 \mathrm{~s}\end{array}$

0.0025000

Used $\Delta$

$0.12990 \mathrm{~s}$

Table S12. Dynamics Center calculated diffusion coefficients output from user defined integrals for templated starting material sCx5-CHO (1)•pancuronium (2:1).

\begin{tabular}{llll}
\hline Peak name & F2 $[\mathbf{p p m}]$ & $\mathbf{D}\left[\mathbf{m}^{2} / \mathbf{s}\right]$ & error \\
\hline 1 & 9.61 & $2.41 \times 10^{-10}$ & $1.172 \times 10^{-12}$ \\
2 & 7.67 & $2.43 \times 10^{-10}$ & $2.274 \times 10^{-13}$ \\
3 & 3.89 & $2.41 \times 10^{-10}$ & $1.172 \times 10^{-12}$ \\
4 & 2.05 & $2.05 \times 10^{-10}$ & $4.022 \times 10^{-13}$ \\
5 & 1.88 & $2.06 \times 10^{-10}$ & $7.070 \times 10^{-13}$ \\
6 & 0.36 & $2.02 \times 10^{-10}$ & $7.619 \times 10^{-13}$ \\
\hline
\end{tabular}

a)

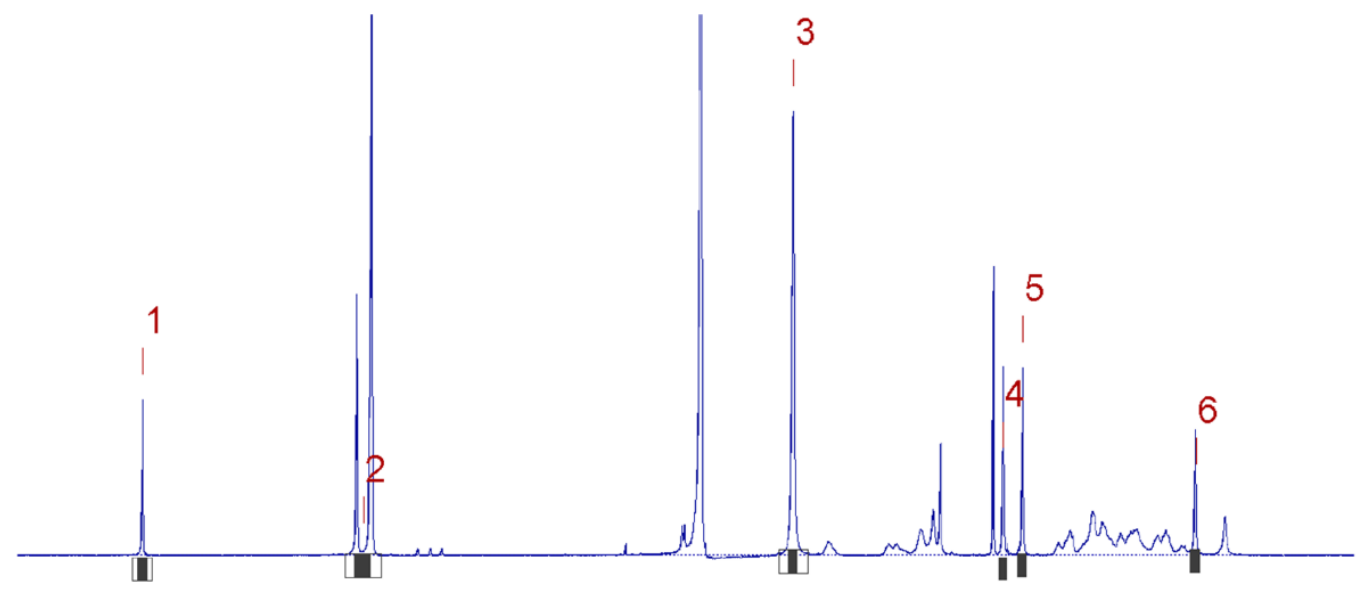

b)
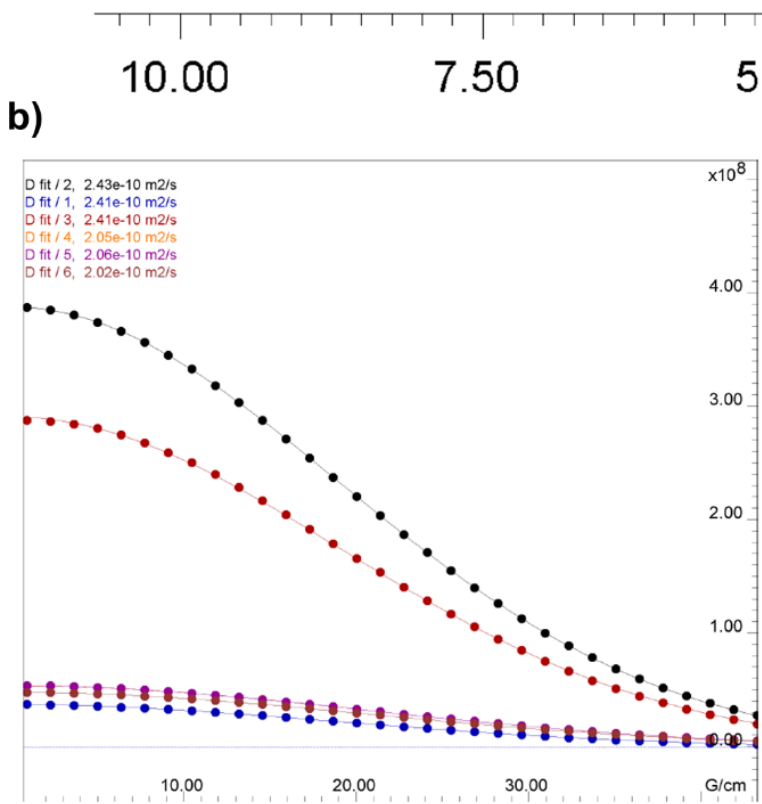

c)

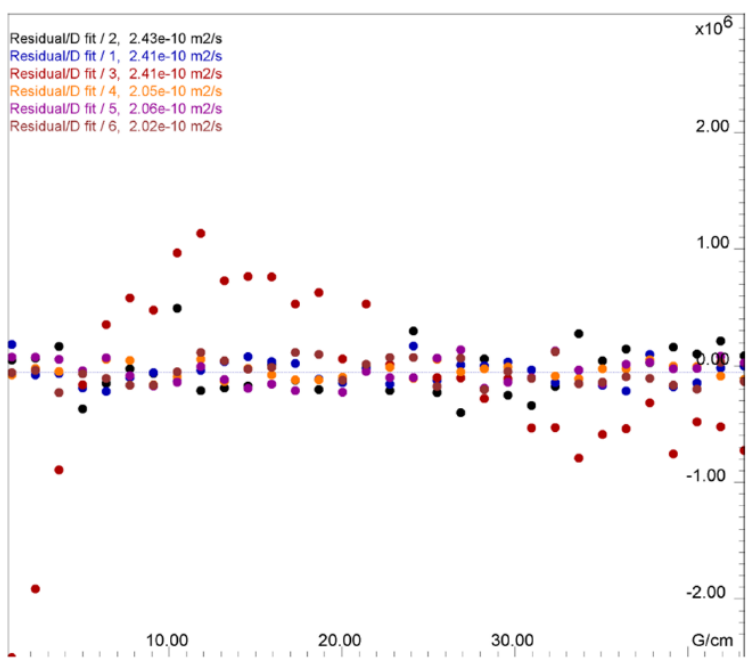

Figure S63. a) ${ }^{1} \mathrm{H}$ NMR of templated starting material sCx5-CHO (1)•pancuronium (2:1), the peak area integrals highlighted in grey were used to calculate diffusion coefficients b) 1D DOSY plots for each integral and c) the corresponding 1D residuals plot. Solution was in ammonium carbonate $(50 \mathrm{mM}, \mathrm{pD} 6.4)$ in $\mathrm{D}_{2} \mathrm{O}(500 \mathrm{MHz}, 297 \mathrm{~K})$. 
Table S13. Parameters used in diffusion analysis of monovalent $\mathbf{s} \mathbf{C} \times 5-\mathrm{CH}_{2} \mathrm{NHNH}_{2}$.

\begin{tabular}{ll}
\hline Used $\mathrm{Y}$ & $26752 \mathrm{rad} /\left(\mathrm{s}^{*} \mathrm{Gauss}\right)$ \\
Used $\delta$ & $0.0025000 \mathrm{~s}$
\end{tabular}

\begin{tabular}{ll} 
Used $\Delta$ & $0.0025000 \mathrm{~s}$ \\
\hline
\end{tabular}

Table S14. Dynamics Center calculated diffusion coefficients output from user defined integrals for monovalent sCx5-

$\mathrm{CH}_{2} \mathrm{NHNH}_{2}$.

\begin{tabular}{llll}
\hline Peak name & F2 $[\mathbf{p p m}]$ & $\mathbf{D}\left[\mathbf{m}^{2} / \mathbf{s}\right]$ & error \\
\hline 1 & 7.52 & $2.61 \times 10^{-10}$ & $4.097 \times 10^{-13}$ \\
2 & 6.96 & $2.74 \times 10^{-10}$ & $8.141 \times 10^{-13}$ \\
3 & 3.92 & $2.82 \times 10^{-10}$ & $4.717 \times 10^{-13}$ \\
4 & 3.79 & $2.50 \times 10^{-10}$ & $8.531 \times 10^{-13}$ \\
\hline
\end{tabular}

a)
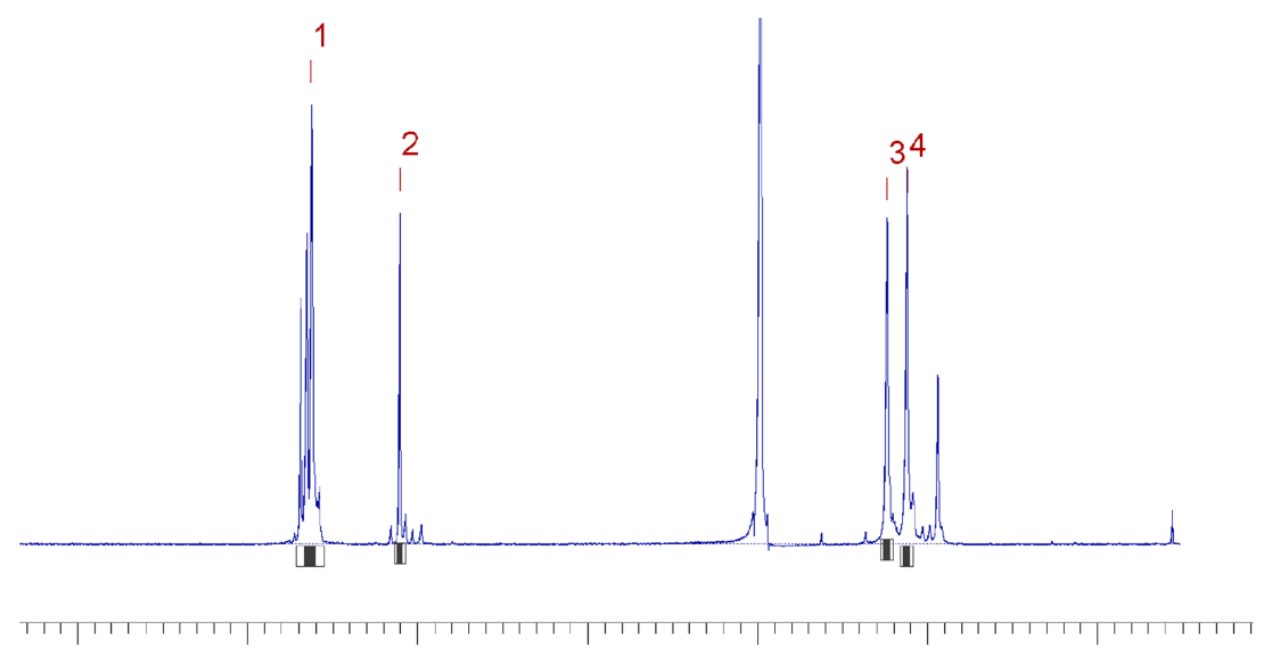
9.00
8.00
7.00
6.00
5.00
4.00
$3.00 \mathrm{ppm}$

b)

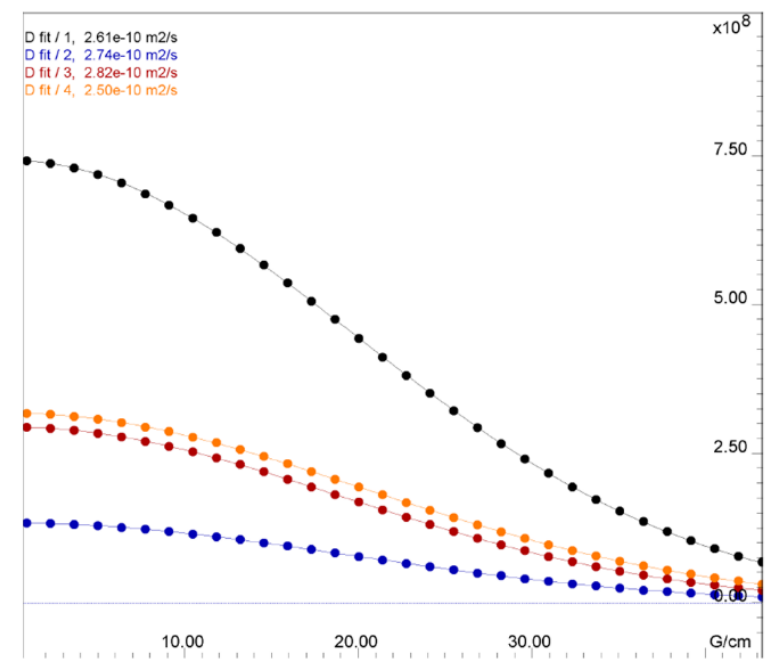

c)

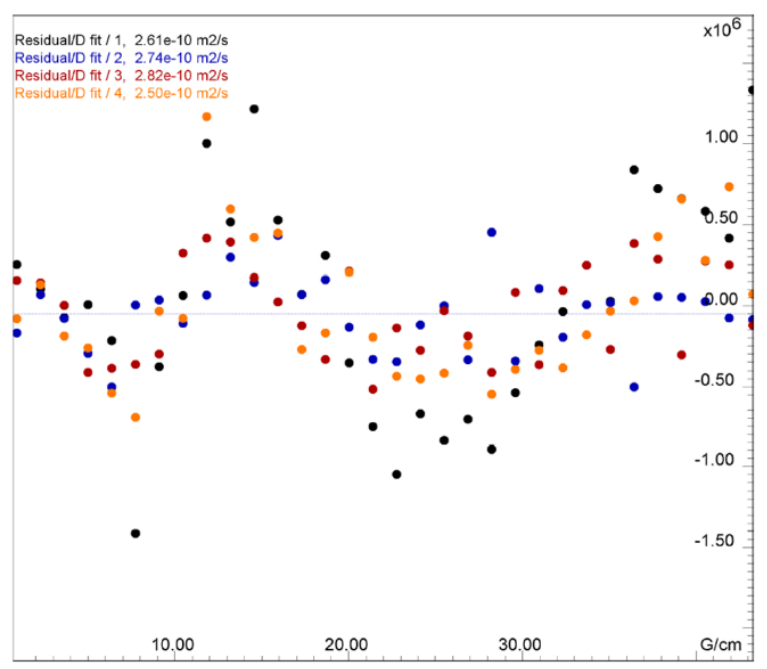

Figure S64. a) ${ }^{1} \mathrm{H}$ NMR of monovalent $\mathbf{s} \mathbf{C} \times 5-\mathrm{CH}_{2} \mathrm{NHNH}_{2}$, the peak area integrals highlighted in grey were used to calculate diffusion coefficients b) 1D DOSY plots for each integral and c) the corresponding 1D residuals plot. Solution was in phosphate buffer (50 mM, pD 7.4) in $\mathrm{D}_{2} \mathrm{O}(500 \mathrm{MHz}, 297 \mathrm{~K})$. 
Table S15. Parameters used in diffusion analysis of bivalent Super-sCx5.

\begin{tabular}{|c|c|c|c|}
\hline $\begin{array}{l}\text { Used } \mathrm{Y} \\
\text { Used } \delta \\
\text { Used } \Delta\end{array}$ & & $\begin{array}{l}26752 \mathrm{rad} /(\mathrm{s} \\
0.0025000 \mathrm{~s} \\
0.14490 \mathrm{~s}\end{array}$ & \\
\hline Peak name & F2 [ppm] & $\mathrm{D}\left[\mathrm{m}^{2} / \mathrm{s}\right]$ & error \\
\hline 1 & 7.45 & $2.03 \times 10^{-10}$ & $2.739 \times 10^{-13}$ \\
\hline 2 & 6.92 & $1.98 \times 10^{-10}$ & $8.215 \times 10^{-13}$ \\
\hline 3 & 3.77 & $1.99 \times 10^{-10}$ & $2.339 \times 10^{-13}$ \\
\hline
\end{tabular}

a)
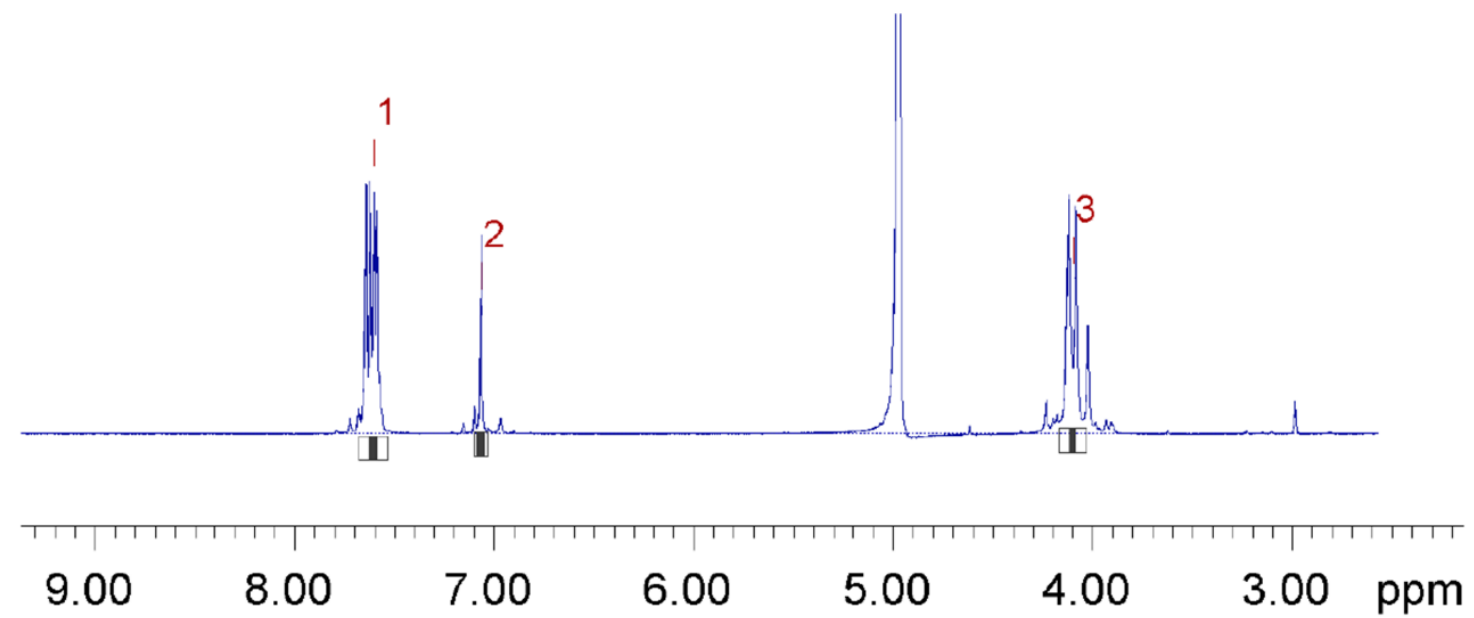

b)

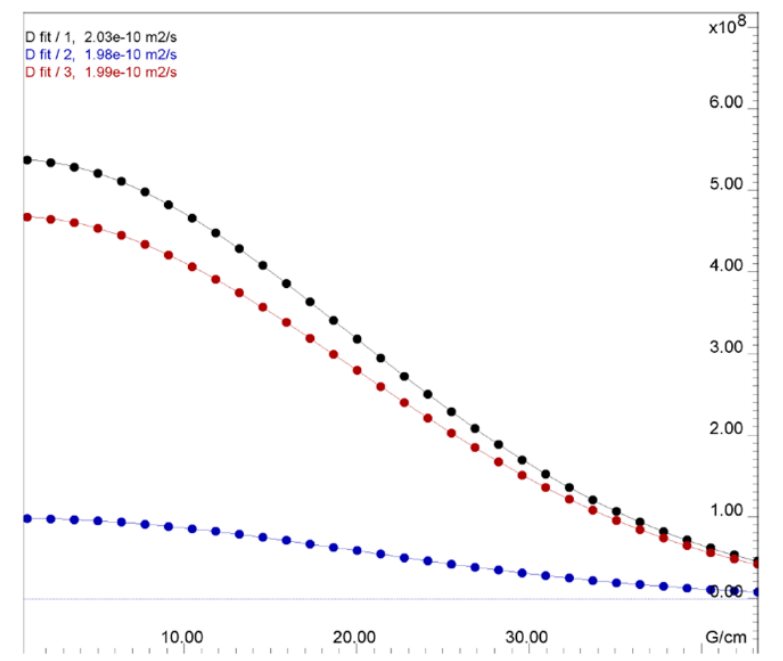

c)

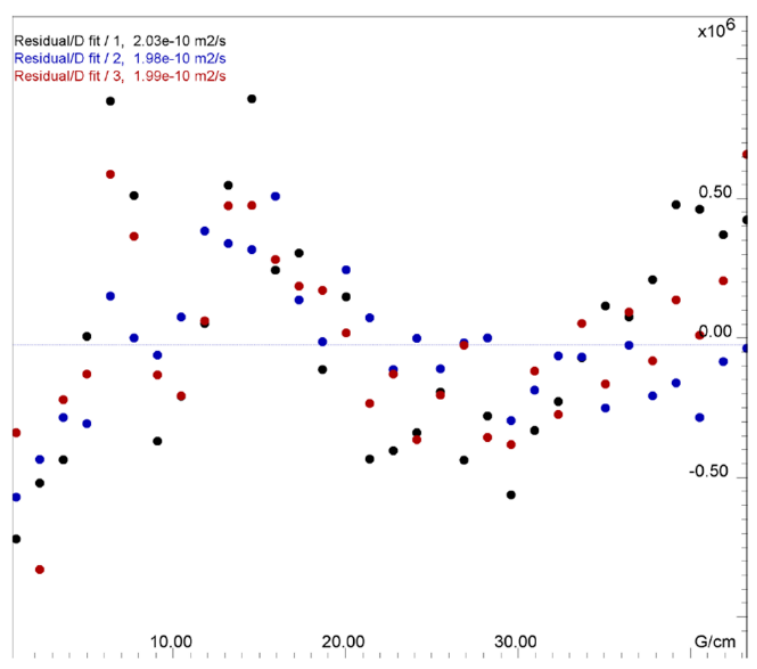

Figure S65. a) ${ }^{1} \mathrm{H}$ NMR of bivalent Super-sCx5, the peak area integrals highlighted in grey were used to calculate diffusion coefficients b) 1D DOSY plots for each integral and c) the corresponding 1D residuals plot. Solution was in phosphate buffer (50 mM, pD 7.4) in $\mathrm{D}_{2} \mathrm{O}(500 \mathrm{MHz}, 297 \mathrm{~K})$. 
Table S17. Parameters used in diffusion analysis of bivalent Super-sCx5•suxamethonium (1:1).

\begin{tabular}{|c|c|c|c|}
\hline \multicolumn{2}{|l|}{$\begin{array}{l}\text { Used } Y \\
\text { Used } \delta \\
\text { Used } \Delta\end{array}$} & \multicolumn{2}{|c|}{$\begin{array}{l}26752 \mathrm{rad} /\left(\mathrm{s}^{*} \text { Gauss }\right) \\
0.0025000 \mathrm{~s}\end{array}$} \\
\hline Peak name & F2 [ppm] & $\mathrm{D}\left[\mathrm{m}^{2} / \mathrm{s}\right]$ & error \\
\hline 1 & 7.58 & $2.05 \times 10^{-10}$ & $3.390 \times 10^{-13}$ \\
\hline 2 & 7.33 & $1.88 \times 10^{-10}$ & $1.522 \times 10^{-12}$ \\
\hline 3 & 3.88 & $2.08 \times 10^{-10}$ & $1.151 \times 10^{-12}$ \\
\hline 4 & 3.32 & $2.04 \times 10^{-10}$ & $3.372 \times 10^{-12}$ \\
\hline 5 & 2.24 & $2.14 \times 10^{-10}$ & $1.218 \times 10^{-12}$ \\
\hline 6 & 1.59 & $2.04 \times 10^{-10}$ & $1.002 \times 10^{-12}$ \\
\hline
\end{tabular}

a)

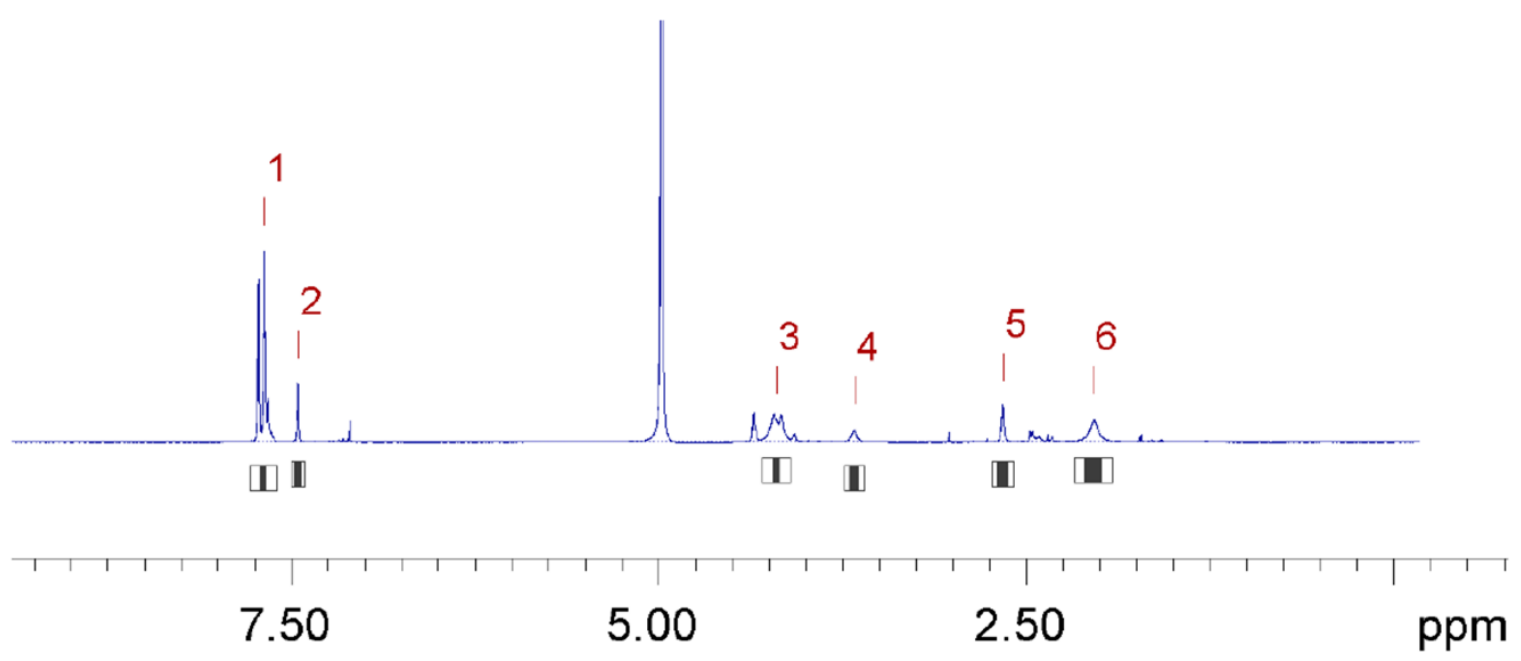

b)

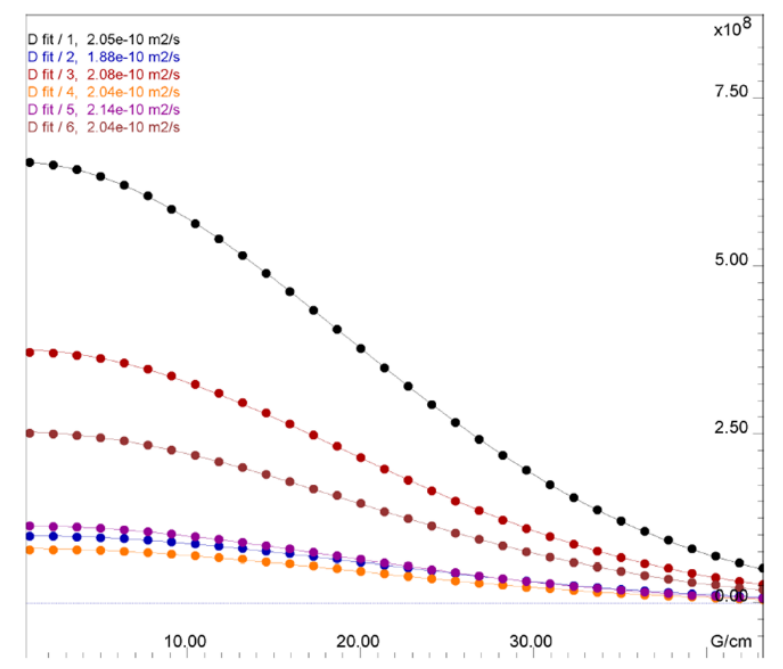

c)

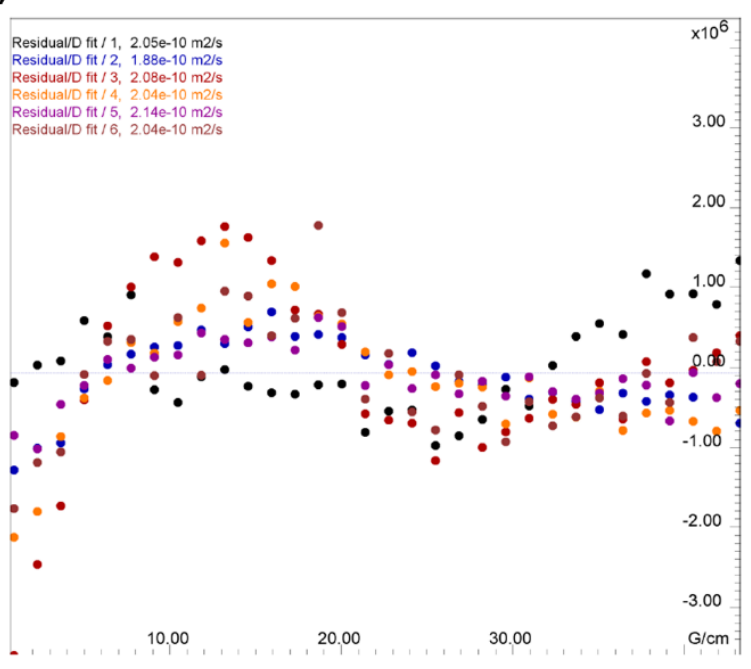

Figure S66. a) ${ }^{1} \mathrm{H}$ NMR of bivalent Super-sCx5•suxamethonium, the peak area integrals highlighted in grey were used to calculate diffusion coefficients b) 1D DOSY plots for each integral and c) the corresponding 1D residuals plot. Solution was in phosphate buffer (50 mM, pD 7.4) in $\mathrm{D}_{2} \mathrm{O}(500 \mathrm{MHz}, 297 \mathrm{~K})$. 


\section{Molecular modelling}

Host•guest complexes were modeled in Avogadro. Each individual host and guest compound was geometry optimized using the molecular mechanics forcefield MMFF94. A systematic rotor search was used to find the lowest energy conformers of each compound. Then geometry optimization of the lowest energy conformer was done using a 5000 step with a steepest descent algorithm and 10e-7 convergence. The pre-optimized structures were then combined to form a host•guest complex, where another systematic rotor search was used to find the lowest energy conformers for each host•guest pair. Optimization of the lowest energy host•guest conformers was completed using a 5000 step with a steepest descent algorithm and $10 \mathrm{e}-7$ convergence.
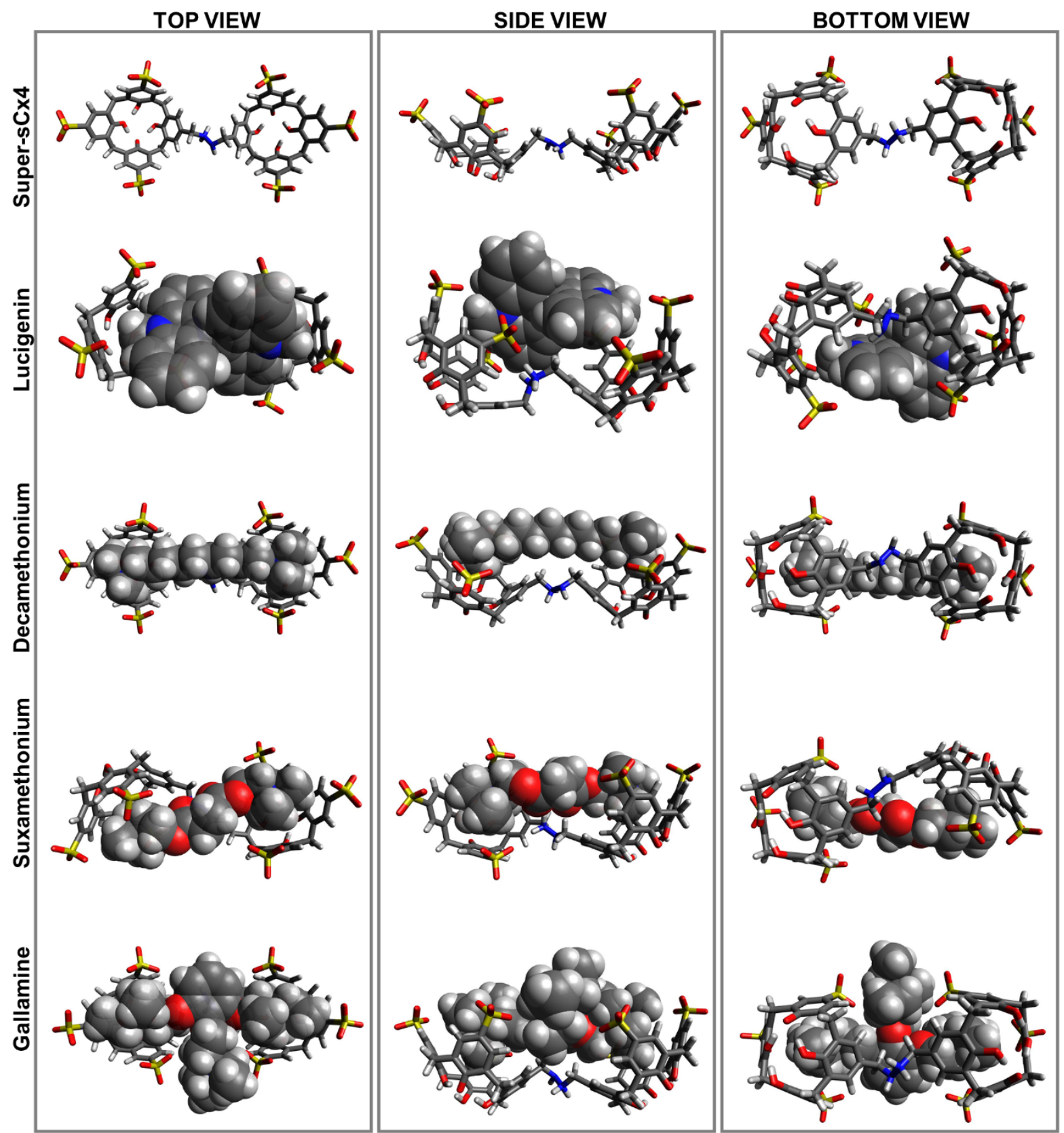

Figure S67. Molecular modelling of Super-sCx4 shows 1:1 complexation with the dye lucigenin and the NMBA's decamethonium, suxamethonium and gallamine. In all cases the bisquaternary amines on the guest bind both cavity sites present on bivalent Super-sCx4. 

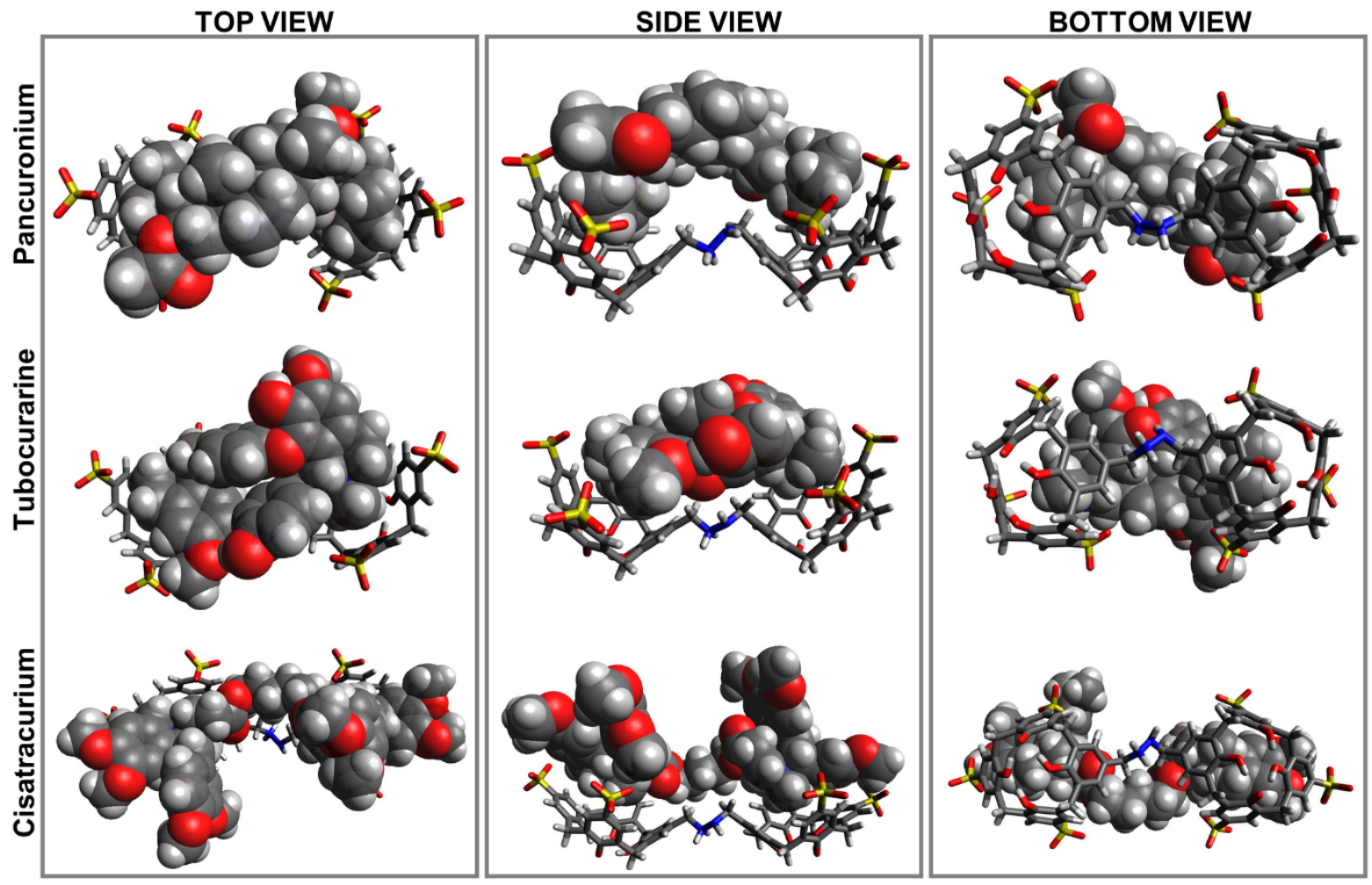

Figure S68. Molecular modelling of Super-sCx4 shows 1:1 complexation with the NMBA's pancuronium, tubocurarine and cisatracurium. In all cases the bisquaternary amines on the guest bind both cavity sites present on bivalent Super-sCx4. 


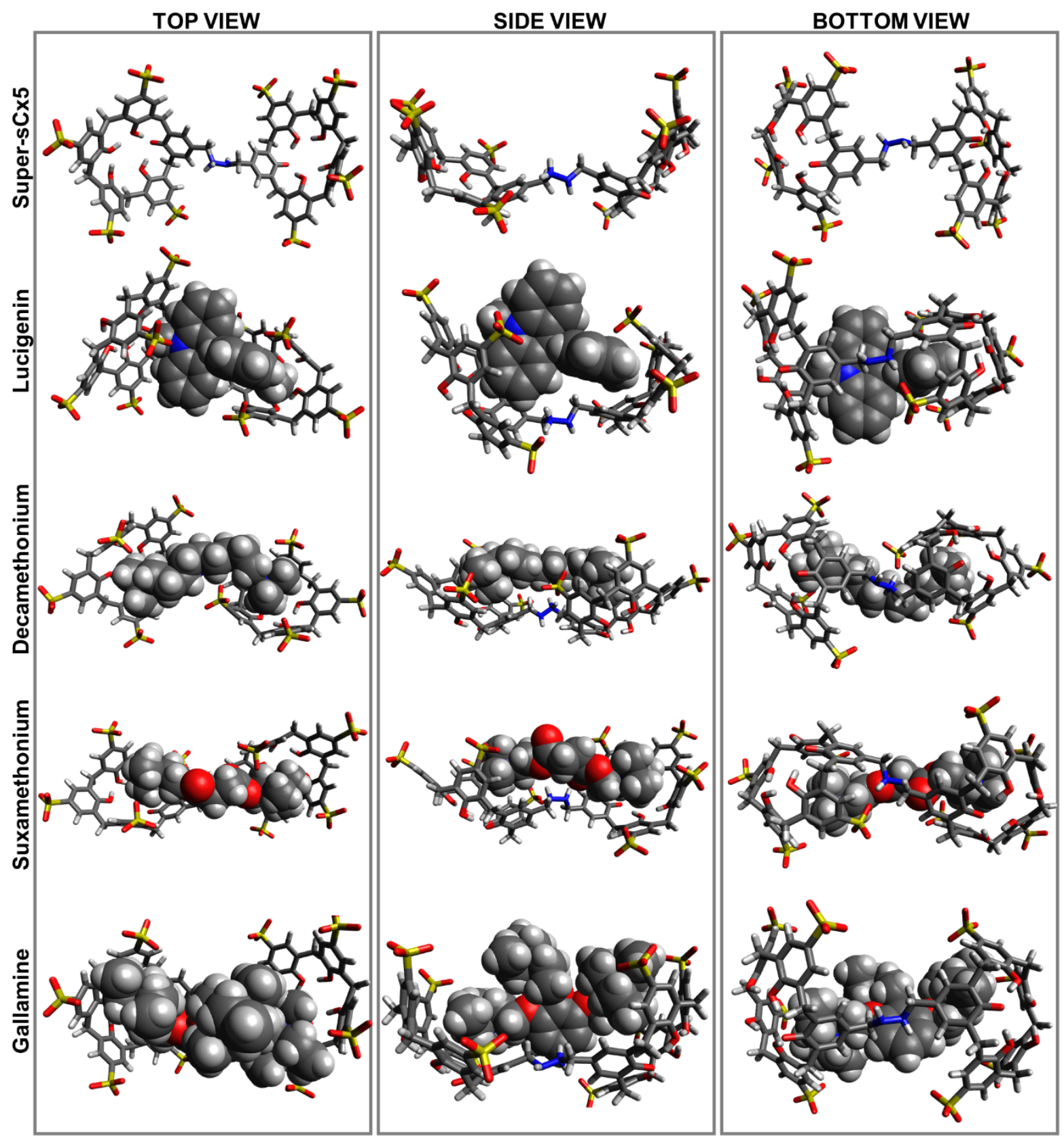

Figure S69. Molecular modelling of Super-sCx5 shows 1:1 complexation with the dye lucigenin and the NMBA's decamethonium, suxamethonium and gallamine. In all cases the bisquaternary amines on the guest bind both cavity sites present on bivalent Super-sCx5. 


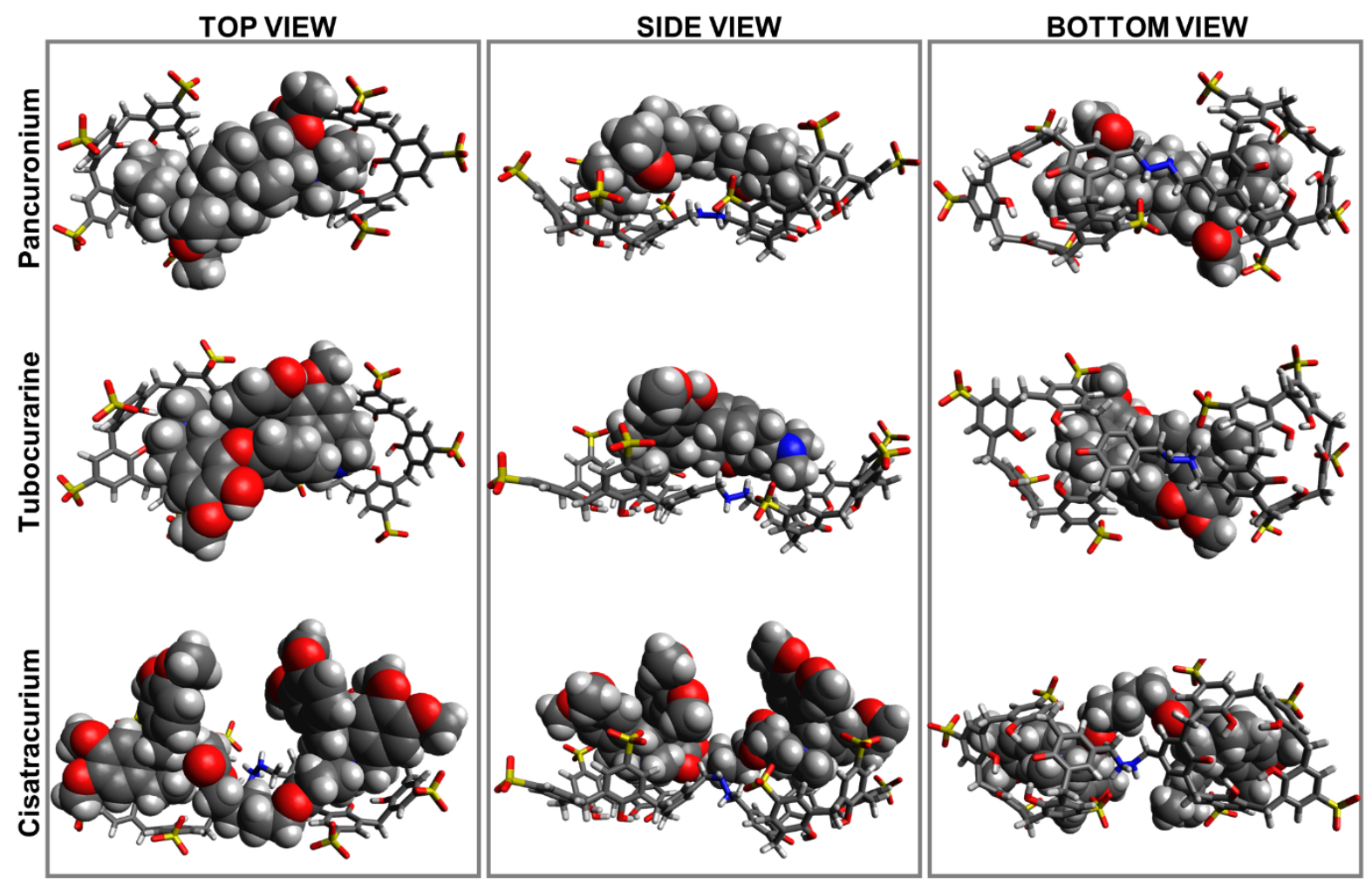

Figure S70. Molecular modelling of Super-sCx5 shows 1:1 complexation with the NMBA's pancuronium, tubocurarine and cisatracurium. In all cases the bisquaternary amines of the guest bind both cavity sites present on the bivalent Super-sCx5 host.

\section{References}

[1] M. A. Beatty, J. Borges-González, N. J. Sinclair, A. T. Pye, F. Hof, Journal of the American Chemical Society 2018, $140,3500-3504$

[2] J. Wang, S. G. Bodige, W. H. Watson, C. D. Gutsche, The Journal of Organic Chemistry 2000, 65, 8260-8263.

[3] J. W. Thompson, T. J. Kaiser, J. W. Jorgenson, Journal of Chromatography A 2006, 1134, 201-209.

\section{Author Contributions}

A.J.S.: investigation, formal analysis, supervision, writing, visualization. N.A.C.: investigation, formal analysis. F.H.: conceptualization, writing, review, and editing. 